


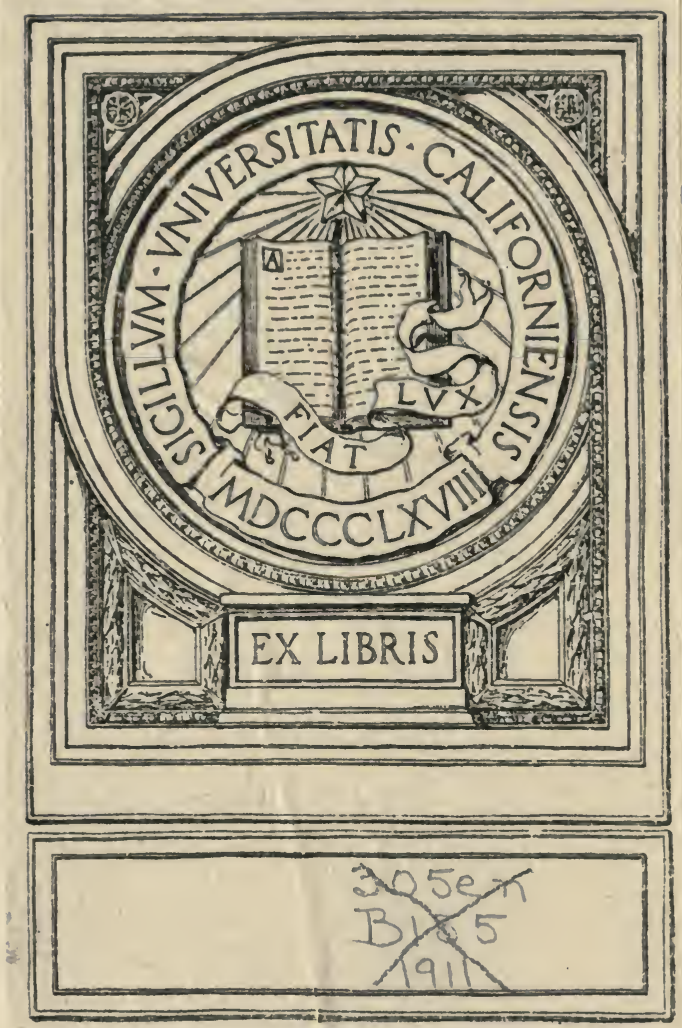


Digitized by the Internet Archive in 2007 with funding from Microsoft Corporation 


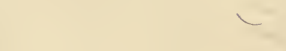


THE NATURE-STUDY IDEA 


\section{The Rural Outlook Set}

The Outlook to Nature (revised)

The Nature-Study Idea

The State and the Farmer

The Country-Life Movement 


\title{
The Nature-Study Idea
}

AN INTERPRETATION OF THE NEW SCHOOL-MOVEMENT TO PUT THE YOUNG INTO RELATION AND SYMPATHY WITH NATURE

\author{
BY \\ L. H. Bailey
}

FOURTH EDITION, REVISED

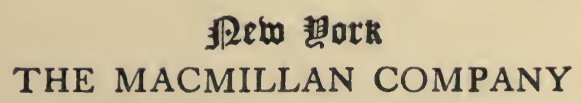

rgI I 


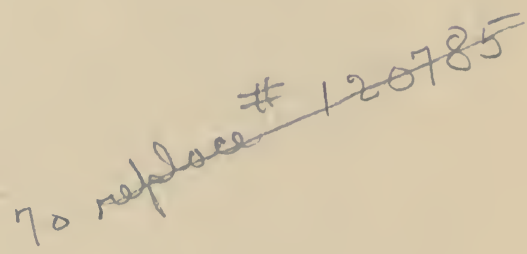

COPYRIGHT, 1903

BY DOUBLEDAY, PAGE \& CO.

COPYRIGHT, 1909

BY THE MACMILLAN COMPANY

Set up and electrotyped. Published October, $190 \%$

Reprinted October, 1911

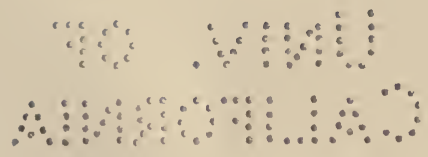

Printed at

The NORWOOD PRESS

Berwick \& Smith Company, Norwood, Massachusetts 
To

99ts. Julia 拈il

A TEACHER WHO ALLOWED

A BOY TO GROW

3 ingcribe this book 



\section{Contents}

\section{PART I \\ Nature-Study Teaching}

II. Who First Used the 3

III. The Meaning of the Nature-Study Movement.... 27

What nature-study is not............... 29

The outlook by fact and by fancy......... 35

How nature-study may be taught.......... 37

What may be the results of nature-study?.... 50

IV. The Integument-Man................. $5_{5}^{8}$

V. Nature-Study with Plants................ 67

Suggestions for plant work.............. 70

VI. The Growing of Plants by Children-The School-

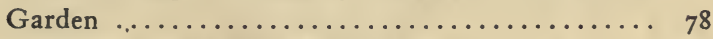

Improving of the school-grounds.......... 84

The school-garden .................. 87

The larger relations ................. 90

VII. Nature-Study Agriculture................ 93

A point of view on the rural-school problem... 96

The prospect .................... 105

\section{PART II}

\section{The Tracher's Outlook to Nature}

I. The Teacher's Interpretation of Nature......... II3

II. Science for Science's Sake............... Ir7

III. Extrinsic and Intrinsic Views of Nature........ 124

IV. Must a "Use" be Found for Everything?...... I3I

V. The New Hunting.................... 139

VI. The Poetic Interpretation of Nature.......... I5I

VII. An Outlook on Winter................... I6r 


\section{PART III \\ INQUIRIES AND ANSWERS}

PAGE

How Shall I Know What Subjects to Choose?........ I7I

But If the Child Choose the Material, the Subject Will

Lack Continuity: What Then?............. I73

Then Would You Give No Heed to Continuity?...... 173

Should Nature-Study Give Way to "Fundamental"

Work? .......................... 74

What is the Proper Pedagogical Starting-Point for Nature-Study? . ................... 178

How Shall I Make a Start?.................. r8 1

How May I Secure Permission from My Principal to

Teach Nature-Study? ................. 183

Would You Teach Heat, Light and Physics as Nature-

Study Topics? ...................... I8 8

Would You Teach "Practical" and "Useful" Things?.. 185

Would You Teach Objects that the Child Cannot See and Determine for Itself?............... 188

How Much Apparatus Do I Need?............. 188

Is It "Thorough"?.................... I 89

But Will Not This Nature-Study Be Called Superficial? I9I

Will Not This Nature-Study Tend Still Further to Overburden the School?.................. r92

Shall We Teach the Child to Collect, and Thereby to Kill? ............................. r94

How May We Develop a Humane Attitude Toward Living Things? .................... I95

Would You Tell the Child the Names of the Things?.. 196

Would You Begin by First Reading to the Child About Nature? ......................... 197

Now That There Are So Many Nature-Books, How Shall

I Choose the Most Useful One?............. r98

How Shall I Acquire Sufficient Knowledge to Enable Me to Teach Nature-Study?................. 199 
Is It Best to Have a Professional Nature-Study Teacher to Go from School to School?...............20r

Should Not Nature-Study Be In All the Grades for All Pupils, and Technical Work Be Left to the HighSchool? ..........................202

Should the Parts of a School-Garden Be Apportioned to Pupils, or Should the Work Be Done in Common? 205

Can I Make a Nature-Study Exhibition Useful as Part of an Exposition?....................212

Why Should This Nature-Study Be Confined to the Schools? .......................... $\mathbf{2 r}_{3}$

What Shall We Do with the Children in the Summer Vacation?

Will Not This Nature-Study Work Interfere with School Discipline? ..................... $2 \mathbf{r}_{7}$

Shall I Correlate the Nature-Study Work with Other Work? ............................ 8

What Can I Do to Put Our Rural Schools in Touch with

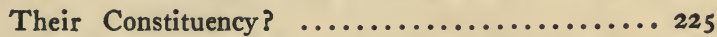

How Can I Reach the Farmers of My Neighborhood?.. 235 How Can a Teacher Prepare Himself to Teach Agriculture in the Special Schools That Are Now Being Established? ........................ 240

How Can I Do Any Nature-Study Work in the Ordinary Kind of Schoolroom?................. 24r

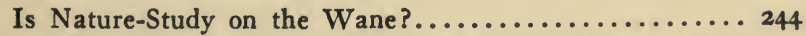
Would You Advise Me to Take Up Nature-Study Teaching? 



\section{PART I}

\section{Being an attempt to define and explain what nature-study is}





\section{I \\ What is Nature-Study?}

A CONTRIBUTOR to a recent issue of a A leading technical journal has endeavored to find a satisfactory answer to the question, "What is nature-study?" by appealing to "eminent scientific men." The answers of these men are printed there in full.

Now, the nature-study movement is not a product of "eminent scientific men," nor directly of the current natural-science movement. It is . a product of the common schools. Eminent scientific attainment, as such, is not to be expected to enable persons to give satisfactory answer to the question, for the subject is not within its realm. Happily, many scientific men are also closely in touch with elementary education, and therefore are fully competent to discuss the nature-study movement, but it is 


\section{4 \\ The Nature-Study Idea}

this very touch with the common schools, not their eminent scientific achievements, that gives them this competency; and some of the answers referred to above are good definitions from the child-teacher's point of view.

To be sure, the term nature-study etymologically implies only the study of nature; and "nature" is conventionally understood to mean the world of outdoor objects and phenomena. But all words and terms mean less or more than their mere etymology would imply, and this meaning is determined by usage. So usage has determined a definite office for the name nature-study: it designates the movement originating in the common schools to open the pupil's mind by direct observation to a knowledge and love of the common things and experiences in the child's life and environment. It is a pedagogical term, not a scientific term.

Nature-study is not synonymous with the old term "natural history," nor with "biology," nor with "elementary science." It is not "popular science." It is not the study of nature merely. Nature may be studied with either of two 


\section{What is Nature-Study?}

objects: 'to discover new truth for the purpose of increasing the sum of human knowledge; or to put the pupil in a sympathetic attitude toward nature for the purpose of increasing his joy of living. The first object, whether pursued in a technical or elementary way, is a science-teaching movement, and its professed purpose is to make investigators and specialists. The second object is a nature-study movement, and its purpose is to enable every person to live a richer life, whatever his business or profession may be.

Nature-study is a revolt from the teaching of formal science in the elementary grades. In teaching-practice, the work and the methods of the two intergrade, to be sure, and as the highschool and college are approached, nature-study passes into science-teaching, or gives way to it; but the intentions or motives are distinct-they should be contrasted mithe than compared. The nature-study methodiss a fundamental and, therefore, a gereral educational process; the formal science-teaching method is adapted to mature persons and to those who would know a particular science. 


\section{The Nature-Study Idea}

Nature-study, then, is not science. It is not knowledge. It is not facts. It is spirit. It is an attitude of mind. It concerns itself with the child's outlook on the world.

Nature-study will endure, because it is natural and of universal application. Methods will change and will fall into disrepute; its name will be dropped from courses of study; here and there it will be incased in the schoolmaster's "method" and its life will be smothered; now and then it will be over-exploited; with some persons it will be a fad: but the spirit will live.

So common is the misconception of the meaning and mission of the nature-study movement, that I cannot resist the temptation to bring together in book form a few notes and essays on some of the more salient features of it, even if the resulting book lack somewhat in homogeneity and have some repetitions. These pieces have been written at intervals in the past six years. Most of them were prepared for specific occasions, for the purpose of discussing disputed points or of answering challenges; some have been written specially for this collection. Some 
of them have been published. They are offered in all humbleness, since every person's view is necessarily colored by his own field of work; but on the main thesis-that nature-study teaching is one thing and that science-teaching for science's sake is another-I have no hesitation.

The foregoing paragraph indicates the makeup of the original edition of this book, which was published by Doubleday, Page \& $\mathrm{Co}_{\text {, }}$ in 1903. The book appears to have found a constituency beyond my expectations, and the continued use of it influences me now (I909) to make a new edition. If I were writing the book anew at this time, I might put it in different phrase; but as it was written when I was actually engaged in teaching and was filled with the practical details of the subject, and as so many parts of it have been so often quoted, I shall leave it much as it was originally prepared. Since the book was written, I have ceased all teaching and have been consumed in educational administrative work. I have therefore seen the subject from a different angle; but on going over the text I find nothing that I would change 
in the fundamental contentions. In fact, I have a deeper conviction than ever that the method and point of view of the nature-study people are bound to exercise great influence in redirecting our education.

I have a growing feeling that the nature-study method is not only a public-school process, but that it is equally needed in colleges and universities for all unspecialized students. The process applies, in fact, from kindergarten to college. From long experience I am convinced that much of our college physics, botany, zoölogy and chemistry is very poorly taught if we are to consider its effect on the student; and this effect is, of course, the end of teaching. A student may take college physics and yet have little conception of the common physical phenomena of life. $\mathrm{He}$ may study physiology and gain little real understanding of his bodily functions or of every-day sanitation. These subjects are likely to be taught with the special student in mind rather than the general student. The teacher is disposed to think of the necessity of developing a whole subject rather than to give the student a 
rational and vivid conception of the material as it relates to him. I have been interested all my life in plants; but I should not care to have one of my pupils devote four or five periods a week for a whole freshman year to the study of botany unless he were specially interested in botany. Much of the beginning teaching in the sciences in colleges and universities is undoubtedly very bad. It is no doubt accurate, and it may also be adapted to the few students who desire to specialize in the subject; but such students should be taken further in courses designed for them. Condensed general courses that give the college student a rational view of the subject, without many details and exceptions, are very much to be desired; and such courses should attempt to relate the student to his own experience in life.

We have been passing through a long epoch of speech-education. This no doubt is largely the outcome of the results of the Reformation, to teach persons to read their own scripture. The schools must undergo a continual process of growth and adaptation if they are to meet the 


\section{0}

\section{The Nature-Study Idea}

needs of the passing generations of men. We now feel that speech-education is not a primary educational process, but that real education should grow out of or result from the common activities of the child. Some day we shall set all our children at work when they go to school and make them to be effective men and women in the common work of men and women.

After all these years of nature-study enterprise, it is naturally assumed by many persons that we ought to be able to give statistics of the number of pupils who are enrolled in the subject, the number of teachers that are teaching it, the number of books that have been read, and other exact figures. This supposition misses the very purpose of the nature-study movement, which is to set pupils at work informally and personally with the objects, the affairs and phenomena with which they are in daily contact. There are very many teachers and very many schools, and very many pupils, who have a new outlook on life as the result, of nature-study work; but if I could give a statistical measure of the nature-study movement, I should consider 
the work to have been a failure, however large the figures might be.

The seed has been planted, and it has germinated. The evolution of a new intention in education is under way and is beginning to be felt. The principles have been stated; the current discussions are of methods, difficulties, and of local and personal adaptations.

We are to open the child's mind to his natural existence, develop his sense of responsibility and of self-dependence, train him to respect the resources of the earth, teach him the obligations of citizenship, interest him sympathetically in the occupations of men, quicken his relations to human life in general, and touch his imagination with the spiritual forces of the world.

If life is worth living it must be invigorated, and there is no invigoration without enthusiasm and spirit. We must all have practice in the common affairs of life; but practice alone is dead, and worse than dead. If we cannot add the spirit and the true sentiment to life, then there is no interest in living excepting for that which is gross. It is better to have a thread of 


\section{2}

\section{The Nature-Study Idea}

inspiring philosophy running through the day's work than to have a very large bank account. This means that a school should have a soul.

The reader will understand that $I$ have approached my subject from the side of fact and of experience, not from the side of pedagogical theory or of the psychology of education. $\mathrm{Na}$ ture-study is experience-teaching. In my first work and writing on nature-study, I think that I was wholly unconscious of any conflict of my views with the current theories of educational procedure; in fact, the pedagogical theories were unknown to me till they were called to my attention. I had merely set forth my convictions, resulting from many years of teaching, to the effect that the best way to teach nature sub-

y jects is to begin with good simple observation rather than with dissection, clässification, theorizing or memorizing. I think that the same process should be followed in the training of the teacher himself. I doubt whether saturation in the psychology of pedagogy affords a good start for the training of a teacher. I observe an 


\section{What is Nature-Study?}

indefiniteness and haziness of ideas in persons who have their theory before they have their facts. They do not have their feet on the ground. They do not drive stakes; or if they do, they ponder the method until the operation becomes lifeless. For nature subjects, the first essential is an intense love of nature; the best training is to acquire the actual facts and to know the subject, and then to go out and teach, without too much burden of doubt as to the kind and propriety of the theoretical methods. I do not doubt the value of the psychological study of education, and all teachers should profit by a discussion of educational history and method; but we should be careful not to fill the young teacher full of abstractions. A teacher may safely theorize and speculate after he has learned how to teach.

Of the criticisms on this book and on my general attitude toward nature-study teaching, the most important is that I insist too much on spontaneousness and informality and thereby provide an excuse for lazy or indifferent teachers who 
do not want to make preparation for their lessons. The lazy teacher can find plenty of excuses. One who fairly reads the book need not be misled. My general plea is a challenge to existing hard-and-fast methods and to those ways of teaching that take the pupil prematurely beyond his depth. There is no danger tha' the school work will lack in formality: our systems encourage formality, and the desire to standardize all methods seems to be extending, but a free and natural procedure needs always to be promoted and defended. In actual school practice, it is of course necessary that a system be followed and that the teacher have ability enough and knowledge enough to be able to teach. I have not cared to prepare an outline for class work: the book is concerned with the nature-study idea. Nor have I desired to make supplemental statements in these intervening years, for I have wanted the idea to sink in.

The recent years have been a time of widespread discussion of all phases of education for the people, and the nature-study idea has received its full share of attention. Whatever 
may be the opinion of individual teachers and writers on the nature-study movement, it is a fact that our educational methods are re-shaping themselves in such a way as to allow the pupil to develop a sympathetic and vital contact with his usual environment; ' and the stiff, dead and painfully exact teaching of rule and fact to the young is rapidly giving way to a free, spirited and natural way of teaching. We can even now begin to see the result in a less restrained and more wholesome outlook on life in the young generation. It will be much satisfaction to me if I can feel at the end that this fragmentary book has had some effect in heartening teachers not to be afraid to teach. 


\section{II}

Who First Used the Term Nature-Study?

$\triangle$ BRIEF history of the origin of the conA temporary nature-study movement will clarify our ideas as to its spirit and purpose. I am aware that the history that follows is incomplete, and that persons who were connected with the beginnings of it are not mentioned; but I think that the account will be useful in giving us perspective, and in establishing an approximate date for the first use of the term.

I have engaged in a large correspondence for the purpose of discovering something of the history of the nature-study movement in North America. Oftenest, perhaps, I have been referred to the teaching of Agassiz at Penikese as the beginning, at least in this country. Agassiz, however, did not teach nature-study in the school sense in which we use the term, although he gave us the motto, "Study nature, not books." He taught the study of nature by the "natural method." His instruction was given from the 
investigator's or the specialist's viewpoint, and it was intended primarily for students and adults.

The present nature-study movement, as I have said, is a product of the elementary schools, not of universities, although many university and college men have been instrumental in forwarding it. Cornell was perhaps the first university to take it up as a distinct enterprise (1895), but the movement was already well under way in many places at that time. At this institution it became an extensionteaching movement. Professor C. F. Hodge of Clark University, under the inspiration of Stanley Hall, began popular work in naturestudy in I897. The Cornell work is not so much a school enterprise as a movement to make use of the schools to reach the people on the farms. This work, more than any other perhaps, has emphasized the nature-sympathy and the nature-relations.

The beginnings of nature-teaching are certainly as old as the time of Socrates and Aristotle. It is concretely expressed in the work 
of the great educational reformers-Comenius, Pestalozzi, Jean J. Rousseau, Froebel and the others. In a large measure, the spirit of our present-day nature-study movement-which seems so new to us-is a recrudescence. Just now it represents a reaction from the dry-as. dust science-teaching.

What we may legitimately call nature-study, in the current acceptation of the term, began to take form in this country from I 884 to I 890 . Who first used the term I do not know; and it is of small consequence, because the term may mean much or nothing. The term appears to have been at first a substitute for "object lessons," "plant work," "elementary science," and the like. Dr. Piez, of the Oswego (N. Y.) Normal School, makes the following comment on the pedagogical origin of the nature-study idea: "I have come to the conclusion that nature-study in spirit, if not in name, is the direct descendant of object teaching. Object teaching aimed at the use of the senses in acquiring knowledge, and was introduced to displace the mechanical 'memory' method current in the 


\section{Who First Used the Term?}

schools. It was responsible for raising the problem of method among thoughtful teachers. But the 'lessons on objects' were justly deserving the criticism that they were disconnected, and that the knowledge resulting from them was a knowledge of isolated facts not organized into a comprehensive whole."

Although the teaching of Agassiz may not have been nature-study, as we understand the term, it is undoubtedly true that the present nature-study movement is a proximate result of the forces that he and his contemporaries set in motion. A strong application of this influence to school life was made in Boston by Alpheus Hyatt and Lucretia Crocker. In various places, others of Agassiz's followers carried his spirit into the schools. One of the most powerful early adaptations of his teaching to the commonschool work was made at the State Normal School at Oswego, N. Y. There was a strong Pestalozzian influence in this institution, under the leadership of the late Dr. Sheldon. Professor H. H. Straight went to Oswego in 1876. He had come under the influence of Agassiz and 
Shaler. He was a student of science, but his views of science-teaching in the elementary school underwent gradual but decided change under the Pestalozzian influence in which he was placed. He saw the insufficiency of "object teaching" as an educational process. The defects he sought to overcome by "correlation of the subjects of study." As director of the practice school, he worked out his ideas of correlation in "nature" subjects and geography subjects. His work included the study of the common things in the neighborhood. In I 883 Professor Straight went to the Cook County (III.) Normal School and taught there until his death, in I886. He had great influence in developing the ideals of this institution, and was given credit therefor by Colonel Parker, the distinguished head of the school. So far as I know, however, Professor Straight did not use the term "nature-study."

The introduction of elementary science as an organic part of school work, ranking with arithmetic and grammar, was made in the Cook County (Ill.) Normal School as early as 1889 , 
under the presidency of Francis W. Parker. This introduction was made by the late Wilbur S. Jackman, whose teaching and writing in. nature-study lines are well known. In I 884 Mr. Jackman began teaching biology in the Pittsburg High School. During five years' connection with that school he became strongly impressed with the necessity of having a broad foundation laid in the elementary grades for the study of science. The pupils were ignorant of the simplest phenomena that occurred about them. In the spring of I 889 he planned a general course in nature-study and presented it to the superintendent and the principals of the ward schools in Pittsburg. It was agreed that in the fall he should have the privilege of meeting the teachers for the purpose of starting this work in the primary and grammar grades. Before the year closed, however, he received an invitation from Colonel Parker to enter the Cook County Normal School and take up the work with him. He entered on the work in the Cook County Normal School in the fall of I889. During this year ( 1889 ) he elaborated 
the plan already begun, as above outlined. The features which perhaps most distinguished this scheme of nature-study were: (I) That it adopted the apparently irregular plan of using all the material which the "Rolling Year," season by season, brought into the lives of the children; (2) that it rejected the idea of close and specialized study of inert or dead form and sought to place the children in the fields and woods that they might study all nature at work; and (3) that, instead of looking upon naturestudy as being supplementary to reading, writing and other forms of expression, nature-study in itself became a demand that these subjects should be taught. In the fall of 1890 he published bi-monthly pamphlets averaging about seventy-five pages each, which were called "Outlines in Elementary Science." In the spring of I89I, upon the completion of the series, Henry Holt \& Company asked the privilege of reprinting and issuing them in book form. This was accomplished. There was considerable correspondence concerning the name, which resulted finally in the adoption of the term "Nature-Study 
for Common Schools," and this term has been used continuously ever since.

Another, and an independent, movement started nearly simultaneously in Massachusetts, under the leadership of Arthur C. Boyden, now Vice-Principal of the State Normal School at Bridgewater, Mass. In 1889 a committee was appointed in the Plymouth County Teachers' Association to recommend a plan of introducing nature-study into the schools of the county. For a number of years previous to this time a definite series of lessons on minerals, plants and animals had been taught in the Bridgewater Normal School, and many superintendents and teachers who graduated from the school were teaching the subjects in various parts of the county. It seemed to be the time for a concerted plan of work, and a few persons who were interested in it took this means of starting. An outline for the study of trees was prepared and sent to every school in the county, with provisions for a report from each town at the next annual meeting. This plan was continued for a number of years, and usually an exhibition 


\section{4 \\ The Nature-Study Idea}

of the results was made. The work secured such a good hold that the committee was finally discontinued. In the same year the subject was taught in the institutes, held each fall and spring throughout the State under the auspices of the State Board of Education, and then for ten years Mr. Boyden taught and lectured in these institutes from one end of the State to the other. Printed outlines and illustrated lessons were given. In I 889, also, a department of naturestudy was established in the summer school at Cottage City, and Mr. Boyden carried it till 1901. The definite beginning of the movement, as such, in Massachusetts seems to have been in 1889 . At first the work was called "elementary science," but this seemed to be inappropriate, and "nature-study" was suggested. This term seemed to be a good equivalent of the German "naturkunde"-nature knowledge. On all programs it was thus printed and quickly secured standing. Shortly after the movement began, the "Conference of Educational Workers" was established. One of the committees had charge of 


\section{Who first used the term Nature-Study? 25}

nature-study and met monthly in Boston. Mr. G. H. Martin, Agent of the Board of Education, was chairman, and Mr. Boyden was secretary. They worked out courses of study for distribution, and one year they had a large exhibit from the whole State of the results of the work. These exhibits were common in cities between 1890 and 1895 .

Amos M. Kellogg, editor of the "New York School Journal" from 1874 to I904, was one of the early writers and advocates on the necessity of drawing on the world about us in the education of the young. Visiting a school in Monroe County, Pennsylvania, in I885, where the teacher was imbued with enthusiasm in this direction and asked for special directions, he suggested to Frank Owen Payne (who was then a regular contributor to the "School Journal"), the preparation of specific lessons; as the term nature-study came to be used he suggested to Mr. Payne the need of the hyphen between the words, and this came to be in regular employment. The specific lessons prepared by $\mathrm{Mr}$. Payne took the title of "One Hundred Lessons 


\section{6}

\section{The Nature-Study Idea}

Around the School." Mr. Payne began the employment of practical nature-study in I 884 when a teacher at Corry, Pennsylvania; then in $1885-86$ in New Jersey. He lectured on the subject in Minnesota in $1886-89$, and has written on it for educational journals.

Many schools in several states were introducing elementary science in the latter part of the eighties, and it seems that several of them began to use the word nature-study without knowing where or how the term was suggested. The term is now in widespread use in English-speaking countries.

The word nature-study was used in January, I905, in the title of a monthly magazine, "The Nature-Study Review," edited and published by Professor M. A. Bigelow of Teachers College, Columbia University, with a board of advisory editors. In January, I908, the "American Nature-Study Society" was organized, and the Review is now its official organ. 


\section{III}

The Meaning of the Nature-Study Movement

$T^{T}$ is one of the marks of the progress of the 1 race that we are coming more and more into sympathy with the natural world in which we dwell. The objects and phenomena become a part of our lives. They are central to our thoughts. The happiest life has the greatest number of points of contact with the world, and it has the deepest sympathy with everything that is.

The best thing in life is sentiment; and the best sentiment is that which is born of the most accurate knowledge. I like to make this application of Emerson's injunction to "hitch your wagon to a star"; but it must not be forgotten that a person must have the wagon before he has the star, and he must take due care to stay in the wagon when he rides in space. Mere facts are dead, but the meaning of the facts is life. The getting of information is 
but the beginning of education. "With all thy getting, get understanding."

Of late years there has been a rapidly growing feeling that we must live closer to nature and make our nature-sentiment vital; and we must of course begin with the child. We attempt to teach this nature-love in the schools, and we call the effort nature-study. It would be better if it were called nature-sympathy.

As yet there are no recognized and regulated methods of teaching nature-study. The subject is not a formal part of the course of study; and thereby it is not perfunctory. And herein lies much of its value-in the fact that it cannot be reduced to a mere system, is not cut and dried, cannot become a part of rigid and formal school method. Its very essence is spirit. It is as free as its subject-matter, as far removed from the museum and the cabinet as the living animal is from the skeleton.

It thus transpires that there is much confusion as to what nature-study is, because of the different attitudes of its various exponents; but these different attitudes are largely the reflec- 
tions of different personalities and the working out of different methods. We cannot say that one way is right and another wrong. There may be twenty best ways of teaching naturestudy. The mode is essentially the expression of one's outlook on the world. Heretofore, we have put the emphasis on training for heaven and taking the child out of his world.

The reader who has followed me thus far has got at the kernel of my thought. I shall now go into more detail, with the purpose to relate the discussion to the practical work of the schoolroom, to develop the teacher's attitude, and to state the essential nature of the movement in different ways and from different angles in order that the thought may stick. This chapter, therefore, is a budget of suggestions rather than an analysis.

\section{What nature-study is not}

There are two or three fundamental misconceptions of .what nature-study is or should be; and to these we may now give attention. 
It is not the teaching of science-not the systematic pursuit of a logical body of principles. Its intention is to broaden the child's horizon, not primarily to teach him how to widen the boundaries of human knowledge. It is not the teaching of botany or entomology or geology, but of plants, insects and fields. But many persons who are teaching under the name of nature-study are merely teaching and interpreting elementary science. Fundamentally, naturestudy is seeing what one looks at and drawing proper conclusions from what one sees; and thereby the learner comes into personal relation with the object.

It is not reading from nature-books. Naturestudy is studying things and the reason of things, not about things. A child was asked if she had ever seen the great dipper. "Oh, yes," she replied, "I saw it in my geography." This is better than not to have seen it at all; but the proper place to have seen it is in the heavens. Nature-readers may be of the greatest value if they are made incidental and secondary features of the instruction; but, however good they may 
be, their influence is pernicious if they are made to be primary agents. Nature-study begins with the concrete, as the child does if left to itself. The child should first see the thing. It should then reason about it. Having a concrete impresșion, it may then go to the book to widen its knowledge and sympathies. Having seen mimicry in the eggs of the aphis on the willow or apple twig, or in the walking-stick, the pupil may then take an excursion with Wallace or Bates to the tropics and there see the striking mimicries of the leaf-like insects. Having seen the wearing away of the boulder or the ledge, he may go to Switzerland with Lubbock and see the mighty erosion of the Alps. Now and then the order may be reversed with profit, but this should be the exception: from the wagon to the star should be the rule.

Nature-study is not the teaching of facts merely for the sake of the facts, or materials for the sake of the materials: its purpose is to develop certain intellectual powers by the use of the materials. It is not the giving of information only-notwithstanding the fact that some 
nature-study leaflets are information leaflets. We must begin with the fact, to be sure, but the lesson lies in the significance of the fact. It is not necessary that the fact have direct practical application to the daily life, for the purpose is the effort to train the mind and the sympathies and to develop in the child a correct view of nature. It is a common notion that when the subject-matter is insects, the pupil should be taught the life-histories of injurious insects and how to destroy the pests. Now, nature-study may be equally valuable to the pupil, whether the subject is the codlin-moth or the ant, since both may be within his sphere and his relations; but to confine the pupil's attention to insects that are injurious to man is to give him a distorted, partial and untrue view of nature. A bouquet of daisies does not represent a meadow.

It is not a program for the teaching of morals. Children should be interested more in seeing things live and in studying their habits than in killing them. Yet I should not emphasize the injunction, "Thou shalt not kill." I should prefer to have the child become so much 
interested in living things that it would have no desire to kill them. The gun and sling-shot and steel-trap will be laid aside because the child does not care for them any more. We have been taught that one must make collections if he is to be a naturalist; but collections alone make museums, not naturalists. The scientist needs these collections; but it does not follow that children always need stuffed animals, birds' eggs, and bottled specimens, although it is important to encourage a regulated collecting instinct.

Nature-study is not merely the adding of one more thing to a course of study. It is not coördinate with geography or reading or arithmetic. Neither is it a mere accessory, or a sentiment, or an entertainment, or a means of injecting vacant wonder into the pupils. It is not "a study." It is not the addition of more "work." A new "study" taught by the old method would not represent progress. (The idea has to do with the whole point of view of elementary education, and therefore is underlying. It is the full expression of personality. 


\section{The Nature-Study Idea}

It relates schooling to living. It is a practical working out of the extension idea that has been so much a part of our time. More than any other recent movement, it will reach the masses and revive them.

Nature-study should not be unrelated to the child's life and circumstances. It stands for directness and naturalness. It is astonishing, when one comes to think of it, how indirect and how remote from the lives of pupils much of our education has been. Geography still often begins with the universe, and finally, perhaps, comes down to some concrete and familiar object or scene that the pupil can understand. Arithmetic has to do with brokerage and partnerships and partial payments and other things that mean nothing to the child. Botany begins with cells and protoplasm and cryptogams. History deals with political and military affairs, and only rarely comes down to physical facts and to those events that express the real lives of the people; and yet political and social affairs are only the results or expressions of the way in which people live. Readers begin with mere 
Meaning of the Movement

literature or with stories of scenes the child will never see. Of course these statements are meant to be only general, as illustrating what is even yet a great fault in educational methods. There are many exceptions, and these are becoming commoner. Surely, the best education is that which begins with the materials at hand. A child knows a stone before it knows the earth.

\section{The outlook by fact and by fancy}

There are two ways of interpreting naturethe way of fact and the way of fancy. To the scientist and to the average man the interpretation by fact is usually the only admissible one. He may not be open to argument or conviction that there can be any other truthful way of knowing the external world. Yet, the artist and the poet know this world, and they do not know it by cold knowledge or by analysis. It appeals to them in its moods. Yet it is as real to them as to the analyst. Too much are we of this generation tied to mere phenomena..

We have a right to a poetic interpretation of nature. The child interprets nature and the 
36 The Nature-Study Idea

world through imagination and feeling and sympathy. Note the intent and sympathetic face as the child watches the ant carrying its grains of sand and pictures to itself the home and the bed and the kitchen and the sisters and the school that comprise the ant's life. What does the flower think? Who are the little people that teeter and swing in the sunbeam? What is the brook saying as it rolls over the pebbles? Why is the wind so sorrowful as it moans on the house-corners in the dull November days? There are elves whispering in the trees, and there are chariots of fire rolling on the long, low clouds at twilight. Wherever it may look, the young mind is impressed with the mystery of the unknown. The child looks out to nature with great eyes of wonder.

We cannot say that the good poets have not known nature, because they have not interpreted by fact alone. Have they not left us the essence and flavor of the fields and the woods and the sky? And yet they were not scientists. So different are these types of interpretation 
that we all unconsciously set the poet over against the scientist.

Good poetry is not mere vacant sentiment. The poet has first known the fact. His poetry is misleading if his observations are wrong. Whatever else we are, we must have the desire to be definite and accurate. We begin on the earth; later, we may drive our Pegasus to a star.

Of course I would not teach nature-subjects in order that the poetic point of view may be enforced. I plead only that the poetic interpretation is allowable. It may be one result of knowing nature for the sake of knowing it.

\section{How nature-study may be taught}

How shall nature-study be taught? By the teacher and the object. The teacher will need helps. There are books and leaflets that will help him. These publications may be put in the hands of pupils if it is always made plain that the recitation is to be from objects and situations that the pupil has seen, not from the book. There can be no text-book of real nature-study, for when one studies a book he does 
$3^{8} \quad$ The Nature-Study Idea

not study nature. The book should be a guide to the animal or plant: the animal or plant should not be a guide to the book.

The teacher may need the help of a program or consecutive purpose. The program, however, should not be a tabulated series of regulations or a hard-and-fast system; but there should be some underlying educational principle or intention running through every item of it. The work may be informal and free without being aimless.

This immediate purpose or plan may be to teach the progress of the seasons; the common implements and simple handcrafts; the plant life of the neighborhood; the bird life; the usual insects; the heavens; the weather and its relations with man and animals; something of the farming or industries of the region; one's own mind and body and how they should be governed in the interest of good health; or some other theme that will tie the work together. In practice, the work will almost necessarily be consecutive because the teacher will feel himself competent in two or three lines and will devote 
himself to them. The environment will suggest the work.

There will be opportunity for endless variation in the details and in the little applications of the work. The personality of the teacher must always stand out strongly. We need the very best of teachers for nature-study-those who have the greatest personal enthusiasm, and who are least bound by the traditions of the classroom. The teacher, to be ideal, must have more time, more feeling, and more knowledge. It is better if the teacher have a large knowledge of science, but nature-study may be taught without great knowledge if one sees accurately and infers correctly from the particular subject in hand.

The teacher should avoid startıng with definitions and the setting of patterns. Definitions should be the result or summary of the study, not the beginning of it. Mere patterns should afford means of comparison only, and not be regarded as useful in themselves; and even then they are often misleading. The old idea of the model flower is an unfortunate one, 


\section{The Nature-Study Idea}

because the model flower does not exist in nature. The model flower, the complete leaf, and the like, are inferences; and the pupil should not begin with abstract ideas. In other words, the ideas should be suggested by the things, and not the things by the ideas. "Here is a drawing of a model flower," the old method says; "go and find the nearest approach to it." "Go and find me a flower," is the better method, "and let us see what it is."

Two factors determine the proper subjects for any teacher to choose for nature-study instruction. First, the subject must be that in which the teacher is most interested and of which he has the most knowledge; second, it must represent that which is commonest and which can be most easily seen and appreciated by the pupil, and which is nearest and dearest to his life.

With children, begin with naked-eye objects. As the pupil matures and becomes interested, the simple microscope may be introduced now and then. Children of twelve years and more may carry a pocket lens; but the best place to use this lens is in the field. The best nature- 
study observation is that which is done out-ofdoors; but some of it can be made from material brought into the schoolroom.

The tendency is to go too far afield for the subject-matter. We are more likely to know the wonders of China or Brazil than of our own brooks and woods. If the subject-matter is of such kind that the children can see the objects as they come and go from the school, and collect some of them, the results will be the better. As the pupil matures, he should be taken out to the world activities.

It is a sound educational principle that the child should not be taught mere dilutions of science. The young child cannot understand cross-fertilization of flowers, and should not be taught the subject. It is beyond the child's realm. When we teach it to young children, we are only translating what grown-up investigators have discovered by means of faithful search. At best, it will only be an exotic thing to the child. Pollen and stamens are not near and dear to the child.

There are three steps in the teaching of nature-study: 
(I) The fact,

(2) The reason for the fact,

(3) The interrogation left in the mind of the pupil.

It is impossible to find a natural-history object from which these three factors cannot be drawn, for every object is a fact and every fact has a cause, and children may be interested in both the fact and the cause. It may be better, of course, to choose definite subjects, taking pains, at least at first, to choose those having emphatic characters.

But even in the dullest days of winter sufficient materials may be found to keep the interest aflame. A twig or a branch may be at hand. There should be enough specimens to supply each child. Let the teacher ask the pupils what they see. The replies will discover the first factor in the teaching - the fact. However, not every fact is significant to the teacher or to the particular pupils. It remains for the teacher to pick out the fact or answer that is most significant. The teacher should know what is significant and he should keep the 
point clearly before him. One pupil says that the twig is long; another that it is brown; another that it is crooked; another that it is from an apple tree; another that it has several unlike branchlets or parts. Now, this last reply may appeal to the teacher as most significant. Stop the questioning and open the second epoch in the instruction - the reason why no two parts are alike. As before, from the great number of responses the significant reason may be developed: it is because no two parts have lived under exactly the same conditions. One had more room or more sunlight and it grew larger. The third epoch follows naturally: are there any two objects in nature exactly alike? Let the pupils think about it.

Choose a stone. If similar stones are in the hands of the pupils, you ask first for the observation or the fact. One says that the stone is long; another, it is light; another, it is heavy; another, that the edges are rounded. This latter fact is very significant. You stop the observation and ask why it is rounded. Some one replies that it is because it is water-worn. 


\section{The Nature-Study Idea}

Query: Are all stones in brooks rounded? Numberless applications and suggestions can be made from this simple lesson. What becomes of the particles that are worn away? How has soil been formed? How has the surface of the fields been shaped and molded?

It is not necessary that the teacher always know the reason. He may propose that they all find out and report. It is the strong teacher who can say: "I do not know." If a problem had been sent to Agassiz or Asa Gray and he had not understood it, would he have dissimulated or have evaded in the answer? Would he not have said unhesitatingly, "I do not know"? Such men delve for knowledge, but for every fact that they discover they turn up a dozen mysteries. Knowledge begins in wonder. The consciousness of ignorance is the first result of wonder, and it leads the pupil on and on: it is the spirit of inquiry.

These illustrations are given merely as examples. They may not be ideal, but they show what can be done with very common material. In fact, the surprise and interest is often all the 
greater because the objects are so very common and familiar.

To my mind, one of the best of all subjects for nature-study is a brook. It affords studies of many kinds. It is near and dear to every child. It is an epitome of the nature in which we live. In miniature, it illustrates the forces that have shaped much of the earth's surface. It reflects the sky. It is kissed by the sun. It is rippled by the wind. The minnows play in the pools. The soft weeds grow in the shallows. The grass and the dandelions lie on its banks. The moss and the fern are sheltered in the nooks. It comes one knows not whence; it flows one knows not whither. It awakens the desire to explore. It is fraught with mysteries. It typifies the flood of life. It "goes on forever."

In other words, the reason why the brook is such a perfect nature-study subject is the fact that it is the central theme in a scene of life. Living things appeal to children. To relate the nature-study work to living animals and plants should constitute the burden of the effort. 
46 The Nature-Study Idea

I would study a brook or a fence-corner or a garden-bed or a bird or a domestic animal or an insect or a plant. The life-histories of certain insects, and all common forms of life, afford excellent nature-study exercise for pupils of proper age.

However, the teacher and the way of teaching are more important than the subject-matter, and there are good nature-study teachers who are better fitted to teach inanimate than animate subjects. There is no better nature-study exercise than to observe the erosion by brooks, floods, and rains, if the teacher is prepared to handle it; and surely nothing can be more important than to put the child in sympathy with the weather; and all persons should have the habit of looking at the heavens in day and night.

It is due to every child that his mind be opened to the voices of nature. The world is always quick with sounds, although our ears are closed to them. Every person hears the loud songs of birds, the sweep of heavy winds and the rush of rapid rivers or the sea; but the small 


\section{Meaning of the Movement}

voices with which we live are known not to one in ten thousand. To be able to distinguish the notes of the different birds is one of the choicest resources in life, and it should be one of the first results of a good education. It is but a step from this to the other small voices, - of the insects, the frogs and toads, the mice, the domestic animals, the flow of quiet waters, and the noises of the little winds. It is a great thing when one learns how to listen. At least once, every young person should sleep far out in the open, preferably in a wood or the margin of a wood, that he may know the spirit and the voices of the night and thereafter be free and unafraid.

Similar remarks may be made of the odors, for the world breathes a multitude of fragrances of which most persons are wholly unaware. Usually only the strong smells are known to us, and we merely divide them into two classes,those that we like and those that we do not like.

All the senses should be so trained and adjusted that all our world becomes alive to us. Then we are really sensitive.

One of the first things that a child should 


\section{The Nature-Study Idea}

learn when he comes to the study of natural history is the fact that no two objects are alike. This leads to the correlated fact that every animal and plant contends for an opportunity to live, and this is the central theme in the study of living things. The world has a new meaning when this fact is understood. This is the key that unlocks many mysteries, and it is the means of establishing a bond of sympathy between ourselves and the world in which we live.

It is a common mistake to attempt to teach too much at each exercise; and the teacher is also appalled at the amount of information that he must have. Suppose that one teaches two hundred and fifty days in the year. Start out with the determination to drop into the pupils' minds two hundred and fifty suggestions about nature. One suggestion is sufficient for a day. Let them think about it and ponder over it. We stuff our children so full of facts that they cannot digest them. I should prefer ten minutes a day of nature-study to two hours; but I should want it quick, sharp, vivid and spontaneous. I should want it designed to develop 
Meaning of the Movement

the observing and reasoning powers of the child and not to gorge the pupil. Spirit counts for more than knowledge.

It is well to verify observations and conclusions on different days. Let the pupils compare ideas and experiences. This develops an intellectual habit of taking nothing on hearsay or for granted.

Taught in this way, nature-study work is not an additional burden to the teacher, but may be made a relief and a relaxation. It may come at the opening of the school hour, or at the close of a hard period, or at other time when an opportunity offers. It may often be combined with the regular studies of the school, and in that way it may be introduced in places where it would otherwise meet with objection. For example, the subject-matter of the nature-lesson may be used for the exercise in drawing or in geography. Let the child draw the twigs; but always be careful that the drawing does not become more important than the twigs.

$\mathrm{My}$ remarks on procedure are meant, of course, to apply to children. As the pupil ad- 


\section{The Nature-Study Idea}

vances, the work will naturally become more systematic, until, in the high school, it may develop into more formal teaching, and then a regular period will be required. Those who complain that nature-study is desultory are really thinking of science, not of nature-study. Although not the teaching of science, as such, nature-study is not unscientific. It is not in any sense a letting down of standards, if properly handled, but a new intention in education.

What may be the results of nature-study?

Its legitimate result is education-the developing of mental power, the opening of the eyes and the mind, the civilizing of the individual. As with all education, its central purpose is to make the individual happy; for happiness is nothing more nor less than pleasant and efficient thinking, coming from a consciousness of the mastery, or at least the understanding, of the conditions in which we live.

The happiness of the ignorant man is largely of physical pleasures; that of the educated man is of intellectual pleasures. One may find com- 
radeship in a groggery, the other may find it in a dandelion; and inasmuch as there are more dandelions than groggeries (in most communities), the educated man has the greater chance of happiness.

Some persons object to nature-study because it is not systematic and graded. They think that it leads to disjunctive and discursive work. The informality may be its charm. Thereby comes the contrast with the perfunctory school work; and thereby, also, arises its naturalness and its freedom. It is easily possible to "organize" nature-work until it becomes as automatic as other work. The formal school work will supply the drill in method and system. Naturestudy will afford relaxation, and it will be valuable because it is short, forceful, and voluntary; and this result is worth securing.

The mode of presentation that naturally develops in nature-study teaching is really very important in its effect on the pupil's approach to subject-matter and on his outlook to the world. The presentation is quick, simple, 
direct, little confused by apparatus and selfconsciousness and side issues.

Good nature-study teaching develops personality and encourages the pupil to think for himself and to maintain an individual relation to his world. It emphasizes adaptation to life as distinguished from the tendency of much of our teaching to produce uniformity of thought and action.

Nature-study not only educates, but it educates nature-ward; and nature is ever our companion, whether we will or no. Even though we are determined to shut ourselves in an office, nature sends her messengers. The light, the dark, the moon, the cloud, the rain, the wind, the falling leaf, the fly, the bouquet, the bird, the cockroach-they are all ours. Few of us can travel. We must know the things at home.

Nature-love tends toward simplicity of living. It tends country-ward. "God made the country."

Nature-study ought to revolutionize the school life, for it is capable of putting new force and enthusiasm into the school and the child. It is new, and therefore is called a whim. A movement is a whim until it succeeds. We shall learn 
Meaning of the Movement

much, and shall outgrow some of our present notions, and shall eliminate the vagaries. It is in much the stage of development that manualtraining and kindergarten work were twenty-five years ago. We must take care that it does not crystallize into science-teaching on the one hand, nor fall into mere sentimentalism and gush on the other.

In many ways we are now in a transition period in our school systems. We are living in an era of the material equipment of schoolsthe erecting of magnificent buildings, the gathering of extensive outfits. This is true of colleges and universities as well as of the common schools. When this era is past, we shall have more money to spend for teachers. Teaching will be a profession requiring better training and commanding more pay, and men teachers will come back to it.

In this evolved and emancipated school, the nature-study spirit will prevail, even though the name itself be lost. This spirit stands for a normal outlook on life. It is the active and 


\section{The Nature-Study Idea}

creative method. It is a developing of the powers of the pupil, not hearing him recite. In spirit and method, it is opposed to the pouring-in and dipping-out process.

The nature-study effort sets our thinking in the direction of our daily doing. It relates the schoolroom to the life that the child is to lead. It makes the common and familiar affairs seem to be worth the while. It ought to make men and women effective and responsible. Essentially, it is not an ideal for the school any more than it is for the home; but so completely do we delegate all work of teaching and instructing to the school, that nature-study effort comes to be, in practice, a schoolroom subject. The ideal of the parent or the teacher should be to bring the child into natural relations with its world; but whatever may be in the mind and hope of the teacher, so far as the child is concerned the nature-sympathy must come as a natural effect of actual observation and study of definite objects and phenomena.

I will mention two forms of adaptation to life, as illustrations of what I mean. (I) Na- 


\section{Meaning of the Movement}

ture-study teaching ought to utilize, as means of education, the tools that a boy or girl naturally uses. The habits of men are as important as those of other animals. How to use a jackknife, a hoe, a saw, an auger, a hammer, or other implement by means of which man adapts himself to his conditions, is a very essential part of good teaching, but one that is almost universally neglected. The tools of the household may be made the means of training a girl to a new hold on life. These devices are not to be studied merely as implements, but as a part of the study of the natural history of human beings. All this would constitute a manual-training that would be founded on good sense. (2) The pupil should be taught to make observations on himself. He will find himself to be a very interesting natural-history object. It is just as well to know how a man walks as to know how a horse or a crow walks. The unconscious and automatic habits of men and women are as interesting as those of fish and insects. This kind of observation ought to have remarkable significance to health. It is most strange how 
${ }_{5} 6$ The Nature-Study Idea

little we reason from cause to effect in our own habits of eating and drinking and sleeping and exercise, and how much we rely on the physician to advise us in matters on which we ourselves would be much better judges if we observed ourselves as closely as we observe other objects. The simple regulation of the daily habits of life lies at the foundation of all good health. The application of the naturestudy spirit of direct and simple observation of ourselves, with less of the physician's physiology, would benefit the pupil and also our civilization immeasurably.

The great intention of nature-study is to cultivate a sensible interest in the out-of-doors, and to remove all conventional obstacles thereto. Real interest in the out-of-doors does not lie in the physical comfort of being in the open in "good" weather (persons who have this outlook do not know nature), but in spiritual insight and sympathy. One sleeps in the woods or fields not because these are the most comfortable places in which to spend the night, but that he may have communion and freedom. 


\section{The Nature-Study Idea}

There is a large public and social result of simple and direct teaching of common things. It explains the relations between man and his environment. It establishes a new sense of our dependence on the natural resources of the earth, and leads us not to abuse nature or to waste our resources. It develops a public intelligence on these matters, and it ought to influence community conduct. All teaching that is direct, native and understandable should greatly influence the bearing of the individual toward his conditions and his fellows, awaken his moral nature, and teach him something of the art of living in the world. 


\section{IV}

\section{The Integument-Man}

T WOTE a nature-study leaflet on "How a 1 Squash Plant gets out of the Seed." A botanist wrote me that it were a pity to place such an error of statement before the child: it should have read, "How the Squash Plant Gets Out of the Integument."

Of course my friend was correct: the squash plant gets out of an integument. But I was anxious to teach the essence of the squash plant's behavior, not a mere verbal fact-and what child was ever interested in an integument?

It is the old question over again-the question of the point of view and what one is driving at. A person may be so intent on mere literal veracity that he misses the pupil. Much of our natural-science teaching is as hard and dead as the old Latin and mathematics.

It is the fear of the Integument-Man that keeps many a good teacher from teaching nature-study. $\mathrm{He}$ is afraid that he will make a 
mistake in statements of small fact. Now, the person who is afraid of making a mistake is the very person to trust, because he will be careful. Of course he will make mistakes-every one does who really accomplishes anything; but the mistakes will be relatively few: he will at once admit the mistakes and correct them when they are discovered, and the pupils will catch his desire for accuracy and admire the sincerity of his purpose. Pity the man who has never made an error!

The teacher often hesitates to teach naturestudy because of lack of technical knowledge of the subject. This is well; but technical knowledge of the subject does not make a good teacher. Expert specialists are so likely to go into mere details and to pursue particular subjects so far, when teaching beginners, as to miss the leading and emphatic points. They are so cognizant of exceptions to every rule that they qualify their statements until the statements. have no spirit and no force. There are other ideals than those of dead accuracy. It is more important that any teacher be a good teacher 


\section{0}

The Nature-Study Idea

than a good scientist. But being a good scientist ought not to spoil a good teacher. The Integument-Man sees the little things and teaches details, and his teaching is "dry." $\mathrm{He}$ lacks imagination.

The child wants things in the large and in relation; when it gets to the high-school or college it may carry analysis and dissection to the limit.

The Integument-Man teaches science, although it is not necessarily the best science. The child wants nature.

The Integument-Man thinks that if any work is only accurate it is thereby of value; and accuracy in nature-study begets accuracy in science, when the pupil takes it up later on. This is all well enough; but the child can be accurate only so far as it can comprehend: it must work in its own sphere; integuments are not in the child's sphere.

The degree of statement is more important than final accuracy-if there is such a thing as final accuracy; all knowledge is relative, and 
what is within the range of one mind may be far beyond the range of another, and it is folly to try to make the statement as full and accurate for the latter mind as for the former. A very imperfect statement of osmosis is accurate for a child or a young pupil; a fuller statement is accurate for the college student; and a still fuller and exacter statement is accurate for the physicist; but perhaps it is impossible to make any statement of it that is finally accurate. The Integument-Man confuses all these degrees, and thinks that because the statement is inaccurate for the physicist, it is therefore inaccurate for the pupil or the child. Refined verbiage that safeguards the statement to the scientist, may confuse it to the beginner. It may be only pedantry and narrowness. It is not an accident that some of the most useful text-books have been made by persons who do not know too much about the subject.

The Integument-Man is fearful of every word that seems to imply motive or direction in plants and the lower animals. "The roots go here and there in search of food" is wrong 
because roots do not "go." Seeds do not "travel." Plants do not "prepare" for winter. I wonder, then, whether water "runs" or winds "blow." This verbal preciseness forgets that words are only metaphors and parables, their significance determined by the use of them, and that the essential truth, or the spirit, is what we should search for-expressing it, when found, in language that is alive, unmistakable, and conformed to best usage. We must measure the value of any statement to the child in good part by the strength and vitality of the picture that it raises in the mind (p. I 59).

The Integument-Man insists on "methods." The other day a young man wanted me to recommend him as a teacher of one of the sciences in a public school. He explained that he had had a complete course in this and in that; he could teach the whole subject as laid down in the books; he knew all the methods. It was evident that he was well drilled. $\mathrm{He}$ had acquired a repertory of facts. These facts were carefully assorted and ticketed, and tucked away in his mental cupboard as embroidered 
and perfumed napkins are laid away in a drawer. Poor fellow!

Mere details have little educative value. An imperfect method that is adapted to one's use is better than a perfect one that cannot be well used. Some school laboratories are so perfect that they discourage the pupil in taking up investigations when thrown on his own resources. Imperfect equipment often encourages ingenuity and originality. A good teacher is better than all the methods and laboratories and apparatus.

I like the man who has had an incomplete course. A partial view, if truthful, is worth more than a complete course, if lifeless. If the man has acquired power for work, a capability for initiative and investigation, an enthusiasm for the daily life, his incompleteness is his strength. How much there is before him! How eager his eye! How enthusiastic his temper! $\mathrm{He}$ is a man with a point of view. This man will see first the large and significant events; he will grasp relationships; he will correlate; later, he will consider the details. $\mathrm{He}$ 
64 The Nature-Study Idea

will study the plant before he studies the leaf or germination or the cell. He will discover the bobolink before he looks for its toes. He will care little for mere "methods." His teaching will have freshness.

The Integument-Man is afraid that this popular nature-study will undermine and discourage the teaching of science. Needless to say, the fear is absurdly groundless. Science-teaching is a part of the very fabric of our civilization. All our goings and our comings are adjusted to it. No sane man wishes to cheapen or discourage the teaching of science. Nature-study

- is not opposed to it. Nature-study prepares the child to receive the science-teaching. Gradually, as the child matures, nature-study may grow into science-learning if the pupil so elect. Science-teaching has more to fear from desiccated science-teaching than it has from naturestudy. It is the Integument-Man himself who is discouraging the teaching of science. Everything that is true and worth the while will endure.

All youths love nature. None of them, 
primarily, loves science. They are interested in the things that they see. By and by they begin to arrange their knowledge and impressions, and thereby to pursue a science. The idea of the science should come late in the educational development of the youth, for the simple reason that science is only a human way of looking at a subject. There is no natural science, but there has arisen a science of natural things. At first the interest in nature is an affair of the heart, and this attitude should never be stifled, much less eliminated. When the interest passes from the heart to the head, nature-love has given way to science. Fortunately, it can always remain an affair also of the heart, but the dry teaching of facts alone tends to divorce the two. When we begin the training of the youth by the teaching of a science we are inverting the natural order. A rigidly graded and systematic body of facts kills nature-study; examinations bury it.

Then teach! If you love nature and have living and accurate knowledge of some small part of it, teach! Do not fear your scientific 
66 The Nature-Study Idea

reputation if you feel the call to teach. Your reputation is not to be made as a geologist or zoölogist or botanist, but as a leader. When beginning to teach birds, think more of the pupil than of ornithology. The pupil's mind and sympathies are to be expanded: the science of ornithology is not to be extended; the science will take care of itself. Remember that spirit is more important than information. The teacher who thinks first of his subject teaches science; he who thinks first of his pupil teaches nature-study. With your whole heart, teach!

Do not be afraid of the Integument-Man $\mathrm{N}_{<}$ 


\section{V \\ Nature-Study with Plants}

A LL the so-called natural sciences are conA tributing to the nature-study movement. Plants are so much a part of every landscape, however, we have such constant association with them, and the plant material is so easy to secure, that they afford the very best subjects for naturestudy work. One cannot understand the world if he does not know plants.

The methods in plant-study show a distinct development in pedagogical ideas which it may be well to recapitulate. One can make out four fairly well marked stages in the teaching of plant subjects.

First, was the effort to know the names of plants and to classify the kinds. This was a 'direct reflection of the systematic or classificatory studies of the botanists. The external world had been unknown as to its details, and botanists necessarily attempted inventories of the plant kingdom. Plants must be collected 
and named. From this impulse arose the herbarium collecting, a method of teaching which was so thoroughly impressed into school methods a generation or two ago that it is still troublesome in many places.

The second stage in plant-study in the American schools was the desire to know the names of the parts of plants. It came with the excellent text-books of Asa Gray and others, in which the results of studies in organography, morphology and histology were organized and defined. These books were nearly as rigid in their systems and methods as text-books of physics; and the pupil recited mostly from the book, with perhaps some accessory observation on plants.

The third epoch is that of training for independent investigation. In very recent times, and chiefly since the death of Gray, the German laboratory methods have been widely copied in America by the many young and painstaking botanists who have studied abroad. As a result there are many high-schools that are equipped with microscopes and apparatus that would 
have done credit to a college or university a few years ago. The customary laboratory method is a distinct advance on the preceding methods of teaching in the fact that the pupil actually studies plants; but its motive and point of view are distinctly wrong for the elementary school because it attempts primarily to teach botany rather than to educate the pupil. The field of view is also very narrow, and the pupil's mind is likely to be closed to nature and restricted in its range. The stage of the microscope and the tables of the laboratory are poor and narrow ranges for the young mind when there are fields and gardens adjacent. The German laboratory method is no doubt quite perfect for the training of investigators and specialists, but it lacks the inspiration and the educative impulse that young minds need.

The fourth stage is the effort to know the plant as a complete organism living its own life in a natural way. It is marked by a new and vital plant physiology. In the beginning of this epoch we are now living. 


\section{The Nature-Study Idea}

\section{Suggestions for plant work}

The pupil should come to the study of plants and animals with little more than his natural and native powers. Study with the compound microscope is a specialization to be made when the pupil has had experience and when his judgment and sense of relationships are trained.

A difficulty in the teaching of plants is to determine what are the most profitable topics for consideration. Much of the teaching attempts to go too far and the subjects have no vital connection with the pupil's life. Good botanical teaching for the young is replete with human interest. It is connected with the common associations.

Plants always should be taught by the "laboratory method": that is, the pupil should work out the subjects directly from the specimens themselves; but I should want it understood that the best "laboratory" may be the field, and that the plants are to be studied as plants rather than as dissected pieces.

Specimens mean more to the pupil when he 


\section{Nature-Study with Plants}

collects them. No matter how commonplace the subject, a specimen will vivify it and fix it in the pupil's mind. A living, growing plant is worth a score of herbarium specimens.

In the secondary schools, botany should be taught for the purpose of bringing the pupil closer to the world with which he lives, of widening his horizon, of intensifying his hold on life. It should begin with familiar plant forms and phenomena. It is often said that the high-school pupil should begin the study of botany with the lowest and simplest forms of life. This is wrong. The microscope is not an introduction to nature. It is said that the physiology of plants can be best understood by beginning with the lower forms. This may be true: but the customary technical plant physiology is not a subject for the beginner. There are better ways of putting the beginner into touch with physiology. The youth is by nature a generalist. He should not be forced to be a specialist.

Just what kind of plant or animal subjects should be taught must depend (I) on the de- 
sires and capabilities of the teacher; (2) on the place in which the school is-whether city or country, North or South, prairie or mountainfor it is important that the subject be common and have relation to the experiences of the pupils; (3) on the desires of the pupils, particularly if they are to do the collecting; (4) on the time of the year.

Whenever possible, let the pupil first come into cognizance of the plant as a whole. It is well to choose one species that is common and familiar; then endeavor to determine where it grows, why it grows there, how it is modified in different circumstances. If it is a dandelion, one lesson may be devoted to dandelions in the school-yard; another to dandelions in the meadow; another to dandelions along hard and dry roadsides; another to dandelions in rich farmyards and gardens; another to dandelions in the borders of woodlands. Compare the relative abundance of dandelions in these different places: why? Do the plants "look" the same in these different places: how differ and why? (Note the size and form of plants, rela- 
tive number of leaves, form and size of leaves, root habit, abundance of bloom, length of flower stems.). It is a practice in some schools to teach mathematics by means of dandelions, on the mistaken notion that nature-study is being taught; putting the word dandelion into problems, where the words stone, book, box or knife might just as well be used, is only verbal substitution and will have little effect on the pupil's relation to dandelions except to make him dislike them.

Having known one kind of common plant, the pupil may well study plant societies-how plants live together, and why. Every distinct or separate area has its own plant society. There is one association for the hard-tramped door-yard-knotweed and broad-leaved plantain with interspersed grass and dandelions; one for the fence-row-briers and choke-cherries and hiding weeds; one for the dry open field-wiregrass and mullein and scattered docks; one for the slattern roadside-sweet clover and ragweed and burdock; one for the meadow swale - smartweed and pitchforks; one for the barnyard—rank pigweed and sprawling barn-grass; 


\section{The Nature-Study Idea}

one for the dripping rock-cliff-delicate bluebells and hanging ferns and grasses. These categories may be indefinitely extended. We all know the plant societies, but we have not thought of them.

In every plant society there is one dominant note: it is the individuality of one kind of plant that grows most abundantly or overtops the others. Certain plant-forms come to mind when one thinks of willows, others when he thinks of an apple orchard, still others when he thinks of a beech forest. The farmer may associate "pussly" with cabbages and beets, but not with wheat and oats. $\mathrm{He}$ associates cockle with wheat, but not with oats or corn. We all associate dandelions with grassy areas, but not with burdocks or forests.

It is impossible to open one's eyes out-ofdoors outside the paved streets of cities without seeing a plant society. A lawn is a plant society. It may contain only grass, or it may contain weeds hidden away in the sward. What weeds remain in the lawn? Only those that can withstand the mowing. What are 
they? Let a bit of lawn grow as it will for a month and see what there is in it. A swale, a dry hillside, a forest of maple, a forest of oak, a forest of hemlock or pine, a weedy yard, a tangled fence-row, a brook-side, a deep quiet swamp, a lake shore, a railroad, a river bank, a meadow, a pasture, a dusty roadway-each has its characteristic plants. Even in the winter one may find these societies-the tall plants still asserting themselves, others of less aspiring stature, and others snuggling just under the snow.

Later, special attributes or forms of plants may be considered-forms of stems, bark, ways of branching, root forms, leaf forms, position and size of leaves with reference to light, flower forms, falling of the leaves, germination, seed dispersal, pollination (for older pupils), injuries of various kinds (as by snow, ice, wind, sun-scalding, drought, insects, fungi, browsing by cattle), simple physiological experiments of many kinds (such as are now described in our best text-books). In winter, studies may be made of the forms of trees and bushes and of 


\section{The Nature-Study Idea}

persisting weeds, leaf-buds and fruit-buds, bark forms, preparation for spring, tubers and bulbs, seed-sowing and germination, struggle for existence in the tree-top, evergreens and how they shed their leaves, how the different kinds of trees hold the snow, where the herbs and tender things are, cones and seed pods, apples and turnips and other things from the cellar, knots and knot-holes, how vines hold to their supports, and others. These subjects are intended only as suggestions of the kind of work that may be taken up with profit.

As far as possible, the study of form and function should go together. Correlate what a part is with what it does. What is this part? What is its office, or how did it come to be? It were a pity to teach phyllotaxy without teaching light-relation: it were an equal pity to teach light-relation without teaching phyllotaxy.

There are those who discourage the teaching of plant societies until the pupil is well grounded in "physiology"; but this, again, is the scienceteaching point of view. Of course the child cannot understand the fundamental reasons for 


\section{Nature-Study with Plants}

plant association-I wonder whether the botanist does?-but the child can comprehend the phenomena, and he will be interested in them because they are so intimately associated with him and are observable.

There are those, again, who say that such subjects as those suggested above do not prepare the pupil to enter college. My reply is that the elementary schools do not exist for the sake of the college or the university. Those that are to enter college are a small and special class, and they may receive special instruction.

I have spoken of the herbarium stage of plant-study and have said that it is passing away. It is perfectly possible, however, to make herbaria without in any way lessening the value of beginning plant-work (the rather increasing its value), but the herbarium should be a result of the work rather than constitute the work itself. After the pupil has come to know the dandelion or a plant society or the flora of the neighborhood, he will do well to make specimens; these specimens will be a part of his records. 
The Growing of Plants by Children-The School-Garden

CTUALLY to grow a plant is to come A into intimate contact with a specific bit of nature. The numbers of plants that we grow, and also the kinds of them, increase with every generation. The intensity of our plant-growing, as well as the increasing care for animals, is coming to be a measure of our interest in the world about us.

Not only has the cultivation of plants itself increased our contact with plants and with nature, but, in connection with the growth of the spirit of art, of sport, and of suburbanism, it has taken us afield and has impelled us to know things as they are and as they grow. The modern popularization of plant-knowledge is probably due more to these agencies than to the progress of botany.

There are many practical applications to the lives of children and to the home that may be 


\section{The Growing of Plants}

made from a knowledge of plants and horticulture. This knowledge means more than mere information of plants themselves. It takes one into the open air. It enlarges his horizon. It brings him into contact with living things. It increases his hold on life. All these facts were well understood by Froebel, Pestalozzi, and other educational reformers.

It is important that one does not assume too much when beginning plant-work with children. We forget that things which fail to appeal to us, because of our busy lives and great experience, may nevertheless mean very much to the child. Often we attempt to teach the child so much that it is confused and nothing makes an impression. An interest in one simple, living problem that is near to the child's life is worth a whole book of facts about nature.

It is not primarily important that children know the names, although the name is an introduction to a plant as it is to a person. The essential point is that there should be plants about the home, or in the school grounds, or in the schoolhouse windows. Even though the 
80

\section{The Nature-Study Idea}

children are not conscious that they are receiving any impression from these plants, nevertheless the very presence of them has an influence that will be felt in later life, even as the presence of good literature and furniture and the association of refined surroundings has influence.

I dropped a seed into the earth. It grew, and the plant was mine.

It was a wonderful thing, this plant of mine. I did not know its name, and the plant did not bloom. All I know is that I planted something apparently as lifeless as a grain of sand and there came forth a green and living thing unlike the seed, unlike the soil in which it stood, unlike the air into which it grew. No one could tell me why it grew, nor how. It had secrets all its own, secrets that baffle the wisest men; yet this plant was my friend. It faded when I withheld the light, it wilted when I neglected to give it water, it flourished when I supplied its simple needs. One week I went away on a vacation, and 
The Growing of Plants

when I returned the plant was dead; and I missed it.

Although my little plant had died so soon, it had taught me a lesson; and the lesson is that it is worth while to have a plant.

Provide some little means of growing plants, not only to teach how to grow plants themselves, but to instruct the child in the care of things, to show that other beings besides itself have vicissitudes and-lives of their own, and to implant the germ of altruism-the interest in something outside of oneself. These means of growing plants should be simple. A pot, a box or a hotbed may be sufficient. Every child should have the handling of at least one plant during the period of childhood. One plant cannot be handled without leaving an impression on the life.

The love of plants should be inculcated in the school. It can usually be better done in school than at home, particularly when one or both of the parents is opposed to it and constantly discourages the child. Even when the parents 
are ready and competent, the teacher may be able to reach the children more effectively than they. In nearly every school it is possible to have a few plants in the window. They may not thrive, but it is worth while to set the children to inquiring why they do not. Sometimes the poorest plants awaken the most effort and inquiry. If nothing else will thrive, a beet will. Secure a good fresh beet-root from the cellar. Plant it in a box or tin can. Surprisingly quick it will throw out clean bright leaves. The thick root will hold moisture from Friday to Monday.

A desire for school-gardens is gradually taking shape. This movement must grow and ripen; it cannot be perfected in a day. Through the centuries there have been few school-gardens: we must not expect to overcome the lack at once. The movement has not been aided much, if at all, by those who have "complete" schemes for gardens for the district schools. Such schemes may be advisable later. Start the work by suggesting that the school-grounds be cleaned or "slicked up." Take one step at a time. The propaganda for school-gardens must have 


\section{The Growing of Plants}

relation to the economic and social conditions under which the school exists.

There is some confusion as to the objects of school-ground improvement. The purposes may be analyzed as follows:

(I) Ornamenting the grounds, comprising (a) cleaning and tidying them, (b) securing a lawn, (c) planting. This is always the first thing to be done. It stands for thrift, cleanliness, comfort, beauty, progressiveness.

(2) Establishing a collection to supply material for nature-study and class work.

(3) Making a garden for the purpose of (a) supplying material (as in No. 2), (b) affording manual-training, object lesson work, and instruction in plant-growing.

(4) Providing a test ground or experiment garden where new varieties may be tried, fertilizer and spraying experiments conducted, and other definite studies undertaken.

These purposes fall into two main groups: (I) The improvement or adornment of the 
$84 \quad$ The Nature-Study Idea

grounds; (2) the making of distinct gardens for purposes of direct instruction, or schoolgardening proper. Much of the current discussion does not distinguish these two ideals, and thereby arises some of the loss of effort and effectiveness in the movement.

\section{Improvement of the school-grounds}

Every school-ground should be picked up, cleaned up and made fit for children to see. There are three stages in the improving of any ground: Cleaning up; grading and seeding; planting.

To improve the school-grounds should be a matter of neighborhood pride. It is an expression of the people's interest in the things that are the people's. We are ashamed when our homes are not fit and attractive for children to live in; but who cares if at the school the fence is tumble-down, the wood or coal scattered over the yard, the clapboards loose, the chimneys awry, the trees broken, the outhouses sagged and yawning?

The first thing to do is to arouse the public 
conscience. Begin with the children. As soon as they are directed to see the conditions they will believe what they see. They are not prejudiced. They will talk about it: teacher, mother, father will hear.

The next step is to "clean up." Do not begin with any ideal plan of landscape-gardening improvement to be carried out at oncenot unless some one person is willing to do all the work and bear all the expense out of his public spirit; and this would be unfortunate, because most of the value in improving a ground is to interest the children in the work. Develop the children's enthusiasm-it is easy to do-in removing stones and litter and rubbish, in filling the holes, piling the wood, raking the grounds. If one school year were required to accomplish this work alone it would be time well used. Children and teachers have many interests. We are likely to expect too much of them.

The cleaning up once done, and the civic pride aroused to the pitch of keeping it done, the next step is to make a base or foundation 
86

The Nature-Study Idea

upon which all the gardening or planting features are to stand: the land must be graded. In some cases the soil must be removed and new earth put in its place, for the soil about a schoolhouse is very likely to be poor sand or clay, or a mixture with building material and other rubbish; but in general this labor will not be necessary if only a lawn and ornamental planting are desired. In some places a lawn is impracticable, but a good and even earth surface should always be secured. The early spring is the season in which to do all this shaping and seeding of the land. The spring fever is on and enthusiasm is new-born. If the school is in the country, the farmers can be interested to do the heavy work. If the subject has been well discussed in the school for some weeks or months, it should not be difficult to organize the farmers into a "bee" to grade, till and seed the ground. There is always at least one energetic man in the community who is ready to take the lead in such movements as this. Much of the value of improving the school-ground lies in its arousing of public interest. 


\section{The Growing of Plants}

The next year, plant. Let the matter be discussed in school. Ask the children to make plans. When the time is ready, choose the simplest plan that seems to fulfil the requirements. It is well to get expert advice on this plan. Remember that during a large part of the year the school-ground will be practically without care; the planting must be able to maintain itself, if necessary. Leave the centers open. Throw the planting mostly to the borders or margins. Be careful not to have scattered effects in planting. Have the planting as little and as simple as possible and yet accomplish the desired results. Avoid all elaborate designs in bedding. Leave ample space for playgrounds. Cover the out-buildings with vines, and screen them with bushes and trees. Use chiefly of hardy and well-known trees and shrubs and herbs. Aim to have the ground interesting because it appeals to the onlooker as a picture and not as a collection of plants.

\section{The school-garden}

The real school-garden is for direct instruc- 
tion. It is an outdoor laboratory. It is a part of the school equipment, as books, blackboards, charts and apparatus are. The school-garden is not adapted to all schools; or, to speak more correctly, not all schools are yet adapted to the school-garden, any more than they are all ready for an equipment in physics or chemistry. All grounds can be improved and embellished; we shall be glad when all schools will also have a school-garden. The making of a definite garden is an epoch in the life of each school: it marks the progress of the school in educational ideals.

The school-garden should have a special area set aside for it, as any other garden, room or laboratory has. Its prime motive is not to be ornamental, but to be useful. The garden should be a good garden, if it is to do its best work. By this I do not mean that it be perfect from the gardener's standpoint, but that it be carefully planned and the ground put in good condition. The children should do the gardening; a gardener or teacher should not take care of the children's beds for them. (For a description of actual school-garden work, see p. 205.)) 
A school-garden has a large range of usefulness. It supplants, or, at least, supplements mere book training; presents real problems, with many interacting influences, affording a base for the study of all nature, thereby developing the creative faculties and encouraging natural enthusiasm; puts the child into touch and sympathy with its own realm; develops manual dexterity; begets regard for labor; conduces to health; expands the moral instincts by making a truthful and intimate presentation of natural phenomena and affairs; trains in accuracy and directness of observation; stimulates the love of nature; appeals to the art-sense; kindles interest in ownership; teaches garden-craft; evolves civic pride; sometimes affords a means of earning money; brings teacher and pupil into closer personal touch; works against vandalism; aids discipline by allowing natural exuberance to work off; arouses spontaneous interest in the school on the part of both pupils and parents; sets ideals for the home, thereby establishing one more bond of connection between the school and the community. ${ }^{1}$

'From "Outlook to Nature," p. I29 (Rev. Ed.) 
The larger relations

There is a broader significance to the growing of plants, as indicated in the foregoing catalogue, than that associated with mere garden-making or with the furnishing of schoolroom material alone. There are social and national aspects. Children in the home and school should be interested in horticulture and agriculture as a means of introduction to nature. Farming introduces the human element into nature and thereby makes it more vivid in the child's mind. More than half the people of the United States live outside the cities. More persons are engaged in farming than in any other single occupation. The children in the schools are taught much about the cities, but little about the farming country. The child should be taught something from the farmer's point of view, and the teaching of gardening is one of the ways in which to begin. This will broaden the child's horizon and quicken his sympathies. Every person is now supposed to know something of the country. He will spend part of his vacations therein. The more knowl- 
edge he has of farming methods the more these vacations will mean. It is not necessary, and perhaps not even important, that the child be taught these subjects with the purpose of making him a farmer, but rather as a means of education and of interest to him in the out-ofdoors.

There must be a greater interest in parks and public gardens. These institutions have now come to be a part of our civic life. They no longer need apology. We build parks in the same spirit that we build good streets and make sanitary improvements; but the park should be more than a mere display of gardening. It should have an intimate relation with the lives of the people. All parks should be open to nature-study teachers, at least on certain days. There should also be children's days in the parks. In some places the park may grow specimens for the school. In large cities some of the common vegetables and farm crops may be grown in small areas at one side of the park. The tendency, perhaps, is to make our parks too exotic, and to give relatively too 


\section{The Nature-Study Idea}

much attention to mere roads, statuary, and architecture.

The general appearance and attractiveness of the home can be greatly improved by simple gardening. The perfect garden, from the gardener's point of view, may not be the most useful or most decorative one: The garden should be so common and so easy to make as to become a part of the child-life. 


\section{VII}

Nature-Study Agriculture

7 HE nature-study idea is bound to have a 1 fundamental influence in carrying a vital educational impulse to farmers. The accustomed methods of education are less applicable to farmers than to any other people, and yet countrymen are nearly half our population. The greatest of the unsolved problems of education is how to reach the farmer. He must be reached on his own ground. The methods and the results must suit his needs. The ultimate test of good extension work will be its ability to reach into the remotest districts.

We have failed to reach the farmer effectively because we still persist in employing old-time and academic methods. Historically, the common public school is a product of the university and college. "The greatest achievement of modern education," writes W. H. Payne, "is the gradation and correlation of schools, whereby the ladder of learning is let down 


\section{4}

\section{The Nature-Study Idea}

from the university to secondary schools, and from these to the schools of the people." This origin of "the schools of the people" from the university explains why it is that these schools are so unrelated to the life of the pupil, and so unreal; they are exotic and unnatural. If any man were to find himself in a country devoid of schools and were to be set the task of originating and organizing a school system, he would almost unconsciously introduce some subjects that would be related to the habits of the people and to the welfare of the community. Being freed from traditions, he would teach something of the plants and animals and fields and people and affairs.

So long have we taught the text-book routine that we do not seem to think that there may be other and better means. We may allow the Greek idea of education for culture, but we must have other education along with it. It is possible to acquire culture at the same time that we acquire power. Education for culture alone tends to isolate the individual; education for sympathy with one's environment tends to 
make the individual an integral part of the activities and progress of his time. At all events, there must be as great possibility for culture in the nature-studies as there is in the customary subjects of the common schools. My plea is that new educational methods must be employed before we can really reach the farming communities. I am not insisting that we make more farmers, but that we relate the rural school to the lives of people and that we cease to unmake farmers.

Man is a land animal and his connection with the earth, the soil, the plants, animals and atmosphere is intimate and fundamental. This earth-relationship is best expressed in agriculture,-not agriculture merely as a livelihood, but as the expression of the essential relationship of man to his planet home Agriculture affords a primary educational course for the development of the race. If this kind of instruction is really to come and to be effective, nature-study agriculture is not to be added to the school work so much as to grow out of it as a redirection or reconstruction of it. The best agriculture is 
96 The Nature-Study Idea

a perfect adaptation of man to his natural environment.

$A$ point of view on the rural-school problem

A fundamental necessity to successful living is to be in sympathy with the nature-environment in which one is placed. This sympathy is born of good knowledge of the objects and phenomena in the environment. The process of acquiring this knowledge and of arriving at this sympathy is now popularly called naturestudy.

The nature-study process and point of view should be a part of the work of all schools, because schools train persons to live. Particularly should it be a part of rural schools, because the nature-environment is the controlling condition for all persons who live on the land. There is no effective living in the open country unless the mind is sensitive to the objects and phenomena of the open country; and no thoroughly good farming is possible without this same knowledge and outlook. Good farmers are good naturalists. 
Inasmuch as this nature-sympathy is fundamental to all good farming, the first duty of any movement is to establish an intelligent interest in the whole environment,-in fields and weather, trees, birds, fish, frogs, soils, domestic animals. It would be incorrect to begin first with the specific agricultural phases of the environment, for the agricultural phase (as any other special phase) needs a foundation and a base: it is only one part of a point of view. Moreover, to begin with a discussion of the so-called "useful" or "practical" objects, as many advise, would be to teach falsely, for, as these objects are only part of the environment, to single them out and neglect the other subjects would result in a partial and untrue outlook to nature; in fact, it is just this partial and prejudiced outlook that we need to correct (p.32).

The colleges of agriculture have spread the nature-study movement. Such work was begun as early as 1895 and 1896 by the College of Agriculture of Cornell University. The colleges would have been glad if there had been sufficient nature-study sentiment to have enabled 


\section{The Nature-Study Idea}

them to emphasize the purely agricultural phases in the schools; but this sentiment had to be created or quickened. At first it was impossible to secure much hearing for the agricultural subjects. Year by year such hearing has been more readily given, and the work has been turned in this direction as rapidly as the conditions would admit,-for it is the special mission of an agricultural college to extend the agricultural applications of nature-study.

In making these statements I have it in mind that the common schools do not teach trades and professions. I would not approach the subject primarily from an occupational point of view, but from the educational and spiritual; that is, the man should know his work and his environment. The mere giving of information about agricultural objects and practices can have very little good result with children. The spirit is worth more than the letter. Some of the hard and dry tracts on farming would only add one more task to the teacher and the pupil if they were introduced to the school, making the new subject in tıme as distasteful as arith- 


\section{Nature-Study Agriculture}

metic and grammar often are. In this new agricultural work we need to be exceedingly careful that we do not go too far, and that we do not lose our sense of relationships and values. Introducing the word agriculture into the scheme of studies means very little; what is taught, and particularly how it is taught, is of the greatest moment. I hope that no countrylife teaching will be so narrow as to put only technical farm subjects before the pupil.

We need also to be careful not to introduce subjects merely because practical grown-up farmers think that the subjects are useful and therefore should be taught. Farming is one thing and teaching is another. What appeals to the man may not appeal to the child. What is most useful to the man may or may not be most useful in training the mind of a pupil in school. The teacher, as well as the farmer, must always be consulted in respect to the content and the method of teaching agricultural subjects. We must always be alert to see that the work has living interest to the pupil, rather than to grownups, and to be on guard that it does not become 
lifeless. Probably the greatest mistake that any teacher makes is in supposing that what is interesting to him is therefore interesting to his pupils.

It has recently been said that the naturestudy idea must disappear in rural schools and that agriculture must take its place. Nothing can be farther from the mark. Nature-study may be directed more strongly in agricultural applications, as the schools are ready for it, but the process is still nature-study. All good agricultural work in the grades must be naturestudy.

All agricultural subjects must be taught by the nature-study method, which is: to see accurately; to reason correctly from what is seen; to establish a bond of sympathy with the object or phenomenon that is studied. One cannot see accurately unless one has the object itself. If the pupil studies corn, he should have corn in his hands and he should make his own observations and draw his own conclusions; if he studies cows, he should make his observations on cows and not on what some one has said about cows. 


\section{Nature-Study Agriculture}

IOI

So far as possible, all nature-study work should be conducted in the open, where the objects are. If specimens are needed, let the pupils collect them. See that observations are made on the crops in the field as well as on the specimens. Nature-study is an out-door process: the schoolroom should be merely an adjunct to the outof-doors, rather than the out-of-doors an adjunct to the schoolroom, as it is at present (pp. 40, $56,70)$.

'A laboratory of living things is a necessary part of the best nature-study work. It is customary to call this laboratory a school-garden. We need to distinguish different types of garden (page 83): (r) The ornamental or planted grounds; this should be a part of every school enterprise, for the premises should be attractive to pupils and they should stand as an example in the community. (2) The formal plat-garden, in which a variety of plants is grown and the pupils are taught the usual handicraft; this is the prevailing kind of school-gardening. (3) The problem-garden, in which certain specific questions are to be studied, in much the spirit that problems are studied in the indoor 
IO2

\section{The Nature-Study Idea}

laboratories; these are little known at present, but their number will increase as school-work develops in efficiency; in rural districts, for example, such direct problems as the rust of beans, the blight of potatoes, the testing of varieties of oats, the study of species of grasses, the observation of effect of fertilizers, may well be undertaken when conditions are favorable, and it will matter very little whether the area has the ordinary "garden" appearance. In time, ample grounds will be as much a part of a school as the buildings or seats now are. Some of the school-gardening work may be done at the homes of the pupils, and in many cases this is the only kind that is now possible; but the farther removed the laboratory, the less direct the teaching.

To introduce agriculture into any elementary rural school, it is first necessary to have a willing teacher. The trustees should be able to settle this point. The second step is to begin to study the commonest and most available object concerning which the teacher has any kind of knowledge. The third step is to begin to con- 
nect or organize these observations into a plan or system. This simple beginning made, the work ought to grow. It may or may not be necessary to organize a special class in agriculture; the geography, arithmetic, reading, manual-training, nature-study and other work may be modified or re-directed. It is possible to teach the state elementary syllabus in such a way as to give a good agricultural training.

In the high-school, the teacher should be well trained in some special line of science; and if he has had a course in a college of agriculture he should be much better adapted to the work. Here the teaching may partake more of the indoor laboratory method, although it is possible that our insistence on formal laboratory work in both schools and colleges has been carried too far. In the high-school, a separate and special class in agriculture would better be organized, and this means, of course, the giving up of something else by the pupil.

In many districts the sentiment for agricultural work in the schools will develop very slowly. Usually, however, there is one person 


\section{I04 The Nature-Study Idea}

in the community who is alive to the importance of these new questions. If this person has tact and persistence, he ought to be able to get something started. Here is an opportunity for the young farmer to exert influence and to develop leadership. He should not be impatient if results seem to come slowly. The work is new: it is best that it grow slowly and quietly and prove itself as it goes. Through the grange, reading-club, fruit-growers' society, creamery association, or other organization the sentiment may be encouraged and formulated; a teacher may also be secured who is in sympathy with making the school a real expression of the affairs of the community; the school premises may be put in order and made effective; now and then the pupils may be taken to good farms and be given instruction by the farmer himself; good farmers may be called to the schoolhouse on occasion to explain how they raise potatoes or irrigate their land. A very small start will grow by accretion if the persons who are interested in it do not lose heart; and in five years 


\section{Nature-Study Agriculture}

every one will be astonished at the progress that has been made.

\section{The prospect}

In recent years there has been a marvelous application of knowledge and research to agricultural practice. We have exerted every effort to increase the productiveness and efficiency of the farm, and we have entered a new era in farming - a fact that will be more apparent in the years to come than it is now. The burden of the new agricultural teaching has been largely the augmentation of material wealth. Hand in hand with this new teaching, however, should go an awakening to the less tangible but equally powerful things of the spirit. More attractive and more comfortable farm homes, better reading, more responsive interest in the welfare of the community and the events of the world, closer touch with the common objects about him-these must be looked to before agriculture really can be revived. Appeal to greater efficiency of the farm alone cannot permanently relieve the agricultural status. This is all well 
Io6 The Nature-Study Idea

illustrated in the attitude of children toward the farm. In a certain rural school in New York state of say forty-five pupils, I asked all those children that lived on farms to raise their hands: all hands but one went up. I then asked all those who wanted to live on the farm to raise their hands: only that one hand went up. Now, these children were too young to feel the appeal of more bushels of potatoes or more pounds of wool, yet they had this early formed their dislike of the farm. Some of this dislike is probably only an ill-defined desire for a mere change, such as one finds in all occupations, but I am convinced that the larger part of it was a genuine dissatisfaction with farm life. These children felt that their lot was less attractive than that of other children; I concluded that a flower-garden and a pleasant yard would do more to content them with living on the farm than ten more bushels of wheat to the acre. Of course, it is the greater and better yield that will enable the farmer to supply these amenities; but at the same time it must be remembered that the increased yield does not itself awaken a 
desire for them. I should make farm life interesting before I make it profitable.

It will be seen at once that all these new ideals are bound to result in a complete revolution or re-direction of our current methods of rural school-teaching. The time cannot be very far distant when we shall have systems of common schools that are based on the fundamental idea of serving the people in the very lives that the people are to lead. In many places there are strong protests against the old order; in other places there are distinct beginnings of the new order.

The beginnings of the new order are seen in the nature-study movement, the establishing of special agricultural schools, the strong agitation for county or district industrial schools, the spread of reading-courses, the rise of pupils' gardens, the extension work of the colleges of agriculture, the general awakening of rural communities. Books and methods are now derived for town schools rather than for country schools; the real texts for the rural schools are just now beginning to appear, and they repre- 


\section{I08 The Nature-Study Idea}

sent a new type of school literature. In the future, the text-book is to have relatively less influence than in the past. We have been living in a text-book and museum age. All this old method is not to be complained of. The fact that so many new subjects and propaganda are coming in shows that we are in the midst of an evolution: we are in the making of progress.

Nature-study teaching may seem to be an indirect way of reaching the farmer; but it is not. It is direct because it strikes at the very root of the difficulty. Nature-study teaches the importance of actually seeing the thing and then

$<$ of trying to understand it. The person who really knows a pussy-willow will know how to become acquainted with a potato-bug. He will introduce himself. One of the most significant comments I have heard on nature-study work came from a country teacher who said that because she had taught it, her pupils were no longer ashamed of being farmers' children. If only that much can be accomplished for each country child, the result will be enough for one generation. What can be done for the country 


\section{Nature-Study Agriculture}

child can be done, in a different sphere, for the city child. Fifty years hence the result will be seen.

A nature-study movement alone is not sufficient to awaken and reconstruct the agricultural interests. There should be coördinate efforts outside the schools. It particularly devolves on the colleges of agriculture to develop good extension teaching. The extension movement is already under way, several immediate causes combining to make it imperative, as (I) the people are ready for the work: they want to learn; (2) certain persons are ready to do the work: they want to teach; (3) the states appropriate money: the appropriations are made because work is done. Of these factors, the money is the least. No institution is so poor that something cannot be done if only the first three requisites are present. Time by time, perhaps little by little, the money will come. The work must be born, grow and mature:

This new teaching for the farmer is a most attractive field for well-directed effort. We . 
need more teachers for it in the colleges and normal schools and common schools. The teaching in our agricultural colleges should be seized with the missionary spirit, with the desire to send out young persons who care not so much to make professors and experimenters in the great institutions, as to give themselves to spread the gospel of nature-love and of self-respecting, resourceful farming through all the colleges and all the public schools. The time is coming quickly when the college or school that wants really to reach the people must teach rural subjects from the human point of view.

We are on the borderland of a mighty country: we are waiting for a leader to take us into it: 


\section{PART II}

Containing several pieces that attempt to direct the teacher's outlook to nature 



\section{I}

The Teacher's Interpretation of Nature

TWO sisters stood on the doorstep bidding 1 good-by to their husbands, who were off for a day's outing. One looked at the sky and said: "I am afraid it will rain." The other looked at the sky and said: "I know that you'll have a good time." There was one sky, but there were two women. There were two types of mind. There were two outlooks on the world. There are many persons who will not be pleased if they can help it.

I know a nature-study teacher whose first inquiry about any object is, "What is it worth ?" Or, "What value has it to mankind?" Some objects are to be studied and protected because they are useful to man in supplying his wants, and all others are passed over as not worth knowing. I doubt whether this attitude can bring about any close and satisfying touch with nature. The long-continued habit of looking at 
I 4 The Nature-Study Idea

the natural world with the eyes of self-interest -to determine whether plants and animals are "beneficial" or "injurious" to man-has developed a selfish attitude toward nature, and one that is untrue and unreal (pp. 32, 97). The average man to-day contemplates nature only as it relates to his own gain and enjoyment.

The satisfaction that we derive from the external world is determined by the attitude in which we consider it. All unconsciously one's habit of mind toward the nature-world is formed. We grow into our opinions and habits of thought without knowing why. It is therefore well to challenge these opinions now and then, to see that they contain the minimum of error and misdirection.

The greatest thing in life is the point of view. It determines the current of our lives.

However competent a person may be in biology or other science, he cannot teach nature-

- study unless he has a wholesome personal outlook on the world.

The more perfect the machinery of our lives, 
the more artificial do they become. Teaching is ever more methodical and complex. The pupil is impressed with the vastness of knowledge and the importance of research. This is well; but at some point in the school-life there should be the opening of the understanding to the simple wisdom of the fields. One's happiness depends less on what he knows than on what he feels.

In these increasing complexities we need nothing so much as simplicity and repose. In city or country or on the sea, nature is the surrounding condition. It is the universal environment. Since wedsannot escape this condition, it were better that we have no desire to escape. It e better that we know the things, small and great, which make up this environment, and that we live with them in harmony, for all things are of kin; then shall we love and be content.' The growing passion for country life and the natural unspoiled world is a soulmovement.

More and more, in this time of books and 


\section{6 The Nature-Study Idea}

reviews, do we need to take care that we think our own thoughts. We need to read less and to think more. We need personal, original contact with objects and events. We need to be self-poised and self-reliant. The strong man entertains himself with his own thoughts. No person should rely solely on another person for his happiness.

The power that moves the world is the power of the teacher. 


\section{II}

Science for Science's Sake

A DEMURE little woman at the teacher's A convention told of the enthusiasm with which her pupils had collected butterflies and plants, and she described the museum that they had made. She showed a folio of mounted plants, and a cigar-box containing insects. I admired the specimens, and mentally I complimented her judgment in finding so good use for such a box. The tobacco odor kept the carnivorous bugs away, and I also commended the judgment of the bugs. There was genuine enthusiasm in the little woman's manner, and I wanted to be a young naturalist. When she was talking, I strayed far in the fields and picked a dandelion.

But there was a man in the audience who squelched the little woman. Her methods were all wrong. They were worse than wrong: the children must unlearn what she had taught 
them. She should have begun with some definite subject, and followed it systematically and logically. The pupil must be held to the task day after day, until he masters the topic. To skip from subject to subject is to be superficial. This way of teaching does not result in mental drill. To make a collection is only play, and names are vulgar. The pupil must be impressed with the completeness of his sub- ject, and, above all things, he must be accurate. When he was talking, I smelled alcohol and I saw a frog in a museum jar.

Which was right? No doubt each was correct from the personal point of view, but wrong from the other's point of view. I recalled that the little woman recited only what she had done; the man upbraided her for not doing something else. Perhaps it is easy to advise and to criticize. The little woman was teaching children. She wanted to lead them to love the things they saw. She approached the subject from the human side, for are not the boy and the girl a part of what we call nature? They are not yet tamed and conventionalized. 


\section{Science for Science's Sake}

Does not every boy and girl like to go in the fields and "get" things? She was not thinking of the subject-matter; or if she did think of it, she knew that it could take care of itself. All she was thinking of-poor soul!-was to interest and educate the children. And she knew that if she set a subject and followed it unremittingly day by day the seats would soon be vacant.

The man was thinking of his college students; perhaps he had not considered that these students already liked the subject and needed only instruction. He forgot that you cannot force a person to choose a thing, although you may force him to take it. His were picked students, one from this town and another from that; hers were all the pupils in her little community. His pupils had seen and had chosen; to hers the world was all unseen and untried. His were the one in a hundred; hers were the entire hundred. His students had elected the subject; for this subject perhaps they were to live; they would increase the boundaries of knowledge; 
they would be scientists. He did not consider that all pupils would not be scientists.

Sometimes it seems as if scientists assume that they have the right of way in the subjects which they espouse; but there is more than one way of interpreting nature. This domination is well illustrated in the usurpation of common words. The word "organic" relates to organisms and their products. But when the chemist studies the composition of organic compounds he defines the word in terms of chemistry. To him an organic compound may be a carbon compound or a carbohydrate derivative; and he can make an organic compound without any relation to an organism! Organic is a biological, not a chemical idea. Again, our forefathers used the word "bug" for many kinds of insects; but scientists have taken this word "bug" and have made it mean only a particular kind of a bug. This is all well enough amongst themselves, but when they attempt to make all the rest of the world use "bug" as they do, they go too far. Our forefathers have prior claims. It would be better if newly-made words could 
be used for new ideas. Science needs a technical language of its own.

What is the kernel of all this discussion about the pedagogical sin of making collections and of attaching names? It is no doubt derived from the older practice of merely naming things. The old idea of the study of nature was to make an inventory of the objects in the world. The objects are bewilderingly numerous, and to put them away in a cabinet, with a proper ticket attached, was to know them. The great want was names and classification; and these names must be arranged in books. This natural history bookkeeping received its largest impetus from the binomial method of naming, which might be called a system of "double entry."

This naming of objects is necessary. It is the starting-point, as a city directory is. But it is only the beginning of wisdom. It is not an end. The speculations of the modern evolutionists have emphasized the importance of the objects themselves in a new way. The point of view has changed. Do not let your pupils 


\section{I22 The Nature-Study Idea}

make an herbarium, the modern teacher may say, but tell them to study the plants. We all sympathize with this point of view; but what are we going to do with this native and exuberant desire of the child to explore and to collect? And what better way is there to know plants and animals than actually to collect and to study them? One of my friends will not let his little boy make an herbarium, because that is mere superficial amusement; so the child collects postage stamps. He does not care to have him know the names of plants, but he is very careful to have him properly introduced to visitors; and what is an introduction but a conventional passing of names (p. I96)?

I think that science teaching has gone too far in discouraging the making of collections. We can make the collecting the means of securing real information. We can fasten the attention of the child. The one caution is not to make it an end. The child cannot collect without seeing the object as it lives and grows. It appeals to him more in the field than it does in the museum. Let him collect for the purpose 


\section{Science for Science's Sake}

of understanding a problem. Where does the dandelion grow? What are the plants in the bog? How many are the weeds in the orchard? What are the borers in the old log? Set the child a field problem and he will collect in spite of himself. Teach him at the same time to respect the rights of every living thing, and never to be wanton. Then the collecting has teaching power. But to make a collection of one hundred specimens in order to obtain a pass-mark is scarcely worth the effort (p. 77).

The point I urge is that there is no reason in the nature of things why subjects always should be taught this way or that, so long as they are taught truthfully and with purpose-and there are many ways of teaching the truth. At one time or place we may teach for science's sake; at another time or place with equal justification we may teach for the pupil's sake. 
Extrinsic and Intrinsic Views of Nature

"THE purpose of this exercise is to tell 1 children how to see the hidden beauties of flowers." Thus ran the announcement at the opening of the classroom period. Is it worth while to tell them any such thing? Why not teach them to be interested in plants? Why give them a half-truth when they might have the whole truth?

The "beauty" of a flower or a bird is only an incident: the plant or the bird is the important thing to know. Beauty is not an end. The person who starts out to see beauty in plants is often in the condition of mind that the dear old lady was who came into my conservatory and exclaimed, as she saw the geraniums, "Oh, they are as pretty as artificial flowers!"

But these people are not looking for beauty, after all; they look for mere satisfying form or color or oddity. They confound beauty with 


\section{Extrinsic and Intrinsic Views 125}

prettiness or with outward attractiveness. Real beauty is deeper than sensation. It inheres in fitness of means to end as well as in striking features. The child should see the object itself before he sees its parts or its attributes. Teach first the whole bug, the whole bird, the whole plant, with something of the way in which it lives. The botanist may well devote his life to a cell, but the layman wants to know the trees and the woods.

I dislike to hear people say that they love flowers. They should love plants; then they have a deeper hold. Intellectual interest should go deeper than shape or color. Teachers or parents ask the child to see how "pretty" the object is; but in most cases the child wants to know how it lives and what it does.

It is instructive to note the increasing love for wild animals and plants as a country grows old and mature. This is particularly well illustrated in plants. In pioneer times there are too many plants. The effort is to get rid of them. The forest is razed and the roadsides are cleaned. The pioneer is satisfied with things 


\section{I26 The Nature-Study Idea}

in the gross. If he plants at all, he usually plants things exotic or strange to the neighborhood. The woman grows a geranium or fuchsia in a tin can, and now and then makes a flower-bed in the front yard; but the man is likely to think such things beneath him. If a man has flowers at all, he must have something that will fill the eye. Sunflowers are satisfying.

But the second and third generations begin to plant forests and to allow the roadsides to grow wild at intervals. Persons come to be satisfied with their common surroundings and to derive less pleasure from objects merely because they are unlike their surroundings. Choice plants come into the yards here and there, and the men of the household begin to care for them. The birds and wild animals are cherished. (I know a man who in his pioneer days took no interest in crows except to get rid of them, but who later in life wept when a crow's nest in an apple tree was robbed.) Love of books increases. All this marks the growth of the intellectual and spiritual life. 


\section{Extrinsic and Intrinsic Views}

'America is a land of cut flowers. Nowhere 'does the cut-flower trade assume such commanding importance. Churches and homes are decorated with them. One sees the churches of the Old World decorated with plants in pots or tubs. The Englishman or the German loves to care for the plant from the time. it sprouts until it dies: it is a companion. The American snips off its head and puts it in his buttonhole: it is an ornament. I have sometimes wondered whether the average flower-buyer knows that flowers grow on plants.

All of us have known persons who derive more satisfaction from a poor plant that never blooms than others do from a bunch of American Beauty roses at five dollars. There is individuality - I had almost said personalityin a growing, living plant, but there is little of it in a detached flower. And it does not matter so much if the plant is poor and weakly and scrawny. Do we not love poor and crippled and crooked people? A plant in the room on washday is worth more than a bunch of flowers on Sunday. 
But the American taste is rapidly changing. Each year the florist's trade sees a proportionately greater demand for plants. The same change is seen in the parks and home grounds. Every summer more gross carpet-beds are relegated to those parts of the grounds that are devoted to curiosities, or they are omitted altogether, and in their stead are restful sward and attractive plant forms. Flowers are not to be despised, but they are accessories.

This habit of looking first at what we call the beauty of objects is closely associated with the old conceit that everything is made to please man: man is only demanding his own. It is true that everything is man's because he may use it or enjoy it, but not because it was designed and "made" for "him" in the beginning. This notion that all things were made for man's special pleasure is colossal self-assurance. It has none of the humility of the psalmist, who exclaimed, "What is man, that thou art mindful of him?"

"What were these things made for, then?" asked my friend. Just for themselves! Each 
thing lives for itself and its kind, and to live is worth the effort of living for man or bug. But there are more homely reasons for believing that things were not made for man alone. There was logic in the farmer's retort to the good man who told him that roses were made to make man happy. "No, they wa'n't," said the farmer, "or they wouldn't 'a' had prickers." A teacher asked me what snakes are "good for." Of course, there is but one answer: they are good to be snakes.

Being human, we interpret nature in human terms. Much of our interpretation of nature is only an interpretation of ourselves. Because a condition or a motive obtains in human affairs, we assume that it obtains everywhere. The only point of view is our own point of view. Of necessity, we assume a starting-point; therefrom we evolve an hypothesis which may be either truth or fallacy. Asa Gray combated Agassiz's hypothesis that species were originally created where we now find them and in approximately the same numbers by invoking Maupertuis's "principle of least action"- "that it is 
I30 The Nature-Study Idea

inconsistent with our idea of divine wisdom that the Creator should use more power than was necessary to accomplish a given end." The result may be secured with a less expenditure of energy than Agassiz's method would entail. But who knows that "our idea of the divine wisdom" is correct? It is only a human metaphor; but, being human, it may be useful.

Much of our thinking about nature is only the working out of propositions in logic, and logic is sometimes, I fear, but a clever substitute for truth. It is impossible to put ourselves in nature's place-if I may be allowed the phrase; that is, difficult to work from the standpoint of the organism that we are studying. If it were possible to get that point of view, it would be an end to much of our speculation; we should then deal with things as they are.

We hope that we are coming nearer to an intrinsic view of animals and plants; yet we are still so intent on discovering what ought to be, that we forget to accept what is. 
Must a "Use" be found for Everything?

$\mathrm{H}^{\mathrm{VERY}}$ pupil had a plant of the spring C buttercup. The teacher called attention to the long fibrous roots, the parted leaves, the yellow flowers; but these parts were apparently only incidentals, for she touched them lightly. But the hairs on the stem and leaves were important. They must be of some use to the plant. What is it? Evidently to protect the plant from cold, for does not the plant throw up its tiny stem in the very teeth of winter? It was clear enough; and thus are we taught that not the least thing is made in vain. Everything has its place and use; it is our business to determine what the uses are.

I wondered how these children would look on the plants and animals they meet, and what the great round world would mean to them. The blackberry has thorns to keep away the animals that would harm it; the rabbit has soft short fur that it may pass through 


\section{The Nature-Study Idea}

brush and briers; the mud-turtle is flat so that it will not sink in the mud; the poison sumac has venom to protect it from those who would destroy it; the crow is black that it may not be seen at night; the nettle has stings to punish its enemies; the dog fennel has rank scent to protect it from the browsing animals; certain insects have a zigzag flight to enable them to elude their enemies. All the world is as perfect as a museum!

I wondered what would happen if some inquisitive child were to ask what becomes of all the plants that have no thorns or hairs or poison or ill scent. What if he should ask why the thornless blackberry does not perish, or why the sumacs that are not poisonous still live, or if he should suggest that the dandelion comes up earlier in the spring than the buttercup and yet has no hairs on its soft flower-stem? As I wondered, a little hand went up. The teacher granted a question. "Pigweeds ain't got prickers," said the boy. I saw that the boy was a philosopher. "True enough," replied 


\section{A "Use" for Everything}

the teacher promptly, "but I am sure that it has something with which to protect itself."

Thereby I knew her point of view: she had made up her mind what to see, and it was necessary only to hunt until she saw it; and in this respect she was like many another. Persons seem to interpret the struggle for existence as a fight. It is a sanguinary combat between adults. Everything must protect itself with armor. A botanist, in writing a description of a new and strange plant, noted the peculiar spines and then remarked: "That these are of some use to the plant can hardly be doubted. Perhaps they serve to prevent the access of undesirable insects."

Nothing is easier than to find an explanation for anything; the only difficulty is to determine whether the explanation is true. I have just read in an old book that the reason why a particular kind of graft failed to grow was because of the "disappointment of the sap." I laughed at the expression; and yet is it not as scientific as to say that the hairs exist to keep the crowfoot warm or that the sumac has poison to pro- 


\section{34 The Nature-Study Idea}

tect it from its enemies? The teacher may as well have said that Jimmie Brown has freckles so that the sun will not tan his skin; and the statement would be hard to disprove.

A teacher asked me whether it is not true that her cactus has spines in order to protect it from browsing animals. I told her that I did not know. As I was a stranger to her, she wondered at my ignorance. She wanted to know why I did not know. I told her that I had no good evidence that an animal ever wanted to browse on her cactus or its ancestors. Perhaps the cactus spines are older than the browsing animals. Perhaps there was some special condition or reason in geologic time. Perhaps the spines were in some way an incidental result of the contraction of the plant body, which contraction was associated with the necessity of reducing the evaporating surface in an arid climate. Perhaps a hundred things. She was surprised that I had to go into geologic time to bury my ignorance. She wanted cause and effect side by side, and in the present. Then 


\section{A "Use" for Everything}

she could see them. It is a bother to look behind for causes.

This is a typical case. This attitude toward nature comes almost daily to the teacher; in fact, it sometimes comes from the teacher. The mischief is increased by many popular books on science, and some of these books have been written by persons who have done noble work for truth.

This is one of the greatest faults with the popular outlook on nature-the belief that every feature of plant or animal has a distinct use in the present time and that one has only. to look to be able to see what this use is. Persons often look at the little things and miss the big ones. They look for the hairs and miss the plant. They see the unusual and overlook the common.

Having seen a feature of which the function is not evident, they assume a condition and jump at a conclusion. A plant has poison; various creatures eat plants; the creatures are killed by poison: therefore the plant has poison to protect itself from the creatures. Now, it 


\section{I36 The Nature-Study Idea}

may even be true that the poison does protect the plant, but there is no proof thereby that the poison was produced for that purpose. The physiologist may find that the poison in the given case is merely a waste product of some chemical metabolism, and that the plant is fortunate in getting rid of it. If the plant is now and then protected, the result is an incident. If it should appear that one kind of plant, by natural selection or otherwise, has developed poison in order to protect itself, the fact would be spread abroad in book and magazine, but it would not be stated that it was one case out of a thousand. The exception is enlarged into the rule.

Persons like to believe in perfect adaptation of means to ends, without a slip or break in the process. They assume that all organisms have definite protectional features. A teacher brought a flower and asked what mechanism it had to insure cross-pollination. I told her that I was not aware that it had any; and she was surprised. She asked what mimicry protection a certain animal had; I was obliged to make a 


\section{A "Use" for Everything}

similar reply. I wish that somebody would write a book about non-adaptations and misfits in nature.

No one knows what spines and thorns are "for," and the true naturalist does not ask the question. He does not assume that because they would protect a man they would also protect another animal or a plant. $\mathrm{He}$ wants to know how they came to be, and what is their significance in the development of this particular race. He wants proof that adaptations are adaptations. He sets to work to find out. $\mathrm{He}$ cannot find out as he rides by on his horseespecially if he rides a hobby-horse.

This everything-has-a-use dogma is in part a reaction from the teachings of Darwin and his followers. The dogma of special creation was overthrown. We were told that organisms and attributes have persisted because of natural selection-because they were best fitted to persist. The result, in many cases, is perfect adaptation of every organ and attribute. There followed a special literature on adaptation, mimicry and the like. The precision and design 


\section{I38 The Nature-Study Idea}

of the special-creation theory was transferred to the adaptation theory. The examples may all have been true, but one result has been to lead persons to look for adaptations and mimicry everywhere, and to assume that they exist. What does it matter if there is no special creation?-there is complete and universal adaptation, vindicating the wisdom of the Creator and our notions of what ought to be are verified.

But some one will say, if there is natural selection and survival of the fittest, adaptation must follow as a consequence. Yes; but it does not follow that every part or feature of the organism is specially adapted, at least not at the present epoch of time. A strong feature may carry other features that are merely innocuous or even harmful, as a horse carries a rider; and then, if unfit features tend to pass away, these features are misfits and remnants until they have disappeared. 


\section{V}

\section{The New Hunting}

THE world is full of animals and plants.

1 Every animal and plant has the power to multiply itself many fold. Every one contends for an opportunity to live.

This contention forces the individual to live for itself. Self-preservation, it is said, is the first law of nature. The animal appropriates food, usurps territory, kills and even devours its contestants. It kills because it must. It is goaded by the whip of necessity. To live is the highest desire that it knows. Its acts need no justification.

Man also is an animal. He has come up from the world-fauna. On his way he contended hand to hand with the other animal creation. He killed from necessity of securing food. As he rose above his contestants, this necessity became less urgent. $\mathrm{He}$ has now obtained dominion, but he is not yet fully eman- 


\section{I40 The Nature-Study Idea}

cipated from the necessity of taking life. Perhaps complete emancipation will come.

The old desire to kill—first born of necessity -still lingers with men. We still have much of the savage in us. But now we kill also for "sport." Practically a new motive has been born into the world with man-the desire to kill for the sake of killing. One generation of white men is sufficient practically to exterminate the bison and several other species. All this needs justification. The lower creation is not the plaything of man.

We are still obliged to kill for our necessities. We must secure food and raiment. More and more we are rearing the animals that we would take for food. We give them less dangerous lives. We protect them from the severities of the struggle for existence. We remove them from the necessities of protecting themselves from violence. We take our own. There is here little question of morals. We give that we may take; and we take because we must.

To kill for mere sport is a very different matter: it lies outside the realm of struggle for 
existence. Too often there is not even the justification of fair play. Usually the hunter exposes himself to no danger from the animal that he would kill. He takes no risks. He has the advantage of long-range weapons. There is no combat. Over on the lake shore every spring I see great cones of ice, built up by the action of the waves. Several stalwart men have skulked behind them and lie secure from observation. A little flock of birds, unsuspecting, unprotected, harming no man, obeying the laws of their kind, skims across the water. The guns discharge. The whole flock falls, the mangled birds struggling and crying, and tainting the water with their blood as they are carried away on the waves, perhaps to die on the shores. There is a shout of victory and a laugh of satisfaction. Surely, man is the king of beasts!

But there is another and fairer side. The lack of feeling for wounded animals is often thoughtlessness. The satisfaction in hunting is often the joy of skill in marksmanship, the pleasure of woodcraft, the enthusiasm of being 


\section{I42 The Nature-Study Idea}

in the open, the keen delight in discovering the haunts and ways of the nature-folk. Many a hunter finds more pleasure in all these things than in the game that he bags. The great majority of hunters are gentle and large-hearted men. They are the first to discourage mere wantonness and brutality. Under their hand, certain animals are likely to increase, because they eliminate the rapacious species. To the true sportsman, hunting is not synonymous with killing. It is primarily a means of enjoying the free world of the out-of-doors. The naturespirit is growing, and there are many ways of knowing the fields and woods. The camera and spy-glass are competing with the trap and gun; and in time they ought to gain the mastery. It is no longer necessary to shoot a bird in order to know it.

I must not be understood as opposed to all hunting with the gun or the rod. Every man has a right to decide these questions for himself. I wish only to suggest that there are other ways of getting satisfaction from an expedition or a camping trip. There was a time when animals 
were known mostly in museums, or in books that suggested museums. We now know them in woods and fields where they live. We know what they do, as well as what they are. Making pictures from stuffed specimens will soon be a thing of the past. Read any book of natural history of fifty years ago; then read one of to-day. Note the road by which we have come: this may color your own attitude toward the nature-world.

A new literature has been born. It is written from the out-of-doors viewpoint, rather than from the study viewpoint. Man is not the only, nor even the chief, actor. Even the stories of animals of the old time do not have the flavor of this bright new literature. Not so very long ago animal stories were told for the purpose of carrying a moral-they were self-conscious. Now they are told because they are worth telling. The real moral is the interest in the animal and the way in which it contrives to live, not in some literary custom that tries to make an application to human conduct. No longer can one write a good nature-piece 


\section{I44 The Nature-Study Idea}

without intimate knowledge of the anımal or plant in the wild, and until he has tried to put himself in its place. Perhaps the old school of literary effort is not losing ground; but it is certain that the new is gaining. The new literature is founded on first-hand knowledge, but it embraces all the human sympathies. It is the outcome of the study of objects and phenomena. The first product was scientific literature. The second is the lucid resourceful nature-writing of the present day. There are new standards of literary excellence.

The awakening interest in the nature-world is strongly reflected in the game laws-for these laws are only an imperfect expression of the growing desire to let everything live its own life. The recent revulsion of feeling against the shooting of trapped pigeons, as expressed in agitations before state legislatures, is an excellent example in point. It is gratifying that a prominent place in the discussions for good game laws is taken by sportsmen themselves. It is recognized that hunting for sport must be 
kept within bounds, and that it must rise above mere slaughter of defenseless animals.

Another expression of this growing sympathy is exhibited in the reservation of certain areas in which animals are to be unmolested. It is most significant that while many country regions are practically shot clean of animal life, sometimes even to songbirds, the parks and other public properties in cities often support this wild life in abundance. Usually it is easier to study squirrels and many kinds of birds in the city parks than in their native wilds. To this awakening interest in the preservation of animals is now added the desire to preserve the wild flowers and to protect scenery. The future will see the wild animals and plants safely ensconced in those areas that lie beyond the reach of cultivated fields; and these things will be the heritage of the people, not of the hunter, marksman, and collector alone.

This desire to protect and preserve our native animals is well expressed in President Roosevelt's reference to the subject when discussing the forest preserves in his first message to Con- 


\section{I46 The Nature-Study Idea}

gress: "Certain of the forest reserves should also be made preserves for the wild forest creatures. All of the reserves should be better protected from fires. Many of them need special protection because of the great injury done by live stock, above all by sheep. The increase in deer, elk and other animals in the Yellowstone Park shows what may be expected when other mountain forests are properly protected by law and properly guarded. Some of those areas have been so denuded of surface vegetation by overgrazing that the ground-breeding birds, including grouse and quail, and many mammals, including deer, have been exterminated or driven away .... In cases where natural conditions have been restored for a few years, vegetation has again carpeted the ground, birds and deer are coming back, and hundreds of persons, especially from the immediate neighborhood, come each summer to enjoy the privilege of camping. Some at least of the forest reserves should afford perpetual protection to the native fauna and flora, safe havens of refuge to our rapidly diminishing wild ani- 


\section{The New Hunting}

mals of the larger kinds, and free-camping grounds for the ever-increasing numbers of men and women who have learned to find rest, health and recreation in the splendid forests and flower-clad meadows of our mountains. The forest reserves should be set apart forever for the use and benefit of our people as a whole, and not sacrificed to the short-sighted greed of a few."

The enlargement of our sympathies is also well reflected in the many societies that aim to lessen cruelty to animals. This movement is an outgrowth of the rapidly growing feeling of altruism-the interest in others-which, in the religious sphere, has ripened into the missionary spirit and into toleration. The prevention of cruelty to animals is of more consequence to man than to the animals. They suffer less than we. Perhaps the movement is in danger here and there of degenerating into mere sentimentalism and faddism; but, on the whole, it is sane and useful, because it measures our increasing sensitiveness.

Hunting to kill is not necessarily cruel. The 
I48 The Nature-Study Idea

best hunting is that which kills quickly. The poorest-for both the hunted and the hunteris that which prolongs the struggle. The "gamey" fish is the one most liked by anglers. The "sport" of catching him depends on his desperate struggle for life; and this struggle is often prolonged that the excitement may be greater! Nature herself could be indicted for cruelty were not her practices dictated by inevitable conditions; but this fact does not release man, who acts largely as a free and moral agent. In nature, many animals meet violent or tragic deaths. The bird of passage that cannot keep up with its fellows is caught by the hawk or owl. The weaklings and stragglers are taken. Raise the curtain of night and behold the tragedies. Where are the graves of the unfit?

Man is not responsible for the tragedies of nature; but he is responsible for the tragedies that he himself inflicts.

The practices of any age are but the expressions of the needs and motives of that age. Much of the hunting is dictated by the desire of profits in money, and these profits often 


\section{The New Hunting}

depend on fashion. Mere fashion has been the cause of the practical extermination of species of birds; but public opinion is finally aroused to check it. The demand for furs is leading to similar results. Many species of animals perish before the continued progress of civilization, by means of which the native haunts are destroyed. We must protect that which we need to grow for our own use. It is inevitable that the animal creation, as a whole, shall recede as the earth is subdued to man. But too often this creation has fallen long before its timefallen as a result of unnecessary killing, and of a desire of bloodthirstiness that is unworthy of us.

The foregoing remarks are meant to illustrate what I think to be an enlarging vision of our own place in the world. The point of view is shifting. The spiritual factors have increasingly more influence in shaping the course of our evolution. In time we shall probably be released entirely from the necessity of taking animal life to supply us with food. This will come as a result of our enlarging spiritual out- 
I 50

The Nature-Study Idea

look rather than as a result of agitations concerned with questions of diet or with any mere propaganda. It is said that the conformation of man's teeth shows that a flesh diet is necessary, but this only indicates what our evolution has been, not what it will be or what is now a necessity for us. The further evolution will come slowly, but whatever it may be, we have reason to think that our points of contact with the nature-world will strengthen and multiply. 


\section{VI}

\section{The Poetic Interpretation of Nature}

MerRILY swinging on brier and weed,

Near to the nest of his little dame,

Over the mountain-side or mead,

Robert of Lincoln is telling his name:

Bob-o'-link, bob-o'-link,

Spink, spank, spink;

Snug and safe is that nest of ours,

Hidden among the summer Howers.

Chee, chee, chee.

Robert of Lincoln is gaily drest,

Wearing a bright black wedding-coat;

White are his shoulders and white his crest.

Hear him call in his merry note:

Bob-o'-link, bob-o'-link,

Spink, spank, spink;

Look what a nice new coat is mine,

Sure there was never a bird so fine.

Chee, chee, chee.

Robert of Lincoln's Quaker wife,

Pretty and quiet with plain brown wings, 
Passing at home a patient life,

Broods in the grass while her husband sings:

Bob-o'-link, bob-o'-link,

Spink, spank, spink;

Brood, kind creature; you need not fear

Thieves and robbers while I am here.

Chee, chee, chee.

Modest and shy as a nun is she;

One weak chirp is her only note.

Braggart and prince of braggarts is he,

Pouring boasts from his little throat:

Bob-o'-link, bob-o'-link,

Spink, spank, spink;

Never was I afraid of man;

Catch me, cowardly knaves, if you can!

Chee, chee, chee.

Six white eggs on a bed of hay,

Flecked with purple, a pretty sight!

There as the mother sits all day,

Robert is singing with all his might:

Bob-o'-link, bob-o'-link,

Spink, spank, spink;

Nice good wife, that never goes out, 


\section{Poetic Interpretation}

Keeping house while I frolic about.

Chee, chee, chee.

Soon as the little ones chip the shell,

Six wide mouths are open for food;

Robert of Lincoln bestirs him well,

Gathering seeds for the hungry brood.

Bob-o'-link, bob-o'-link,

Spink, spank, spink;

This new life is likely to be

Hard for a gay young fellow like me.

Chee, chee, chee.

Robert of Lincoln at length is made

Sober with work, and silent with care;

Off is his holiday garment laid,

Half forgotten that merry air:

Bob-o'-link, bob-o'-link,

Spink, spank, spink;

Nobody knows but my mate and I

Where our nest and our nestlings lie.

Chee, chee, chee.

Summer wanes; the children are grown;

Fun and frolic no more he knows;

Robert of Lincoln's a humdrum crone; 
Off he flies, and we sing as he goes:

Bob-o'-link, bob-o'-link,

Spink, spank, spink;

When you can pipe that merry old strain,

Robert of Lincoln, come back again.

Chee, chee, chee.*

This was the exercise that the children were having as I visited the school on a June morning. It was the new old song by which Bryant is remembered of the country boy and girl. The children had seen and studied the bobolink. They had heard the liquid rattle of his song. They had seen the nest in the grass. They had watched for the Quaker wife. They had seen the purple-flecked eggs. They knew that Robert of Lincoln would leave them. The poem touched their hearts.

With enthusiasm I related the experience to my friend, the teacher of biology in a college. $\mathrm{He}$ doubted the value of such work. He saw only danger in it. Such teaching tends to looseness of ideas. It makes the mind discursive. It does not fix and fasten the atten-

* From Complete Works of William Cullen Brvant. 
tion on the subject-matter. It is unscientific. The child could learn poetry by the yard, he said, and yet not know how many toes the bobolink has, nor the shape and size of its wings. The pupil gains no comparative knowledge of bird with bird. The poem is untrue. The bobolink is not "drest": he has no clothes. He has no wife: he is mated, not wed.

I could only reply that the bobolink's toes have little relation to men's lives, however much they may have to bobolinks' lives; but the bobolink may mean much to men's lives. To a man studying ornithology - and I wish there were more-the toes are important; but I am seeking a fresh and firmer hold on life. I should rather know the song of the bobolink than to know all about the structure of the bird; of course, I should prefer to know both, if I could. To be sure, I should study the bobolink before I studied the poem; but I should want a real bobolink, not a stuffed specimen. If I were obliged to choose between lessons on stuffed bobolinks and the poem, I should take the poem: there is more bobolink in it. 


\section{56 The Nature-Study Idea}

I like Bryant's lyric because it catches so much of the life of a bobolink. A scientific description could tell the facts better, but only ornithologists read scientific descriptions. Yet I have always wished that the poet had told the whole story. After the breeding season is past, the birds gather in flocks in the rice-fields and reeds of the South and are then known as ricebirds and reed-birds. In great numbers they are slaughtered for the market, and thereby the bobolink does not become an abundant species in the North. May we not add:

Far in the South he gathers his clans,

Nor thinks of the regions of ice;

Too early yet for housekeeping plans,

He rev'ls and gluttons in fields of rice.

Rice-bird, bob-o'-link,

Spink, spank, spink;

Hunter is waiting under the bloom,

Robert of Lincoln falls to his doom.

Chee, chee, chee.

Spring comes: swinging on brier and weed,

Near to the nest of his little dame, 


\section{Poetic Interpretation}

Over the mountain-side and mead,

Another proud groom is telling his name:

Bob-o'-link, bob-o'-link,

Spink, spank, spink;

The meadow belongs to wife and me-

Life is as happy as life can be.

Chee, chee, chee.

This is the age of fact, and we are glad of it. But it may be also an age of the imagination. There need be no divorce of fact and fancy; they are only the poles of experience. What is called the scientific method is only imagination trained and set within bounds. Compared with the whole mass of scientific attainment, mere fact is but a minor part, after all. Facts are bridged by imagination. They are tied together by the thread of speculation and hypothesis. The very essence of science is to reason from the known to the unknown.

There can be no objection to the poetic interpretation of nature. It is essential only that the observation be correct and the inference reasonable, and that we allow it only at proper times. In teaching science we may confine ourselves to 


\section{58 The Nature-Study Idea}

scientific formulas, but in teaching nature we may admit the spirit as well as the letter. If I were making a teacher's program for the study of nature, I should want to include a course in English poetry. With pupils, however, one must be careful to have the poem exactly appropriate to the subject and the occasion.

One may not make a list of poems that are always to be used by teachers of nature-study for specified topics. The choice of the poem should lie with the particular teacher or the pupils. These poems should be used sparingly, and not at all when the teacher himself does not have poetic feeling by means of which to interpret them. Better no poems whatever than to have manufactured and idle sentiment. The trouble with much of the sentiment is that it gives us a wrong point of view.

In our day of science, people seem to be afraid of figures of speech. The scientist forbids us to personify; and this is well. But this spirit may be carried so far as to forbid metaphor and to condemn parables. Speech cannot be literally accurate. Even astronomers say 
that the sun sets, but we know that it does not. To say that a potato-plant works all the season in order to provide for its offspring the next year is said to give a wrong conception of the plant because it implies motive. But does this picture mislead any one? Everybody knows that a potato-plant has no brains. Everybody knows that the statement conveys a truth. If the phrase is not justifiable, then it is a question whether I may say that a potato has eyes. Much of the objection to statements of this kind is mere quibbling ( $\mathrm{pp} .60, \mathrm{1} 20$ ).

But, on the other hand, all such allegories must be true in spirit and in their teaching value. Much of the current writing of plants and animals by which human motives are implied, is productive of harm; but we should distinguish between metaphor, or mere literary license, and an untrue point of view. The ultimate test is whether the reader is led to believe what is not true. An animal or a plant may be represented as telling its own story without misleading any one, even as a character in a novel may speak in the first person; we need not imply 


\section{I60 The Nature-Study Idea}

human motives or human points of view in these cases: there remain only the questions as to whether this is really good literary taste, and whether it is the most effective way to reach the audience for which it is intended. In general, a direct and lucid presentation, without circumlocution and invention, is to be preferred; and this direct method allows of the full expression of sentiment and the poetic impulse.

I protest against that teaching of nature which runs into thin sentimentalism, which makes the "goody-goody" part of the work so prominent that it becomes the child's point of view, whether the writing is in prose or verse.

The spirit of science lends itself well to song. The concrete is not unpoetic. If in this day we apostrophize and personify nature less, we have improved in the spirit and intimacy of our song. The point of view gradually has shifted from human interest in natural things to the things themselves. We need a free nature poetry that will give us confidence and a firm hold on life. 


\section{VII}

\section{An Outlook on Winter}

T $\mathrm{N}$ the bottom of the valley is a brook that 1 saunters between oozing banks. It falls over stones and dips under fences. It marks an open place on the face of the earth, and the trees and soft herbs bend their branches into the sunlight. The hang-bird swings her nest over it. Mossy logs are crumbling into it. There are still pools where the minnows play. The brook runs away and away into the forest. As a boy I explored it but never found its source. It came somewhere from the Beyond and its name was Mystery.

The mystery of this brook was its changing moods. It had its own way of recording the passing of the weeks and months. I remember never to have seen it twice in the same mood, nor to have got the same lesson from it on two successive days; yet, with all its variety, it always left that same feeling of mystery and that same vague longing to follow to its source 
and to know the great world that I was sure must lie beyond. I felt that the brook was greater and wiser than I. It became my teacher. I wondered how it knew when March came, and why its round of life recurred so regularly with the returning seasons. I remember that I was anxious for the spring to come, that I might see it again. I longed for the earthy smell when the snow settled away and left bare brown margins along its banks. I watched for the suckers that came up from the river to spawn. I made a note when the first frog peeped. I waited for the unfolding spray to soften the bare trunks. I watched the greening of the banks and looked eagerly for the bluebird when I heard his curling note somewhere high in the air.

Yet, with all my familiarity with this brook, I did not know it in the winter. Its pathway up into the winter woods was as unexplored as the arctic regions. Somehow, it was not a brook in the winter time. It was merely a dreary waste, as cold and as forbidding as 


\section{An Outlook on Winter}

death. The winter was only a season of waiting, and spring was always late.

Many years have come and gone since then. My affection for the brook gave way to a study of plants and animals and stones. For years I was absorbed in phenomena. But now mere phenomena and materials have slipped into a secondary place, and the old boyhood slowly reasserts itself. I am sure that I know the brook the better because I know more about the things that live in its little world; yet that same mystery pervades it and there is that same longing for the things that lie beyond. I remember that in the old days I did not mind the rain and the sleet when visiting the brook. I was not conscious that they were not a part of the brook itself. It was only when I began to dress up that the rain annoyed me. I must make a proper appearance before the world. From that time the brook and I grew farther apart. We are coming together again now. It is no misdemeanor to get wet if you feel that you are not spoiling your clothing. One's happiness is largely a question of clothes. 
I64 The Nature-Study Idea

But the brook is one degree the better now just because it remains a brook all winter. The winter is the best season of the four because there is more mystery in it. There is a new and strange spirit in the air. There are strange bird-calls in the depths of the still white woods. There are strange marks in the new-fallen snow. There are soft noises when the snow drops from the trees. There are grotesque figures on the old fence. There is the warm brown pathway of the brook still winding up between oozing banks. In the spring there are troops of flowergatherers along the brook. In the summer there are fishers at the deep pools. In the fall there are nut-gatherers and aimless wanderers. In the winter the brook and I are alone. We know.

Most of us, I fear, look on winter with some feeling of dread and apprehension. It is to be endured. This feeling it partly due to the immense change that comes with the approach of winter. The trees are bare. The leaves are drifting into the fence-rows. The birds have flown. The deserted country roads 
stretch away into leaden skies. The lines of the landscape become hard and sharp. Gusty winds scurry over the fields. It is the turn of the year.

To many persons, however, the dread of winter, or the lack of enjoyment in it, is a question of weather. We speak of bad weather, as if weather ever could be bad. Weather is not a human institution, and it is not to be measured by human standards. There is strength and mighty uplift in the roaring winds that go roistering over the winter hills. The cold and the storm are a part of winter, as the warmth and the soft rain are a part of summer. Persons who find happiness in the out-of-doors only in what we call pleasant weather have not found the great joys of the open fields.

We speak of winter as bare, but this is only a contrast with summer. In the summer all things are familiar and close; the depths are covered. The view is restricted. We see things near by. In the winter things are uncovered. Old objects have new forms. There are new curves in the roadway through 


\section{I66 The Nature-Study Idea}

the forest. There are steeper undulations in the footpath. Even when the snow lies deep on the earth, the ground-line carries the eye into strange distances. You look far down into the heart of the woods. You feel the strength and resoluteness of the framework of the trees. You see the corners and angles of the rocks. You discover the trail that was lost in the summer. You look clear through the weedy tangle. You find new knot-holes in the tree-trunks. You penetrate to the very depths. You analyze, and gain insight.

Many times in warm countries I have been told that the climate has transcendent merit because there is no winter. But to me this lack is its disadvantage. There are things to see, things to do, things to think about in the winter as in the spring. There is interest in the winter wayside, in the hibernating insects, in the few hardy birds, and the deserted nests, in the fretwork of the weeds against the snow, in the strong outlines of the trees, in the snow-shapes, in the cold deep sky. To many persons these strong alternations of the seasons emphasize 
An Outlook on Winter

and punctuate the life. They are the mountains and the valleys. The winter is a part of the naturalist's year.

The lesson is that our interest in the out-ofdoors should be a perennial current that overflows from a fountain that lies deep within us. This interest is colored and modified by every passing season, but fundamentally it is beyond time and place. Winter or no winter, it matters not: the fields lie beyond. 



\section{PART III}

Comprising a budget of replies to many questions of school people 



\section{Inquiries and Answers}

DRACTICAL problems confront the teacher. 1 However well he may understand the theory and however fully he may agree with it, a new difficulty arises every time that he attempts to teach. A child will ask a question that a philosopher cannot answer; but on every question the teacher must have a point of view. I frequently speak to teachers on means of teaching nature-study. For the time they are pupils and they ask questions: I am obliged to take a point of view, and some of these opinions I have made note of at the time. Questions come in the mail. Some of these many inquiries and answers are here reprinted, not because they may be correct, but because they may be suggestive; and it will not matter if they repeat or expand some of the statements on the earlier pages.

How shall I know what subjects to choose?

Let the children choose the subject now and then. Let them collect the specimens. 
But they may bring things of which the teacher knows nothing. So much the better! These are sometimes best for nature-study. They leave the largest interrogation point. From any subject the teacher can develop a fact. If he does not know the interpretation, say so: the pupils will be the more interested (p. 44). The teacher will not lose standing by the confession, if he is honest. Persons lose standing by pretending to know what they do not know and by being caught at it. The child is relieved to know that there is something yet to be discovered.

In general, choose the subjects you are best prepared to teach and that best express or touch the conditions in which your pupils live. Whatever the subject, be careful to teach it simply and with the least apparent effort. Do not elaborate too much, or inject too much borrowed information. Always tie to the object or the materials. Do not teach zoölogy without animals, botany without plants, geography without knowing the earth, astronomy without stars, 


\section{Inquiries and Answers}

any more than you would teach grammar without language.

But if the child choose the material, the subject will lack continuity: what then?

Nature is not consecutive except in her periods. She puts things together in a mosaic. She has a brook and plants and toads and insects and the weather all together. Because we have put the plants in one book, the brooks in another, and the bugs in another, we have come to think that this divorce is the logical and necessary order.

If all the things mentioned above are taught, then the life of the brook will be the thread that ties them all together (p. 45). It is well to introduce the pupil to a wide range of material, in order to increase his points of contact with the world.

Then would you give no heed to continuity?

How much or how little the continuity will depend on the teacher and the circumstance. With children, the temptation is to have too much rather than too little continuity. First of all, we must develop the child's experience. 


\section{I74 The Nature-Study Idea}

The higher the grade, the more the topics may be correlated and coördinated. I doubt whether a closely graded nature-study is really naturestudy at all. For children, I believe in that continuity and consecutiveness that relate the subject to its place and season. In April, correlate the work with the opening of the spring; in October, with the coming of winter. Compare the nature-study of June with that of May. Relate it to the farm work or other activities of the neighborhood. With living things, the cycle of the year is the fundamental continuity. Life-history is continuity. The procession of nature continues the work.

Should nature-study give way to "fundamental" work?

[Suggestions in reply to a foreign correspondent who asks whether we succeed in America in "getting good nature-study in oneteacher schools"; what attitude we take toward "the old-fashioned object-lesson work"; whether teachers are not in "great danger of forgetting 
that much of the most fundamental naturestudy concerns dead matter, e.g., the simple chemical and physical changes that water and air undergo in relation to daily life."]

If nature-study is a way of teaching, then we ought not to expect ever to arrive at a complete agreement of opinion and practice. At the present time we are not even united on the fundamental educational questions involved, although we are gradually coming nearer to a consensus of opinion.

Many persons expect to find in the United States a great number of schools in which naturestudy is taught, meaning by that to find separate classes set aside for this particular kind of work. In very many schools this will be found; but I suspect the greatest results in the end are to come when the nature-study mode or method runs through the teaching of all the accustomed subjects in the school, gradually reorganizing and revitalizing them ( $p$. Io).

A school with one teacher can handle naturestudy work as well as the school with twenty 


\section{I76 The Nature-Study Idea}

teachers if the teacher arrives at the naturestudy way of teaching. I mean by this that the quality of the teaching may be good, quite independent of its quantity. Of course, we do not find a subject or a class under the name of nature-study in the one-teacher schools to any extent. What I mean by the nature-study spirit is to teach the things nearest at hand in a natural way and with the welfare of the child always in mind.

I am sure that it is perfectly possible to teach a child correctly and to put him into direct and sympathetic touch with the world he lives in by beginning with the biological and general phases of his environment even though he does not know the underlying chemical and physical processes and reasons. In fact, I am convinced that we must give up the idea that the child at first must know the so-called fundamental processes before he can know objects and phenomena. As a matter of fact, not one of us in the world, even the best of us, really knows the fundamental facts. We have merely gone a little further than some others have gone, 


\section{Inquiries and Answers}

but in the end everything is relative. If our first object is to develop the child and to train his capacities and sympathies, then it may not be necessary at all to begin with the underlying or internal reasons of things. These reasons will come out as the child grows and as his mind is able to grasp them.

I hope that we are rapidly passing through the epoch of mere object-teaching. It has very narrow limitations as ordinarily taught, because it has had no vital relation to the child or to the life that he is to lead. Merely to study an object may or may not be of value in the training of the child. If that object has some relation to the life that the child is living so that it will be meaningful to him, it ought to have direct value in interesting him and in being made a means of drawing him out into larger growth.

From these remarks it will be seen that we need not "replace" some of the "fundamental work," as you phrase it, by nature-study. I would have all work, fundamental and otherwise (including "the simple chemical and physical 
I78 The Nature-Study Idea

changes that water and air undergo in relation to daily life"), taught in the nature-study spirit.

What is the proper pedagogical starting-point for nature-study?

[Reply to an inquiry from an officer in a normal college, who is urged to develop the nature-study in accordance with a pedagogical hypothesis. He is advised as follows, and he asks an opinion:

"The first advice is from the standpoint of the biologist, that the child repeats the history of the race and therefore should go to that place in history for material which will correspond with the stage through which the child is passing. The nature-study work would be based upon this idea and the history and literature chosen as nearly as possible from the stages through which the child may be passing at a given time.

"The other point of view makes the child's present environment the standpoint for getting everything, and the child with this as a basis looks back upon and studies the life through 
which the race has passed. The first point of view is really an application of the culture-epoch theory in many ways except that some of our people wish to use nature-study as the starting point instead of literature and history."']

I do not consider myself competent to answer any questions on abstract theories of pedagogy. I did not come to my present work through that route. My educational outlook has developed personally and is founded essentially on the needs of the child, as I have been able to estimate those needs, without reference to pedagogical theory. I have heard discussions of the culture-epoch theory and other hypotheses of the psychology of education, but I am always obliged to come back to the simple fact that the child lives in a real environment and that this environment should be known to him and appreciated by him. I do not depreciate the value of the psychological theories, but I am not able properly to place the nature-study work with reference to them.

I should teach the child's world as he knows it, for the purpose of enabling him to know it 
I80 The Nature-Study Idea

better and to understand it. I should establish the child in his own life and anchor the school to the actual necessities of the community. From this starting point, I go backward or forward as the necessities of the case seem to demand, without any particular reference to the abstract psychology of the process. The child is not conscious of his place in the history of the race until he is told of it; and when he is told of it, it is a bit of extraneous and exotic information, the same as any other extrinsic information is. Of course, the child can be greatly interested in this fact, as he can be in any other fact or set of facts under the inspiration of a first-class teacher; but this of itself does not appeal to me as being sufficient reason for instituting a method. From the teacher's side, I doubt whether it is good practice to use the child as a means of working out an hypothesis. It is natural that every specialist should consider his subject to be the center of the circle.

I should begin with the common and apparent facts of our existence and conditions, or with the 
next-at-hand; beginning at home, I should pursue the exploration, and try to educate the child by the process.

\section{How shall I make a start?}

Persons hesitate, fearing that they will make a mistake. A teacher asked me the other day where he should begin with nature-work. $\mathrm{He}$ had been considering the matter for two or three years, he said, but did not know how to undertake it. I replied, Begin! Head end, tail end, in the middle-but Begin! There are two essential epochs in any enterprise-to begin, and to get done.

For the first lesson, choose the natural object that you know most about. Every teacher has sufficient knowledge of one subject to afford one good nature-study lesson. The second lesson will take care of itself.

If you are a principal, supervisor or other administrative officer and are thinking of starting off a movement in all the schools in a city or a commissioner's district or in a county, first 
choose your teachers. Choose those that have enthusiasm and "good spirit" and that are not tied hand and foot to customary methods. Choose the fearless teachers-the ones that are anxious to arouse the pupils even though they do not do it by the book. Then give these teachers one good lesson yourself. Or, if you cannot give the lesson, put in their hands one good nature-study leaflet. Choose the leaflet as you would a teacher-for cheery outlook, energy, and directness of expression. Choose a leaflet that sends the teacher directly to nature; you do not want stories. Choose the leaflet that has snap and spirit, not mere information. It should be attractive in subject-matter and in mechanical execution. Never put a cheaply illustrated and poorly printed leaflet before a pupil. Remember that children are optimists, and that they want the best in both teacher and leaflet. Let the teacher study the object and the leaflet until the subject is mastered. When the teacher is full of the subject, he cannot help teaching.

If you are fortunate enough to have the 


\section{Inquiries and Answers}

starting of a nature-study movement for a State or other large territory, buy a small quantity of one of the best leaflets you can find. If you do not have the money, borrow it. Send a note to the newspapers to the effect that any teachers who wish to take up nature-study work may write you for literature and advice. All the rest will work itself out. Money will come from some source. Soon you will be publishing leaflets of your own; but be careful who writes them.

Beware of putting your trust in leaflets alone. Follow them up with correspondence and other personal work. The leaflet will not work of itself. It will soon be forgotten unless you keep the spirit and the enthusiasm alive. Organize your teachers and your children. Keep at it.

How may I secure permission from my principal to teach nature-study?

This inquiry I cannot answer, for it is a question of the personal point of view of the supervising officer, and possibly also of your own 


\section{I84 The Nature-Study Idea}

qualification. It is undoubtedly true that many good nature-study teachers are repressed and spoiled by principals, supervisors and trustees; but it is also true that many persons who think they can teach nature-study are self-deceived. Perhaps your superior has been prejudiced against the work by poor teaching on the part of some former teacher; it is scarcely possible that he could be now-a-days opposed to it on principle. If he is opposed on principle, there is probably nothing to do except to wait or to change your place. If he has had experience of shoddy work, you should ask him the privilege of giving a few lessons on trial, or should call his attention to the work or writing of a successful teacher. Perhaps your work with children at their homes would interest him. I think that most of the opposition to this teaching on the part of principals and superintendents is the result of misapprehension of what good nature-work is; it should be the pride of naturestudy teachers to correct this feeling by doing the very best kind of work. 


\section{Inquiries and Answers}

Would you teach heat, light and physics as nature-study topics?

Not as these subjects are ordinarily taught. They are usually taught as abstractions, having little relation to the pupil's life. There are many phenomena in these fields that are within the range of the pupil's experience, and these may be useful in the hands of a good teacher. The best results will be secured, by most teachers, by confining nature-study rather closely to biological fields and to those earth- and skysubjects that are most intimately associated, in the child's mind, with the outside world. Many of the phenomena in this outside world are physical, and I would not exclude them; but I once knew a teacher who began nature-study for children with a disquisition on the conservation of energy!

Would you teach "practical" and "useful" things? (See pp. 32, 97, I I3.)

Yes, if the things are such as appeal to the child and are adapted to the conditions. No, if they do not meet these requirements. In 
I86 The Nature-Study Idea

other words, I should not choose them merely because they are "useless" or "useful to man." I should want the child to have a wider horizon and a truer view of nature. The prime requisite is that the child become interested in the being itself, whether that being chance to be "injurious" or "beneficial." We must be careful not to dwarf the sympathies by purposely confining our work to those things that have "use." It is an error to assume that all the things in the world are important only as they relate to the financial profit and the pleasure of man.

On the other hand, I should not neglect the "practical" things just because they are practical and familiar. A horse, cow, pig, chicken, potatoes, wheat, cotton, alfalfa, and the rest, are excellent nature-study material, not only because they are intrinsically as interesting as other plants and animals, but also because they are common and therefore near to our lives. Familiarity should not breed contempt.

What one shall teach is determined very largely, of course, by the text-books in use in the school. The commonest fault that my 


\section{Inquiries and Answers}

informers find with text-books is that they have little relation to life; or as the persons themselves are likely to put it, the books are not "practical." I do not like to use this word "practical," because it has been employed in such a way as to arouse the antagonism of good teachers. Used in its original and legitimate sense it is well enough; but in order that the larger idea may be expressed, I like to say that text-books ought to be "applicable." The word practical is likely to connote merely dollars-andcents information for the time being or for the place. The word applicable is more central, making the whole course of treatment, rather than a few isolated facts, significant to the life and interests of the pupil. The rigid text-book has been imposed on the schools by the colleges. With the emancipation of the schools, there should come a greater dominance on their part in educational policies. If the schools do not exist for the colleges, then it is very evident that a type of text-book that does not lead college-ward may be needed for the common schools; and this book will apply to the daily life. 
Would you teach objects that the child cannot see and determine for itself?

No! Right here is where much of our nature-study effort shoots wide of the mark. The child should be set at those things that are within its own sphere and within the range of its powers. Much so-called nature-study teaching is merely telling the child what some man has found out. Bacteria, sheep's brains, complicated life-histories, chemical changes in germination, pollination, yeast, fermentation-these and a hundred others are beyond the child's realm.

\section{How much apparatus do I need?}

Perhaps none; possibly some. The apparatus and the method may easily be made too perfect. Any elaborate scheme or equipment is likely to be depressing to those who are less fortunately situated, if they are to teach. A laboratory in a teacher's training-school may be so extensive and complete that the graduates do not take up efficient work for themselves, feeling that they cannot do so without much equip- 
ment. Make the most of common and simple subjects, and leave the extensive outfits to teachers of science. Two pieces of apparatus that you ought to have are an aquarium for things that live in water and a terrarium for those that live on land. These become "scenes of life" and supplement the outdoors. (Sce p. 229).

\section{Is it "thorough"?}

"I do not believe in your nature-study movement," a high-school teacher said, "for it does not lead to thoroughness in school work." I asked her to explain what she meant by thoroughness. She took me to her schoolroom. It was a laboratory. Pupils of sixteen and seventeen were studying the cell. For three weeks the pupils had been working on the cell, and they were to continue the work for a month. This, she told me, was thoroughness. I agreed with her. "But of what educational value is this knowledge to the pupil?" I asked. "The pupil knows the cell," she replied, "and to know the cell is to understand the structure and growth of the plant." 
We all believe in thoroughness, but there is one thoroughness of mere details and another thoroughness of the broader view. So far as mere thoroughness is concerned, one kind may be as perfect as the other. Thoroughness consists only in seeing something accurately and understanding what it means. We can never know all that there is to be learned about any object. Even the months' work on the cell was a mere smattering. Men spend their lives in studying the cell, and then do not understand it. What most school teachers mean by thoroughness is only drill in details. In its proper time and place, $I$ approve this kind of drill in mere detail, but its place is not to dominate the school work.

But the great objection to my teacher's work on the cell, as I see it, is the fact that it means little or nothing to the pupil's life and is a mere acquirement. We should put the child in contact with its own life, and the teacher who does this may teach with thoroughness whether he teach much or little. We can always be thorough and decisive as far as we go. 


\section{Inquiries and Answers}

But will not this nature-study be called superficial? (See pp. 60-61, I 19.)

No doubt. A botanist told me that I was doing superficial work. Judged from the viewpoint of research, perhaps he was right; but I was not teaching science. Judged from the view-point of the child, I hope he was wrong. One is not superficial merely because he does not strike deep into subject-matter. He should try to be accurate as far as he goes. What is superficiality in the specialist may be commendable thoroughness in the layman. Even the specialist is satisfied with the most superficial knowledge in subjects outside his specialty. His knowledge of men and of business, for example, is likely to be superficial.

This charge of superficiality is usually only the opinion of a different point of view. This is well illustrated in the critical reviews of elementary text-books of science. Books that have been criticized severely by the scientist have been accepted with enthusiasm by the schoolmaster. The primary merit of a school- 


\section{I92 The Nature-Study Idea}

book lies in its pedagogy rather than in its science. Statements in such books have two values-the teaching value and the science value. Too often the reviewer thinks only of the science value.

Of course there is danger of superficiality. There is this danger in everything; but the danger is inherent in the person, not in the subject. Solid work is as necessary in naturestudy as in anything else. It is not play, it is not sentimentality, and it is not blind wonder.

Will not this nature-study tend still further to over-burden the school?

The overburdening of the school hours is due as much to the fact that the old subjects do not give way as that new ones are introduced. The old schools had too little variety. Perhaps the new ones have too much congestion. Just now we are in an intermediate stage between the old and the new. Nature-study is not a new subject demanding a place: it is a point of view asserting itself. It is an attitude toward life, 


\section{Inquiries and Answers}

and expresses itself in a way of teaching. Its spirit will eventually pervade and vitalize all school work.

It is some comfort to know that our school hours are now full. They cannot be fuller. If other things are added, old subjects must drop out. It is a struggle for existence. By introducing a freer treatment into some of the existing subjects, nature-study should relieve the congestion rather than increase it. If naturestudy becomes a burden, it is likely to be because the teacher tries to teach too much and makes too hard work of it, or does not properly relate it to the other school work.

We still hear of many teachers who cannot find time to "introduce" nature-study; on the other hand we find many others, just as busy, who are able to flavor the whole school with it. If we accept that the nature-study spirit must be an attitude and a direction of thinking, then it does not at all follow that best results are to be secured merely by adding it as a separate period or task. The nature-study idea is something deeper and finer than simply another addi- 
I94 The Nature-Study Idea

tion to the course of study, coördinate with customary school work.

We may need to take out subjects rather than put them in, and make every one of those that remain mean more. In time, the beginning schools will probably not teach any of the present-day subjects under their present names; but this will adjust itself in the natural course of evolution. The greatest need is to reorganize the teaching of the subjects that are already in the country schools.

Shall we teach the child to collect, and thereby to kill? (See pp. 32, 67, 70-7 I, 77, 122.)

Properly directed, the collecting spirit should be encouraged, because one never comes closely into contact with his materials till he collects them with his own hands. To be close to one's material, develops enthusiasm and works itself into one's character. Every person should know the joy of finding something new.

How much or how little the collecting habit shall be encouraged must be determined for each case by itself; but, in general, the child 
should be taught to respect the life of every creature. Collecting should be an incident, particularly with very young children, and it should be encouraged only when it has some definite purpose. The spirit of savagery should be discouraged. I do not like to encourage young children to "catch things" for the mere excitement of catching them, but to study the habits of things as they are. I have little sympathy with the development of shallow sentimentalism regarding the life of animals and plants; but it is a safe principle, with children, to respect the life of everything, and to discourage the spirit of the hunter.

How may we develop the humane attitude toward living things?

In reply to your letter, asking how I would advise the teaching of "humane education" in the schools, I will say that I should let such teaching come as a result of a natural and welldirected development of the child. I should not teach tenderness, sympathy and morality directly as abstractions. I should try to inter- 
196. The Nature-Study Idea

est the child in all living things, including other human beings, leading him to see their lives as they live them and enabling him to understand them. He then would have a reason for caring for them, and instruction would not be mere preaching (pp. 32, 143).

Of course, it does not follow that an understanding of the habits of animals and plants always insures humane feelings towards them, but if sympathy and spirit are a part of the teaching, it must inevitably lead in that direction. All first-hand contact with the verities of nature makes for ethical development of the individual.

Would you tell the child the names of the things?

Certainly, the same as I should tell him the name of a new boy or girl. But I should not stop with the name. Nature-study does not ask finally "What is the thing?" but "How does the thing live?" or "What does it do?" or "How did it get here?" or "What can I do with it?" The name is only a part of the lan- 
guage that enables us to talk about the object. Tell the name at the outset and have the matter done with (pp. 79, I2 I). Then go on to questions.

Would you begin by first reading to the child about nature?

No, not in the school as a part of naturestudy work. The reading should come after, not before (pp. 30, 37). Order will gradually come out of experience. The child should first come in contact with things rather than with ideas about things. This is the natural order. Animals come before zoölogy, plants before botany, fields and rocks before geology, words before language, religion before theology. Experience should come before theory.

There will be times, of course, in the exigencies of school work, when the teacher may feel obliged to read to the children in advance of taking up the particular study; but these occasions will be exceptions, and not a part of the system. In many cases, a vacant period or a rainy day may be made useful by good nature reading. 
198

The Nature-Study Idea

Now that there are so many nature-books, how shall I choose the most useful one?

Only by finding out what you want. The multitude of books may be confusing, but the greater the number the greater is the chance that you will find one to your liking. Some persons deplore the making of many books, because they then have more difficulty in choosing; but the time has already passed when one book, or even two, can satisfy a good teacher. The teacher may not be able to purchase several books, but the school should supply a reasonable number. In these days the library is part of the equipment of the school. There is a general feeling that a new book-particularly a new school-book-is made for the purpose of displacing some other book. I once wrote a book. It seemed to occupy a field for which one of my best friends also had written. This friend wrote that perhaps I was right and he was wrong. I hope I was right but this does not imply that he was wrong. I hope that we are both right. There is more than one point of view. 
It is not essential that we have uniform methods of teaching any subject in all parts of the country, and there is reason why we should not have them in nature-teaching. When one text-book satisfies everybody, it is because everybody is uncritical and unpersonal.

How shall I acquire sufficient knowledge to enable me to teach nature-study?

In the same way that you acquire other knowledge-by means of work and study. There is no way by which you can dream it or absorb it. There is no excellence without labor. The teacher should know more than he attempts to teach.

Yet, you must not magnify the importance of mere information. The ambition to teach and the love of doing for a child are the fundamental requisities. Fill yourself full of some subject, however small it may be. When you cannot hold it longer, teach. Yes, you may make mistakes. But every one makes mistakes, even with the best of pains. Every person who, by teaching or writing, has helped the world to 


\section{The Nature-Study Idea}

a higher plane, has said or written errors. Every person, and particularly every teacher, should make all effort to be accurate; but if we wait till every possibility of error is removed, the world's work will never be done. Many a man sacrifices his chances of usefulness for fear of making a mistake. The real work is not performed by timid persons (p. 59).

The best way to acquire the knowledge is to work for a time with a good teacher, who has enthusiasm and human sympathy. Read books and leaflets. Above all, go into the field and study the objects themselves. Do not wait until you are thoroughly equipped before you begin to teach, else you will never begin. When you have begun and your pupils begin to press for answers, you will learn. When you discover that you have made an error, admit it and acknowledge it. The pupil will respect you. Honesty always wins respect. (Pp. 44, I 72.)

It is not necessary that you become a scientist in order to teach nature-study. You simply go as far as ycu know, and then say to the pupil that you cannot answer the questions which you 
cannot. This at once elevates you in the pupil's estimation, for the pupil is convinced of your truthfulness, and is made to feel-but how seldom is the sensation!-that knowledge is not the peculiar property of one person, but is the right of any one who seeks it. It ought to set the pupil inquiring for himself. The teacher never needs to apologize for nature. $\mathrm{He}$ is teaching only because he is an older and more experienced pupil than his pupil is. This is the spirit of the teacher in the colleges and universities to-day. The best teacher is the one whose pupils the furthest outrun him; his pride is in the good.pupils that he sends out.

Is it best to have a professional nature-study teacher to go from school to school?

This is a local, personal, and administrative problem. Ideally, it is best that every teacher handle the nature-study, because, as nature-study is a way of approach and a means of teaching, its effect is greatest when it is most continuous. In practice, however, some teachers will be sure 
to develop special aptitudes for the work, and these persons should be retained for this particular effort. The best talent should be employed for nature-study, as for anything else.

If there is a domestic science teacher going from school to school, perhaps she could also qualify in nature-study. Much of what we call domestic science is, or should be, pure naturestudy; and all home questions should find expression in the schools.

Should not nature-study be in all the grades for all pupils, and technical work be left to the high-school?

[This teacher asks the following questions:

"Should not every teacher who goes out to the grades be prepared for giving the children instruction concerning the life about them? Should not nature-study be planned for all the grades as a means of giving the child his bearings and relations to animals and plants, and should not formal instruction in the principles of agriculture come in the high-school? or, in other words, should not the child's interest in 
things out-of-doors be fostered by means of informal and yet careful instruction during the earlier school years without special reference to the utilitarian phases of nature?"]

Your questions are easy for me to answer because they are framed in such a way that I need only to say "yes" to every one of them.

Nature-study teaching is not specialized teaching. It is a fundamental educational process which should put the child right toward the world and toward life. If every child should have a close connection with his environment, so, also, should every grown-up; and it follows that if the grown-up is a teacher, he will carry this spirit into the schoolroom.

The child who has the proper point of view toward the world in which he lives, and proper sympathy toward the objects and affairs about him, will be better prepared for any kind of study that comes later, whether that study is Latin, mathematics, engineering, agriculture, or other subject. I should leave the technical agriculture for the high-school, and preferably for the upper grades of the high-school. It is 
better to have the formal agriculture come after the student has had chemistry, physics and biology, at least to some extent. This would probably put the formal agriculture in the third or fourth year of the high-school. In the meantime, however, the pupil should have been prepared for all this work by having his mind open to the nature about him. In rural communities this nature-teaching will, of course, bring the child into touch with farms, whereas in cities and towns the farming phase of it would naturally be less emphasized. I should not try to force any child to become a farmer, or to follow any other occupation. When he comes to the realm of the high-school, he may of his own desire wish to begin to specialize. I should hope that the early training would be such that more persons would want to specialize in agricultural subjects than has been the case in the past; but the real nature-study teaching is quite independent of this.

It is undoubtedly a mistake to introduce formal and technical agricultural work into the 
grades. It is easy to refer the pupil in the grammar grades to bulletins and books, when he should be coming into original contact with the life and materials about him. The pupil should be taught to know domestic animals before he is instructed in the breeds of animals. He should know the way in which the neighbors build their houses and barns before he studies the styles of architecture. The grade work should touch many things, first and last, so that the pupil gains some conception of his world at large and, as you say, gets "his bearings and relations."

Should the parts of a school-garden be apportioned to pupils, or should the work be done in common?

In practice this becomes largely a question of administration: sometimes one thing may be done and sometimes the other. Ideally, the parts should be apportioned to pupils in the real laboratory school-garden. Thereby is the sense of proprietorship cultivated and the 


\section{The Nature-Study Idea}

stimulus of emulation aroused. It is always advisable, when it can be arranged, to provide for some culmination or focus of the season's work in the nature of a flower-show or vegetable-show; or, the children may be allowed to sell the products of their gardens or to give them to hospitals or other worthy objects. This individuality of interest can be easily maintained in the plot-garden, but it is more difficult in the ornamental garden in which the plants are grown in continuous borders. (See p. 87.)

In order to indicate how some of the questions are attacked by those who are engaged in the work, I reprint an article on the Whittier School-Garden, by Miss Jean E. Davis, that appeared in Country Life in America:

"What is believed to be the largest schoolgarden in the United States is to be found in Virginia at the Hampton Institute for Negro and Indian youth, where it forms part of the equipment of the Whittier Training Schoolthe practice-school of the institution. Two acres of ground are given up to the garden, the 
larger part being divided into two hundred individual plots, varying in size from four by six feet for the pickaninnies of the kindergarten, to eleven by fifteen feet for the oldest boys and girls. Each plot is owned, for the time being, by two children, who enter into partnership and share equally in the work as well as in the profits of the garden-spading, raking, planting, hoeing, harvesting with their own hands, and using the products in their own homes or selling them to their neighbors. The young farmers are not given carte blanche, however, in regard to the kind of crops they shall raise or the position of them in the beds. The supervision of the work is in the hands of one person-the director of the agricultural department of the Institute-who decides what vegetables and flowers shall be planted and how they shall be arranged. This plan serves to give symmetry and order to the garden as a whole, and adds materially to the educative value of the work. Most of the plants selected are such as are easily cultivated and such as 
mature rapidly, like lettuce, radishes, nasturtiums and marigolds; though peas, beans, cabbage, spinach and tomatoes are also cultivated. The gardens are made and planted both in the fall and in the spring, the crops sown in the spring being cared for during the long summer vacation by volunteers.

"The beds are separated from each other by paths one foot wide, and are arranged for the different classes in sections, having two-foot paths between them. Extra plots, six feet wide, extending the full length of each section, are used for overflow work by pupils who are exceptionally quick and energetic. Strawberries and raspberries are sometimes permitted in these beds. Another opportunity for work out of the usual routine is afforded by a space of three quarters of an acre which is reserved at the rear of the garden for the purpose of teaching the larger boys how to use a horse and plow. In order that the esthetic side of gardening may not be neglected-the cultivation of a sense of beauty being esteemed of 
equal importance with practical instruction in agriculture-a large lawn has been placed at the entrance, while border beds of ornamental flowers form the other boundaries.

"But if school-gardening were confined to the making of gardens, the planting of seeds and the cultivation of crops, beneficial as these experiences might be, it would still fall far short of accomplishing the end desired in introducing this subject into school courses. It would soon degenerate into either play or drudgery. To give it dignity and interest, and to make it of practical value in later life, the gardening is supplemented or preceded by simple experiments in the classroom illustrating the principles of germination and plant-growth; and a study is made of seed dispersion, the comparative value of soils and the work of beneficial and injurious insects. Seeds are planted in window-boxes, the seedlings affording material for language and drawing lessons before being transplanted into the outdoor beds The decorative value of flowers, leaves and berries is considered, and the children are 
encouraged to make gardens at their homes from which they may gather bouquets of flowers for their dinner-tables.

"The results of two years' experience in teaching gardening and nature-study at the Whittier School are most gratifying. While at first it was necessary to use compulsion with some of the older girls, and the little ones merely considered anything 'good fun' that took them out of doors, they now without exception look forward with eager enthusiasm to 'gardening day,' which comes twice a week to each of the four hundred. Large crops have been gathered and proudly carried home; seeds have been in demand for home gardens; sixty or more of which have been made in the neighborhood; and last spring children to the number of one hundred and thirty volunteered to cultivate the gardens during the summer vacation. In the home-gardens there has been great diversity of crops. Besides the usual school plants, children have raised wheat, corn, pumpkins, sweet and Irish potatoes, and also many kinds of flowers. A wholesome rivalry has sprung up 
between the owners of adjoining beds in the school-garden, and pride in the appearance of the school-grounds has been stimulated. An interest in birds and insects, and an appreciation of the beauty of wayside flowers and other common things, have been developed; and the roughest children have been made more gentle by handling the beautiful flowers that they have grown, the result of their own care and patience. A regard for the property and rights of others is among the results of this coöperative gardening, also an appreciation of the advantages of working together, and a certain forbearance and loyalty to one's partner, all of which are lessons of inestimable value, especially to colored children. When we add to these unconscious influences of school-gardening the conscious self-respect and self-reliance that come from the ability to produce from the soil something of one's very own, it will be admitted that this subject is worthy of an honorable place in the course of study of our common schools, of which the Whittier School is only a type." 
Can I make a nature-study exhibition useful as a part of an exposition?

I hope to see good nature-study exhibitions at all the great expositions. It is time that we begin to relate education directly to the affairs of life; or, to put the matter in another way, to make the affairs of life a means of education. I hope that you will find some way of making your educational exhibition dynamic. Most exhibitions are merely passive or static, consisting of pictures and charts, books, apparatus, and such other things as sit still. The very essence and spirit of the new education is activity. I judge from your letter that you are expecting to express this activity by means of a school in actual operation. I hope that you may also have a good school-garden in actual operation, and also some effective outdoor laboratory work. I am not yet satisfied with the school-garden movement. I think that we have not yet developed its laboratory significance.

The time is coming when we shall begin our educational process by putting the child into 
real activities of work and play, and when we shall add the books and apparatus gradually as he grows and the need of them develops. Your exhibition should teach this.

Should this nature-study be confined to the schools?

It should not be confined to schools. Too often it is thus restricted because we are in the habit of delegating the training of our children to a professional class of teachers. Ideally, the home should be the most perfect school, and the parents should be the best teachers. In the increasing complications of our lives, however, the division of labor forces the children more and more from the home-training into the school-training; therefore it is increasingly important that we give good heed to the maintenance of schools. But even so, the home-training should afford an auxiliary to the school-training. There should be more than one common bond of method and purpose. One of these bonds should certainly be the 


\section{I 4 The Nature-Study Idea}

desire to put the child into sympathetic relation with its own necessities.

I fully commend education by means of literature and history and science and art, of course; but if I were confined to one means I should choose that which would lead me to love the things that I see and the work that I do day by day. This outlook I should want to impress on my children; but I could not impress it by any mere intellectual means. It is an affair of the heart; and if I do not live it I cannot teach it.

But it does not follow because one or even both of the parents is in full rhythm with the natural world, that the parents can teach the child effectively. Few persons are good teachers; and when there is marked difference of outlook between the parents, the school may be the only agency that can give the child an harmonious relation.

The school is a distributing agency for all kinds of educational ideas. It must more consciously recognize this function and take pains to aid parents, pastors, and others to encourage 
good work outside the school, particularly such work as contributes to the prosperity of the community. The high-school bears a marked responsibility in this way, because it has greater equipment than the grade-school and deals in more particularized subjects. The influence of the high-school should be felt not only in the school grades, but in the whole daily life of the people. It should set good ideals of public service by enabling the people to meet their problems.

What shall we do with the children in the summer vacation?

This is an exceedingly important question and very difficult to answer. The teacher has no control of the child during this period. He can suggest what the pupil may do, but the probability is that the pupil will merely drift.

I am convinced that there is a great loss of efficiency in the over-long and undirected summer vacation for both child and youth. The colleges are beginning to feel this, as shown in the development of four-term systems. The 
2 I6 The Nature-Study Idea

summer schools are protests against an idle summer. Herein is where the farm boy acquires much of his efficiency for the battle of life-in the fact that he has no long periods of enforced idleness, laziness and emptiness. $\mathrm{He}$ is kept at work. He grows up with an appreciation of the value of time. He knows what industry is and what it brings. Steady effort and application become the warp and woof of his life. The town boy of the upper and middle class, on the other hand, is likely to become accomplished in feats of idleness. One fourth his time is mere vacation, or, rather, mere vacancy. $\mathrm{He}$ is handicapped when later he comes squarely against the realities of life.

I believe in a long vacation if the time is occupied in some well-directed effort. I am glad to see the development of the summer-camp idea for both boys and girls, where, under competent and sympathetic guidance, with firm but kindly discipline and something like Spartan fare, they are led to see and to know the nature in which they are. In such campingout experiences the youth comes hard against 


\section{Inquiries and Answers}

actualities. He gathers materials that are his own and that become a part of his capital throughout life. He comes to his own conclusions and to think for himself, not merely to absorb his knowledge and opinions from teachers and books. In later life he may never have another opportunity to secure this actual experience.

I wonder how many persons ever saw the sun rise?

Will not this nature-study work interfere with school discipline?

That all depends on what you mean by "discipline." If you mean perfect "order," the child sitting erect with clasped hands, then naturestudy work may annoy you. If you mean only that the child is well-behaved, obedient and happy, then no ill result should come from the nature-study effort. Nature-study should supply some of the "busy work" between the regular periods. The best means to secure good discipline is to keep the child busy and interested. "Discipline" is then a result. 
The greater number of mischievous and refractory children can be interested in some piece of personal work or investigation. The boy who is "licked" at home and punished at school is likely to spend his time midway between the two; and yet he may be easy to reach if only he is understood.

Shall I correlate the nature-study work with other work?

This question can be answered only for particular cases. In general, correlation is an advantage to all subjects concerned; however, I fear that in much of the correlation the naturestudy part is little more than a name. If the nature-study can be kept genuine-a real study of native objects and relations at first hand-I see no danger in correlation. The correlation usually is of greater benefit to the other subjects than to nature-study.

Nature-study work can be correlated with various other school work, notably with essay writing, drawing and geography teaching. The very first essential in essay writing is to 
have something from one's own experience to say. Assigned topics are usually "hard" at best. Let the child write of what it has seen or done that day or yesterday-the butterfly, the tadpoles in the pond near by, the plants growing in its garden, the fish in the aquarium, the peaches on the tree by the barn, the little world of life in the terrarium, the woodchuck that lives under the stone fence, the things it saw in the market, the vehicles it sees on the street, the factories and farms near by, the field work, the house work, the school, the highway, the hill, the kinds of fences by the way, the collecting expeditions and the games. If the child has had no such experience, why not begin by assigning him a living topic to look up and report on in writing?

We need to be unusually careful to see that the writing is not exotic to the child. Avoid the model of nature-study "stories" and "writeups" about things; these stories tell what others have found out. They may inform and instruct and entertain, rather than educate and set the child to work. 
We stifle the desire to write if we first lay down rules and formulas as to how to write. Let the child have a personal experience; then allow it to write. Did you ever have a pupil who could not write a composition, but who could write a letter that was full of originality and personality? Why could it write the one and not the other? Too often, I fear, we prevent our children from writing by trying to make them write. Of what use is writing, anyway, if it is not self-expressive? So, let the child have something real and personal to write about. No subject is too mean. Then when the child has written, throw away the blue pencil and suggest tactfully how the piece may be improved here and there. Do not hinder the child.

I well remember my first "composition." For days I had tried to think of a "subject." I had importuned father and mother and friends. "Winter," "Spring," "The pen is mightier than the sword," "The pleasures of farm life," "Shakespeare" - all had equal terrors. Rapidly the days passed away, and 
to-morrow the composition must be ready, and yet of all the well-sounding subjects not one seemed to present a way of escape. The teacher-God bless her!-learned of my plight. She asked me what was the best "time" I had had last summer. Of course I knew-the time when we all went blackberrying, with all of us rolled into the bottom of the wagon-box that went bumping and rattling over the stones and grinding through the sand, when we crept through the deep cool woods and then came into the "clearing" where the skidded logs were covered with the tangle of berries and berries -of course I knew! With what wild delight I told her! and then she said, "Just write that down and it will be your composition." From that day until this I hope I have written only on those things that are dear to me.

I have a similar word to say about drawing. The other day I heard Mrs. Comstock speak on this subject before a convention of teachers. She is herself an artist. She said that there are two kinds of drawing-the kind that is the child's self-expression, and the kind that makes 


\section{The Nature-Study Idea}

an artistic picture. It is natural for every child to make lines and marks to express what it sees or experiences; but when these lines and marks do not conform to the ideals of grown-ups, we discourage the effort and the child ceases to draw. Considered as the effort of the child to express itself, no drawing can be "poor." Mrs. Comstock put on the board a copy of a drawing from a child's pad, and it was as follows:

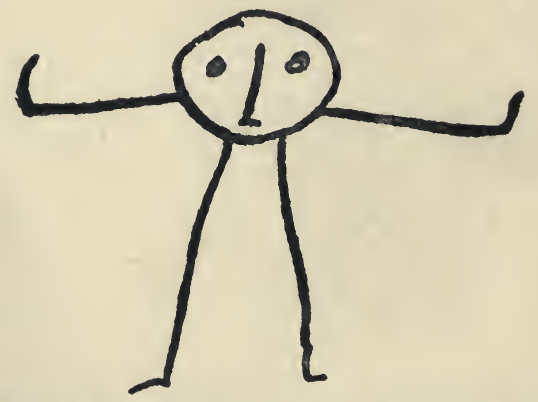

How a man impressed a cbild.-face, arms, legs

We all laughed; but we were told that this was no caricature, but the impression that a man made on the child-face, arms, legs.

More than words, the drawing may show what the world means to the child, even allow- 
ing for all the errors in clumsiness with pencil. Do you not wonder how the world looks to the little girl in the second grade who made all these drawings and sent them to Uncle John? Would you not like to take her on your knee and have her explain them to you?

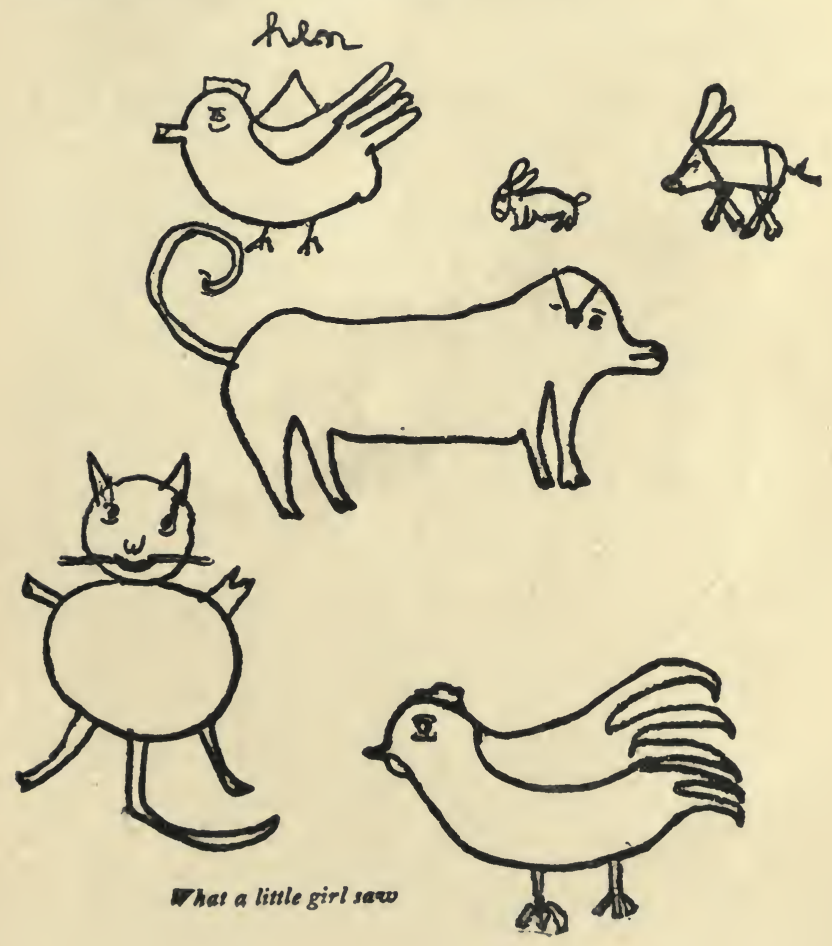


Primarily, drawing is a means of expressing what we see and feel; now and then a person develops the ability to make a picture that pleases others, and he becomes an artist. Primarily, our interest in the external world is one of sympathy and personality; now and then a person develops the ability to make discoveries and to record them, and he becomes a scientist.

Correlation of nature-study and drawing should give excellent results to both subjects. The nature-study should afford objects in which the pupil is genuinely interested; the drawing should aid in focusing the observation and making it accurate. Drawing should be encouraged primarily for the purpose of discovering what the child really sees. As the child sees more, and with greater accuracy, the drawings improve. So the drawings become an approximate measure of the progress of the pupil. Do not measure the drawings merely as drawings, or from the artist's point of view. We are likely to dwell so much on the mere 
product of the child's work that we forget the child.

Too early in the school life do we begin to make pupils mere artists and literators. First the child should be encouraged to express himself; then he may be taught to draw and to compose.

If correlation produces these useful results, it should be encouraged.

What can I do to put our rural schools in touch with their constituency?

What you can do, as a superintendent, to aid your rural schools to better their conditions, is to enter into a general agitation of the subject through the local papers, through correspondence with the teachers themselves and the school officers, with the granges, and other farmers' societies, village improvement societies, pastors, and whoever and whatever else there may be that stands for bettering conditions.

Work of this kind cannot be accomplished in any one way or through any one source. With a determination to alleviate the situation, with 
imagination and with industry a person can accomplish a good deal in the directions about which you inquire.

Following are definite suggestions to make to rural teachers for working out in the schoolhouse (adapted from M. P. Jones, Cornell Rural School Leaflet) :

I. Register with the college of agriculture or experiment station of your state, to receive the publications and to be on the correspondence lists.

2. Write to the state education department for whatever syllabi it may publish on naturestudy, agriculture, and similar subjects.

3. Start an agricultural and nature-study library. A very creditable beginning may be made at no cost except postage, by asking for publications issued by the Department of Agriculture at Washington and the State Agricultural College and Experiment Station. It is recommended

(a) That you write to the Department of Agriculture, Washington, D. C., asking to have the school placed on the mailing list 
Inquiries and Answers

for the monthly list of publications and to have the following sent to you:

I set of Farmers' Bulletins suitable to the locality.

I copy of the list of Publications for Free Distribution.

I copy of the list of Publications for Sale.

I copy each of reprints of areas that have been surveyed by the Bureau of Soils in your state.

I copy each of Bulletins I 86 and 160 and Circulars 77 and 52 of the Office of Experiment Stations. On receipt of these bulletins, holes should be punched through them and strings used to tie them together. Manila paper may be used for covers.

(b) That you write to the Geological Survey, Washington, D. C., inclosing I 5 cents in stamps and asking for the three geological survey maps that cover your region.

(c) That you write to your representative, 
congressman or senator, for copies of state or national documents that are distributed by them.

(d) That you secure the use of a traveling library, if such libraries are issued by the education department or other agency in your state.

(e) That as many agricultural and naturestudy books be added to the library as money will permit.

4. Beautify the school-grounds. Endeavor to interest the trustees and the farmers of the district. In one district, an oyster supper brought forth money and enthusiasm enough to produce a marked improvement. Valuable suggestions will be found in

Farmer's Bulletin (U. S. Dept. Agriculture) No. 43, "Tree Planting on Rural School Grounds."

Farmer's Bulletin No. I 85, "Beautifying the Home."

Farmer's Bulletin No. 248, "The Lawn."

Farmer's Bulletin No. 2 I 8, "The SchoolGarden." 


\section{Inquiries and Answers}

Perhaps the agricultural college of your state, or your state education department, has issued publications on this subject.

5. Begin a school-garden. Every country school should have its garden. If possible, it should be large enough so that every child may have a garden of its own. The children should also be encouraged to have gardens at home. The school-garden may be used as an experiment station to test fertilizers, varieties, methods of planting, and the like. Read books and bulletins on the subject.

It will be found less expensive to buy seeds in bulk and divide these into penny packets to be sold or given to the children, preferably sold.

6. Make a window-box and have plants growing in it.

7. Have a terrarium. This is a box with sides and top made of window screens. The top is hinged so that it can be raised. Earth may be put in the bottom and plants allowed to grow in it. Frogs, toads, insects and other outdoor life can thus be safely housed. The 
terrarium may be used in winter in the study of fowls.

8. Have an aquarium. A glass vessel or a Mason fruit-jar, with water frequently renewed, will serve for a time. Have some water-plants growing in the aquarium and keep a few fishes, salamanders and tadpoles for study.

9. Have a museum of things related to the life and affairs of the region. Let the collection be started and increased by the children themselves. It is suggested that collections be made of the following:

(a) The different types of soil found in the neighborhood: sand, silt, clay, muck, and sandy, silty and clay loams.

(b) Seeds of common vegetables, flowers, fruits, and trees.

(c) Common grasses: timothy, red-top, meadow fescue, Kentucky blue-grass orchardgrass.

(d) Common legumes of the farın and garden : red, white, and alsike clovers, alfalfa, peas, beans, vetch, soy beans, cowpeas. 
(e) Comon cereals : corn, wheat, oats, rye, barley, buckwheat, rice.

(f) Ears of corn: flint, dent, pop, sweet. Secure ears showing the qualities that good ears should have. A lesson in corn-judging may profitably be given.

(g) Fertilizers: nitrate of soda, dried blood, ground bone, acid phosphate, muriate of potash, and as many others as are used in the neighborhood.

(h) Feeds for farm animals: bran, middlings, gluten feed, buckwheat middlings, and others in use. The local feed merchant and seedman might lend their aid in supplying samples of these feeds, samples of fertilizers and seeds.

(i) Fruit. In the fall, different varieties of apples, pears, plums, and grapes could be collected, probably with much enthusiasm, by the children. Part of an afternoon could be given for a short talk on fruit-growing by a local fruit-grower, after which the samples of fruit could be eaten. Similar col- 
lections of root-crops and vegetables might be made, not with the idea of keeping them in the school for a long time, but as one of the best means of teaching children to become familiar with the common things of their farms.

(j) Flowers and weeds. These can be pressed and used as the basis for the school collection. Begin with the most common plants and enlarge the collection slowly.

( $k$ ) Leaves of trees. Press the leaves of some of the most common trees, adding to the collection slowly enough for the children to learn as they go.

(l) Fibers: wools of different kinds, cotton, flax, hemp; ropes, twine (particularly binder twine), bagging, fabrics, etc.

Io. Teach the Babcock milk test. Some schools have demonstrated the use of this test before grange meetings. Complete milk-testing outfits suited for school use are manufactured at small price. Write to dairy supply house for catalogues, and get information from your college of agriculture. 


\section{Inquiries and Answers}

II. Have a reading-table. Secure a few good magazines, agricultural and other kinds. No poor books or poor magazines should be in the schoolroom or home. Some publishers of agricultural magazines will send complimentary copies if, in asking for them, it is stated that they are wanted for the school library.

I2. Have a work-bench with tools, if possible. The boys and girls should become familiar with the handling of common carpenters' tools. Simple things, especially those that can be used on the farm or at play, may be made, such as a window-box, terrarium, stakes for the school-garden, bird-houses, kites, sleds, skees, book-shelves, tables, flower-stands. Hand tools can be repaired. This will provide excellent manual-training, developing naturally into use of wheels and more complex forms.

13. Have one or two vases with flowers well arranged.

14. Have a school fair. These have been found very successful where tried. Children exhibit products from their own gardens and benches. The girls exhibit cakes, pies, biscuits. 
which they have made. Small prizes are given. The people of the district are invited and the fair is made one of the important social events of the year. It will probably be found that the older people enter enthusiastically into a competition of their own, and if this can be arranged it will add greatly to the success of the fair. Take the exhibit to the county fair or state fair.

15. Take occasional trips to neighboring farms, factories, to the woods and fields.

16. Provide some simple apparatus, as, for example, the following to begin with:

I Babcock milk test (if in a dairy country) ............ \$5.00

I tripod lens magnifying glass.... $\quad .75$

I terrarium $\ldots \ldots \ldots \ldots \ldots \ldots \ldots$

I aquarium $\ldots \ldots \ldots \ldots \ldots \ldots .2 .00$

I insect net (home made)

Various cups and boxes to hold specimens.

I7. Try to know the weather. If you have expeditious mail service, apply to the United States Weather Bureau for the daily bulletins 
and a frame to put them in. A good thermometer should be hung in a protected shady place. Thermometers that are reliable at high and low temperatures usually cost more than one dollar. A rain-gauge will be useful and interesting. Some schools may add a barometer, if the teacher understands it; but the cheap instruments are not reliable.

How can I reach the farmers of my neighborhood?

[A teacher is discouraged because she seems to make no headway; and the farmers complain that her work is not practical and they want to know how to make more money.]

While you are under obligation to teach farmers' children, you do not bear the responsibility of making the farms profitable. It is the business of the farmer himself to make his farming pay. You are engaged in the work of education.

How to teach, not how to farm, is therefore your problem. I take it to be axiomatic 


\section{The Nature-Study Idea}

that every person's mind should be expanded in order that he may derive the greatest satisfaction from life. If the occupation in which he is engaged will not allow him to derive this satisfaction, then it is his privilege, and in fact his duty, to change his occupation. I am very sure that the educating of farmer boys and girls will often have the effect of taking them away from the old farm. It is a question, then, whether the whole point of view on farming must not change and whether such new methods and new types of life must be developed as to interest persons with a broad outlook on life. I think that the diffusion of information and the extension of education is bound to have this effect on the farming industry in the long run. In the meantime, it is for us to try to determine just what is the most practicable means of procedure in the educating of the country boy and girl, that will give them a satisfactory outlook on life, and make them least willing to give up their place in the country.

Time and again I have had problems similar to the one that your patron asks of you, namely, 
that instead of giving scientific information about eggs, you tell him how to make his hens lay better when eggs are scarce. It is very easy to ask how to make hens lay in October and November; it is quite another thing to answer the question. Such a question cannot be answered out of hand. A man must first learn something about breeding, and feeding, and care, and other things. In other words, a man must have enough fundamental knowledge to know the reasons why, and this knowledge is necessarily scientific. It is utterly impossible to try to answer the greater part of our agricultural questions until the questioner has some really underlying understanding of the conditions, and processes, and principles involved. The lack of this understanding is one reason why farmers are so backward in utilizing advice, and also why they are unable to use the experiment station bulletins.

But even if you could tell your patron how to make hens lay in October, that would not settle or simplify your teaching. You must lead your pupils to go beyond an isolated fact 


\section{The Nature-Study Idea}

and relate it to other facts. You must give them some conception of the hen's habit of life. You must not allow your advice to farmers to take the place of the training of farmers' children.

I do not doubt but that all elementary educational work for country conditions is yet very crude and fails adequately to reach the mark. On the other hand, I am convinced that we are learning how. In the meantime it seems to me that it is your part as a teacher to endeavor to put the country children, as much as possible, directly into touch with their environment in order that they may understand it and apreciate it. I am quite sure that not all the compensations of farming are in the shining dollars of which you speak. Some of the compensation comes in a sympathetic appreciation of the surroundings and the advantages that a farmer has and may have; and the countryman cannot be really successful until he arrives at this appreciation. Of course, he must first of all have the money, for this enables him to live; but there are other rewards in life. If the 
farmers do not appreciate all this, you must do your work just the same, and wait.

You certainly are not alone in feeling that you cannot carry the children much beyond the printed lesson. As you say, these subjects are so new that there has been no opportunity for adequate training in them. I think that the best teacher I ever had along these lines was a woman who knew very little about the subjectmatter itself, but who encouraged me, answered my questions as best she could, and told me frankly when I had found out more than she knew. I judge, however, that you quite underestimate your own knowledge, else you would not feel so keenly the responsibility of your work.

You can do a great deal outside the school for your people. You can work through farmers' organizations, attend farmers' institutes, help to organize boys' and girls' clubs, reading clubs, help to put educational work in the fairs, and in many other ways quicken the rural life of your vicinity. 
240 The Nature-Study Idea

How can a teacher prepare himself to teach agriculture in the special schools that are now being established?

Beyond pleasing personality and moral character, there are two powers that qualify a person to teach: (I) the teaching ability, which is in part a natural quality and in part gained by experience; (2) knowledge of the subjectmatter.

The subject-matter can be acquired partly by attendance at summer schools and by home reading, but if you are intending to fit yourself for the best positions you will need to attend a good college of agriculture. Even though you are farm bred and know the practical business of farming, you will need the college training to give you a rational grasp of the field and to enable you to put your abilities into teaching form. For these best positions, you must take nothing less than a full four-year course, for you will have to compete with the regular graduates of these institutions; and four years' training is little enough to fit you in the fundamental sciences and arts, and to prepare you 


\section{Inquiries and Answers}

in the modern agricultural subject-matter. For those who cannot take full training, the colleges of agriculture offer short and special courses.

[I have given a full outline statement of these questions in Bulletin No. I, I908, of the United States Bureau of Education, under the title, "On the training of persons to teach agriculture in the public schools."]

How can I do any nature-study work in the ordinary kind of schoolroom?

School buildings are constructed for the work that is known and recognized at the time of their erection; so it follows that they may be very poorly adapted to nature-work. If your room or building is poorly adapted, you will be obliged to shift as best you can, making the most of unsatisfactory conditions. You should not give up the work for that reason. You may have room at one side or end for a table on which you can place a terrarium and aquarium and other things. You may have a window or two in which it will be possible and 
advisable to grow plants. In some cases, the children can germinate a few plants, or even raise them to maturity, on their desks. You may have a yard in which a little can be done in gardening. If you have none of these possibilities, then you can encourage the pupils to grow plants and to make their observations at home (which they should do anyway) and report the results in school. You can have them bring in such specimens as do not require to be kept, and then "clean house" frequently. In the planning of new school buildings, ample provision should be made for naturework. The need of this is particularly apparent in the country schoolhouses. In rural districts, we must have a new kind of schoolhouse. A room or wing should be added for work with tools and with nature objects; or a basement may be provided; or, in many district schools in which the number of children has decreased, one end of the old schoolroom may be partitioned off for this purpose; or some good outbuilding may be requisitioned. The school premises of the new order must be provided 
with good grounds, and these grounds should grow many or most of the native trees and shrubs of the neighborhood, becoming a little local park and a beauty spot.

We have talked much about new teachers, but we need schoolhouses about as much as we need new teachers. I suppose they will come together. There is no use of evading the question of better equipment. We must put more money into our schools if we expect to make them better. Schools are worth about what they cost. We must not only have new pieces of equipment, but a wholly new idea of equipment. We are to go back to the beginning and do it all over again and begin naturally and practically. Different kinds of things must be put into schoolhouses from those that we have been accustomed to put there (pp. 226235). We must put in them products and implements, and make them express the life and enterprises of the neighborhood. We must improve not only the school and premises but we need equally to interest the whole district or constituency in the better things. 


\section{The Nature-Study Idea}

It is not the teacher alone or the schoolhouse alone that we need to improve. We have talked about the little red schoolhouse; but the little red schoolhouse (as one of my farmer friends puts it) is likely to contain the little green teacher.

\section{Is nature-study on the wane?}

Real nature-study cannot pass away. But the more closely we come into touch with nature the less do we publish the fact abroad. We may hear less about it, but it will be because we are living nearer to it and have ceased to feel the necessity of advertising it.

Teaching may not be nature-study merely because it is so called. A superintendent told me that he had forbidden nature-study in his schools. I asked him what the work had been. He said that it was the dissecting of cats. A publisher told me that nature-study is passing out. I asked why he thought so. He replied that his nature-study books were not selling as well as they did. I told him that I was glad.

Much that is called nature-study is only 
diluted and sugar-coated science. This will pass. Some of it is mere sentimentalism. This also will pass. With the changes, the term nature-study may fall into disuse; but the name matters little so long as we hold to the essence.

All new things must be unduly emphasized, else they cannot gain a foothold in competition with matters that are established. For a day, some new movement is announced in the daily papers, and then, because we do not see the headlines, we think that the movement is dead; but usually when things are heralded they have only just appeared. So long as the sun shines and the fields are green we shall need to go to nature for our inspiration and our release; and our need is the greater with every increasing complexity of our lives.

Would you advise me to take up nature-study teaching?

Yes, if you feel the "call" to it; otherwise, no. I would have only those teachers teach nature-study who are well qualified for it, as I 
246 The Nature-Study Idea would advise for grammar or other school work. Every teacher ought to have the nature-study outlook to keep him young and interested in life, but we all recognize that relatively few of them have it. Every pupil should have nature-study, under one name or another; but he should receive his inspiration from the teacher who himself is so full of the subject that he teaches with spirit and with cheerfulness.

After a time, we shall not need to argue for nature-study. Teaching must in the end be natural. 


\section{RURAL SCIENCE SERIES}

Edited by L, H. Bailey

On Selection of Land, etc.

Isaac P. Roberts' The Farmstead .............. \$I 50

On Tillage, etc.

F. H. King's The Soil.................. I 50

Isaac P. Roberts' The Fertility of the Land....... I 50

F. H. King's Irrigation and Drainage......... I 50

Edward B. Voorhees' Fertilizers............. I 25

Edward B. Voorhees' Forage Crops............ I 50

L. H. Bailey's Principles of Agriculture ........ I 25

On Plant Diseases, etc.

E. C. Lodeman's The Spraying of Plants........ I 25

On Garden-Making

L. H. Bailey's Garden Making ............... I 50

L. H. Bailey's Vegetable-Gardening ............. I 50

L. H. Bailey's Forcing Book ................. I 25

On Fruit-Growing, etc.

L. H. Bailey's Nursery Book ................ I 50

L. H. Bailey's Fruit-Growing.................. I 50

L. H. Bailey's The Pruning-Book .............. I 50

F. W. Card's Bush Fruits................... I 50

On the Care of Live-stock

Nelson S. Mayo's The Diseases of Animals...... I I 50

W. H. Jordan's The Feeding of Animals ......... I 50

I. P. Roberts' The Horse ................... I 25

George C. Watson's Farm Poultry .............. I 25

On Dairy Work, Farm Chemistry, etc.

Henry H. Wing's Milk and Its Products........ I 50

J. G. Lipman's Bacteria and Country Life ......... I 50

On Economics and Organization

I. P. Roberts' The Farmer's Business Handbook. I 25 George T. Fairchild's Rural Wealth and Welfare.. I 25

All Prices quoted above are net; postage an extra charge

\section{THE MACMILLAN COMPANY}

64-66 FIFTH AVENUE

NEW YORK 


\title{
CYCLOPEDIA OF AMERICAN AGRICULTURE
}

\author{
By L. H. Bailey \\ Director of College of Agriculture, Cornell University \\ and Professor of Rural Economy
}

With roo Full-page Plates and More Than 2000 Illustrations in the Text-Four Volumes-The Set: Cloth, \$20

net-Half Morocco, $\$ 32$ net-Carriage Extra

\section{Volume I-Farms}

The Agricultural Regions-The Projecting of a FarmThe Soil Environment-The Atmosphere Environment

\section{Volume II-Crops}

The Plant and Its Relations-The Manufacture of Crop Products-North American Field Crops

\section{Volume III-Animals}

The Animal and Its Relations-The Manufacture of Animal Products-North American Farm Animals

\section{Volume IV-The Farm and the Community}

Economics-Social Questions-Organizations - History - Literature, etc.

"Indispensable to public and reference libraries ... readily comprehensible to any person of average education." -The Nation.

"The completest existing thesaurus of up-to-date facts and opinions on modern agricultural methods. It is safe to say that many years must pass before it can be surpassed in comprehensiveness, accuracy, practical value, and mechanical excellence. It ought to be in every library in the country."-Record Herald, Chicago.

\section{Published by \\ THE MACMILLAN COMPANY}




\section{THE EVOLUTION OF OUR NATIVE FRUITS}

Cloth, $12 m 0,472$ pages, 125 illustrations, - $\$ \$ 2.00$

In this entertaining volume, the origin and development of the fruits peculiar to North America are inquired into, and the personality of those horticultural pioneers whose almost forgotten labors have given us our most valuable fruits is touched upon. The conclusions reached. the information presented, and the suggestions as to future develop: ments. cannot but be valuable to any thoughtful fruit-grower, while the terse style of the author is at its best in his treatment of the subject.

\section{LESSONS WITH PLANTS}

Cloth, 12 mo, 432 pages, 446 illustrations, - $\$ 1.10$ net

"I have spent some time in most delightful examination of $\mathrm{it}$, and the longer I look, the better I like it. I find it not only full of interest, but eminently suggestive. I know of no book which begins to do so much to open the eyes of the student-whether pupil or teacher-to the wealth of meaning contained in simple plant forms. Above all else, it seems to be full of suggestions that help one to learn the language of plants, so they may talk to him."-DARWIN L. BARDWELL, Superintendent of Schools, Binghamton.

\section{THE SURVIVAL OF THE UNLIKE}

\section{Cloth, 12 mo, 515 pages, 22 illustrations - $\$ 2.00$ net}

This volume treats of the modification of plants under cultivation upon the evolution theory, and its attitude on this interesting subject is characterized by the author's well-known originality and independence of thought. Incidentally, there is stated much that will be valuable and suggestive to the working horticulturist, as well as to the man or woman impelled by a love of nature to horticultural pursuits. It may well be called, indeed, a philosophy of horticulture, in which all interested may find inspiration and instruction.

\section{THE OUTLOOK TO NATTURE}

$$
\text { Cloth, } 12 m o \text { - - - - - - } \$ 1.25 \text { net }
$$

"It is an instructive and enlightening volume, full of human interest, and of special value to those who have any part in the great work of education."-Toronto Globe.

\section{BOTANY; An Elementary Text Book for Schools} Cloth, 355 pages, 500 illustrations - - $\$ 1.10$ net

"It would be hard to find a better manual for schools or for individual use." - The Oullook.

\section{THE STATE AND THE FARMER

$$
\text { Cloth, } 12 \text { mo, } 177 \text { pages - - - - } \$ 1.25 \text { net }
$$

No one is better fitted to discuss the political and economic status of the farmer than Professor Bailey, and his expositions of Governmental Interference, The Agricultural Shift. The "Abandoned Farm" as an illustration of the Agricultural Shift, Society and the Farmer, The $\mathrm{Na}$ ture of the Social Remedies, are very valuable.

These and other more formal text books are published by

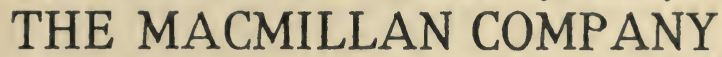




\section{REAL THINGS IN NATURE}

By Edward S. Holden. Cloth, Illustrated, 12mo, $\$ .65$ net

It is the fundamental ideas of science and its methods that are here insisted upon. Simple experiments are described or suggested and the pupil is frequently reminded of the verifications that he himself can make. The illustrations, which are extensive, have been chosen for their educational value.

\section{THE GREAT WORLD'S FARM}

By Selina Gaye. Cloth, Illustrated, $12 \mathrm{mo}, \$ 1.00$ net

A readable account of plants and how they live and grow. The volume is well adapted to young people, being as free as possible from technicalities.

\section{SHORT STUDIES IN NATURE KNOWLEDGE \\ AN INTRODUCTION TO THE SCIENCE OF PHYSIOGRAPHY}

By William Gee. Cloth, Illustrated, 12mo, \$1.10 net

A Brief Synopsis: The Great Globe Itself - Mountains, Valleys and Great Plains-Scenery and Its Causes-The Sea -Rivers and Their Work-Lakes and Their Lessons-Wells and Springs - The Air - The Winds of Heaven - Frost Fires-Showers and Dew.

\section{FRIENDSHIP OF NATURE}

By Mabel Osgood Wright. Cloth, Illustrated, 12 mo, $\$ .75$ net

"A dainty little volume, exhaling the perfumes and radiating the hues of both cultivated and wild flowers, echoing the songs of birds, and illustrated with exquisite pen pictures of bits of garden, field, and woodland scenery. The author is an intimate of nature. She relishes its beauties with the keenest delight and describes them with a musical flow of language that carries us along from a 'May Day' to a 'Winter Mood' in a thoroughly sustained effort." - Richmond Dispatch.

\section{INTERPRETATION OF NATURE}

\section{By C. Lloyd Morgan. Cloth, $16 m 0, \$ .65$ net}

Mr. Morgan here contrasts the two ways of interpreting nature, the one which explains the world in terms of purpose analogous to the purposes of man, and the other which works inward from external mechanism to the human brain. He shows that these two interpretations are really supplements of each other.

\section{Published by

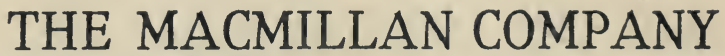




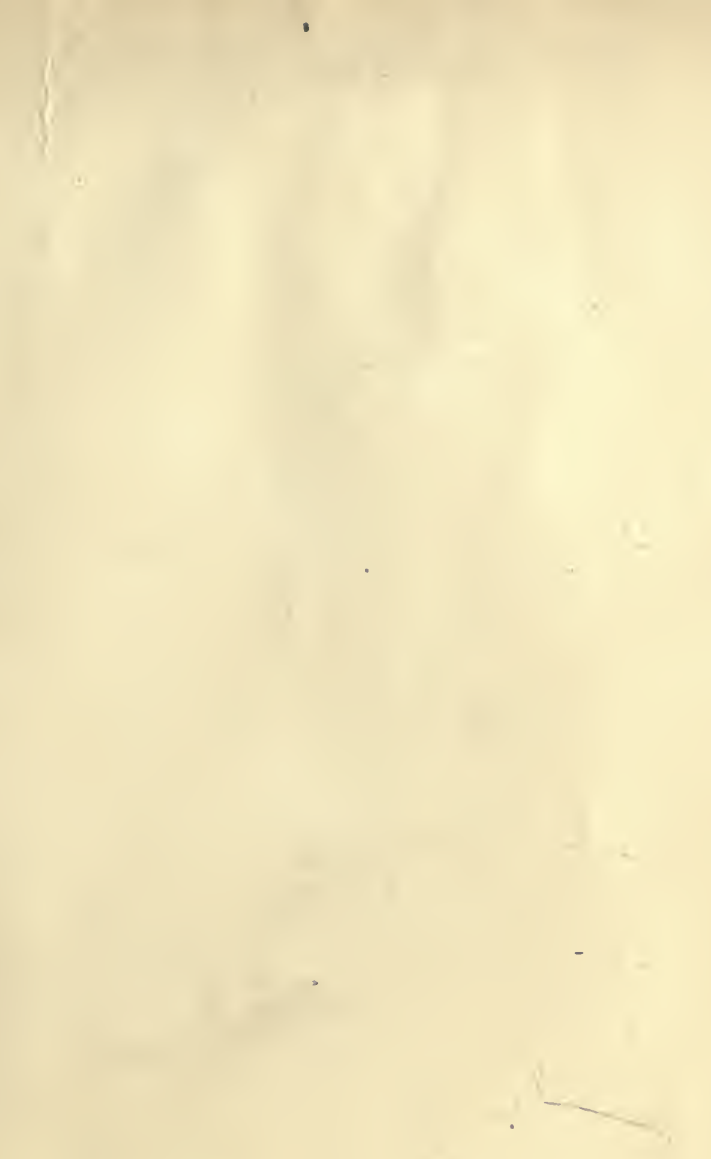


THIS BOOK IS DUE ON THE LAST DATE STAMPED BELOW

AN INITIAL FINE OF 25 CENTS WILL BE ASSESSED FOR FAILURE TO RETURN THY'S BOOK ON THE DATE DUE. THE PENALTY WILL INCREASE TO 50 CENTS ON THE FOURTH DÁY AND TO \$1.00 ON THE SEVENTH DAY OVERDUE.

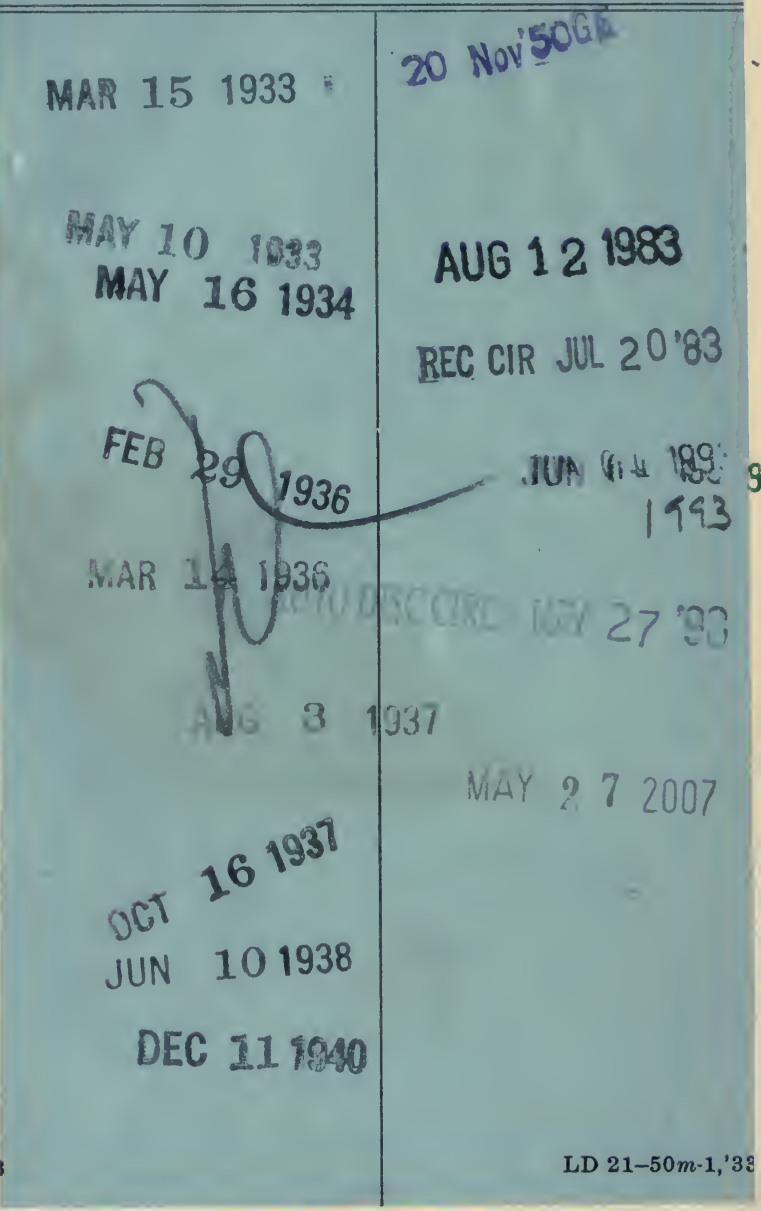


$\sqrt{x^{2}}-x$

YB 05014

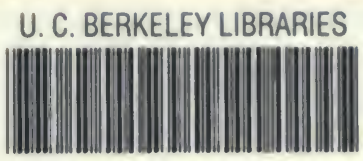

\section{С042844622}

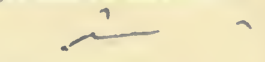


